Aus der Klinik für Nephrologie und Rheumatologie (Prof. Dr. med. G. A. Müller)

der Medizinischen Fakultät der Universität Göttingen

\title{
Bedeutung freier Leichtketten im Urin bei Patienten mit chronisch entzündlicher rheumatischer Erkrankung
}

\author{
INAUGURAL - DISSERTATION \\ zur Erlangung des Doktorgrades \\ der Medizinischen Fakultät der \\ Georg-August-Universität zu Göttingen
}

vorgelegt von

Britta Johanna Frölich

aus

Hildesheim

Göttingen 2018 
Dekan:

Referent:

Ko-Referentin:
Prof. Dr. rer. nat. H. K. Kroemer

PD Dr. med. C. P. Bramlage

PD Dr. Friederike Braulke

Datum der mündlichen Prüfung: $\quad 21.06 .2018$ 
Hiermit erkläre ich, die Dissertation mit dem Titel "Bedeutung freier Leichtketten im Urin bei Patienten mit chronisch entzündlicher rheumatischer Erkrankung" eigenständig angefertigt und keine anderen als die von mir angegebenen Quellen und Hilfsmittel verwendet zu haben.

Göttingen, den

(Unterschrift) 
Teile dieser Arbeit wurden veröffentlicht in:

Bramlage CP, Froelich B, Wallbach M, Minguet J, Grupp C, Deutsch C, Bramlage $P$, Koziolek M, Müller GA (2016): The significance and predictive value of free light chains in the urine of patients with chronic inflammatory rheumatic disease. Clin Rheumatol 35, 2939-2946

Bramlage CP, Froelich B, Wallbach M, Minguet J, Grupp C, Deutsch C, Bramlage $P$, Müller GA, Koziolek M (2017): Urinary free light chains may help to identify infection in patients with elevated systemic inflammation due to rheumatic disease. Rheumatol Int 37, 599-605 


\section{Inhaltsverzeichnis}

INHALTSVERZEICHNIS ........................................................ I

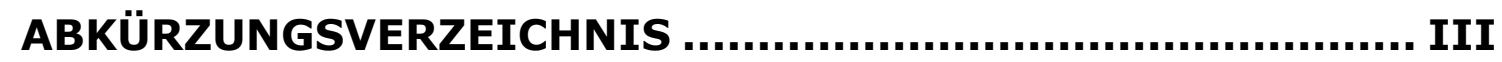

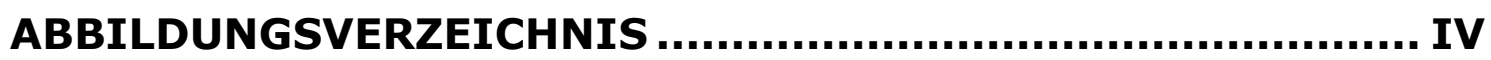

TABELLENVERZEICHNIS ...................................................V

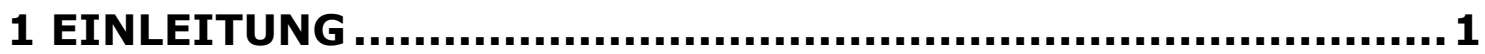

1.1 CHRONISCH ENTZÜNDLICHE RHEUMATISCHE ERKRANKUNGEN $\ldots \ldots \ldots \ldots \ldots \ldots \ldots 1$

1.1.1 Chronische Polyarthritiden ........................................................................................ 3

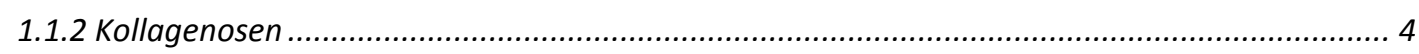

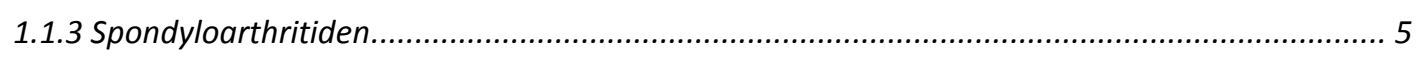

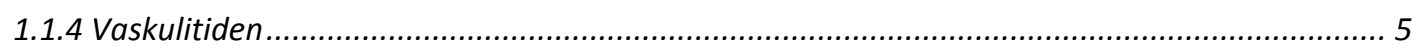

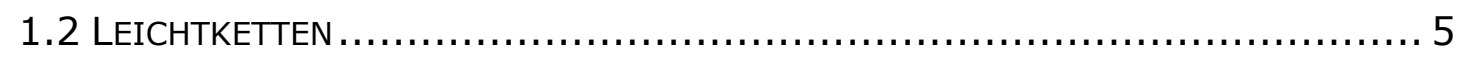

1.2.1 Bedeutung der freien Leichtketten in der Medizin ................................................................... 6

1.2.2 Freie Leichtketten bei chronisch entzündlichen rheumatischen Erkrankungen.......................... 7

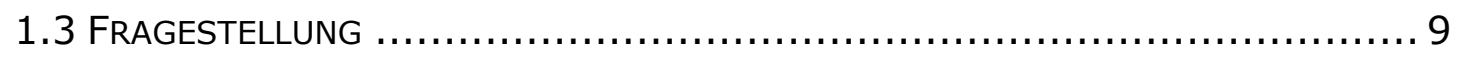

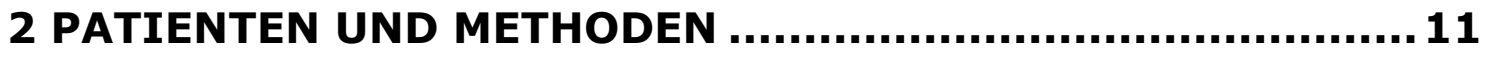

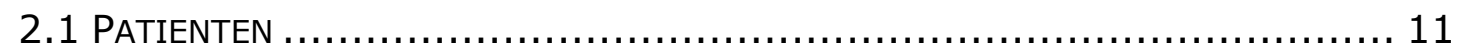

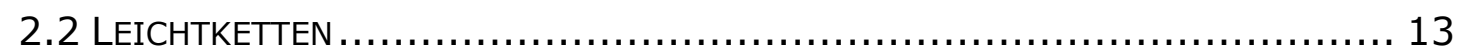

2.3 KRANKHEITSAKTIVITÄT: SCORES UND ENTZÜNDUNGSWERTE............... 13

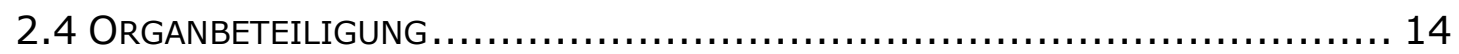

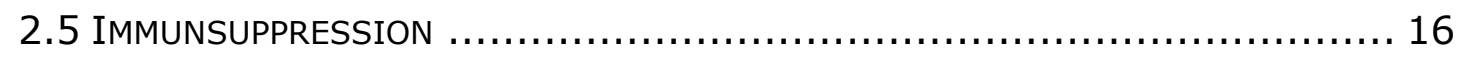

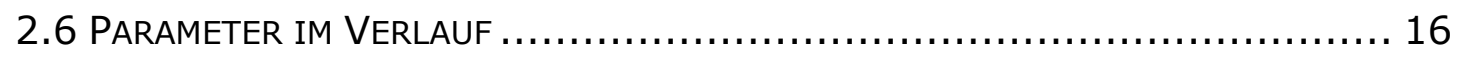

2.7 STATISTISCHE AUSWERTUNG UND GRAPHISCHE DARSTELLUNG .............. 17

3 ERGEBNISSE..................................................................... 18

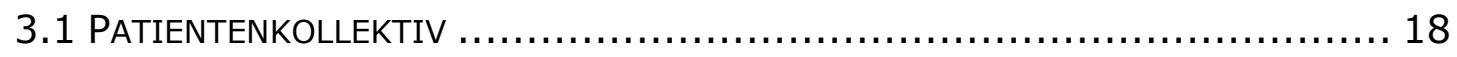

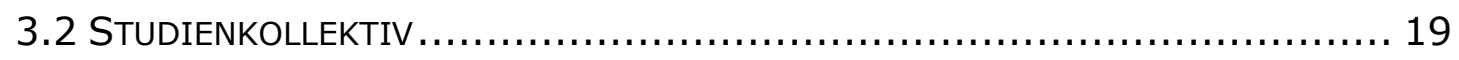

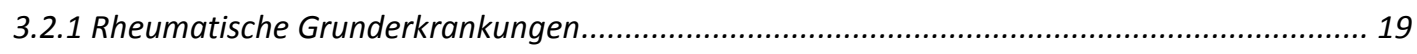

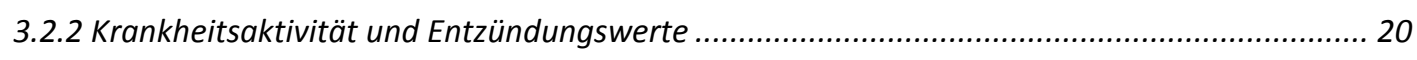

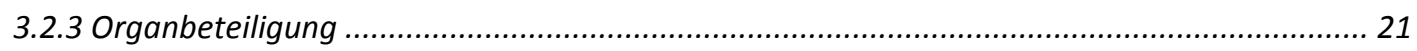




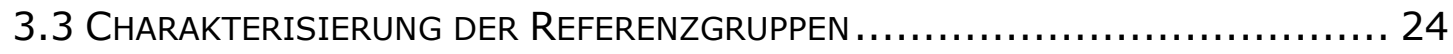

3.4 LEICHTKETTEN UND KAPPA-LAMBDA-QUOTIENT IM URIN .................... 25

3.4.1 Prädiktiver Wert der Leichtketten auf rheumatische Erkrankungen .................................... 29

3.4.2 Einfluss der Krankheitsaktivität und Entzündungswerte ................................................... 30

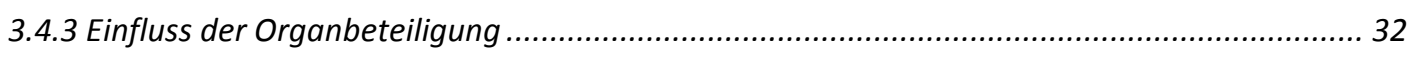

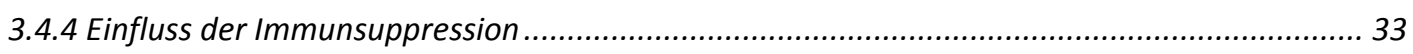

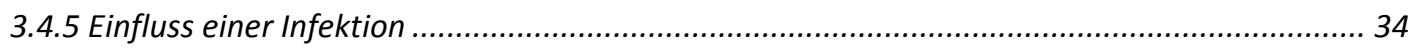

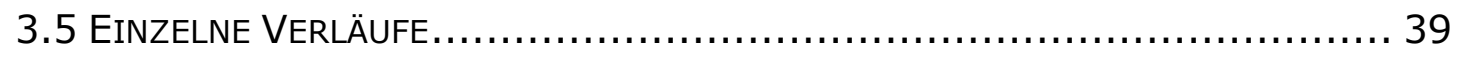

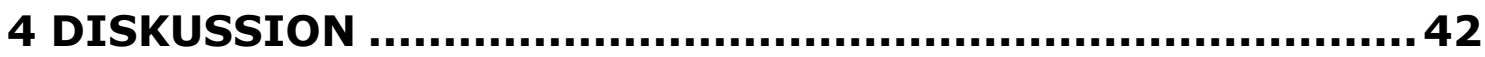

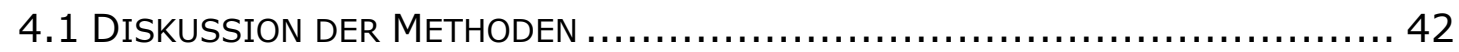

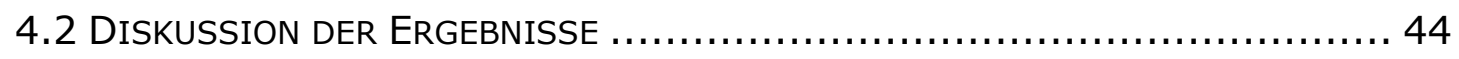

4.2.1 Leichtketten und rheumatische Erkrankungen ............................................................... 45

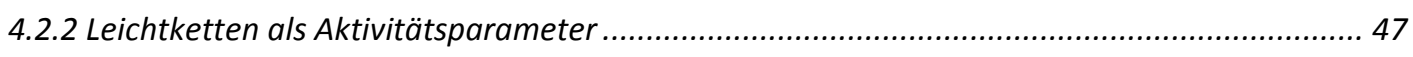

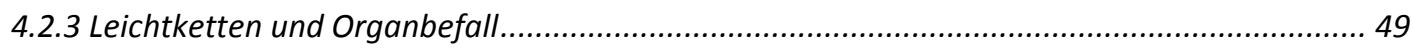

4.2.4 Leichtketten bei immunsuppressiver Therapie und im Verlauf ........................................... 52

4.2.5 Leichtketten und ihre Bedeutung bei Infektionen ........................................................ 53

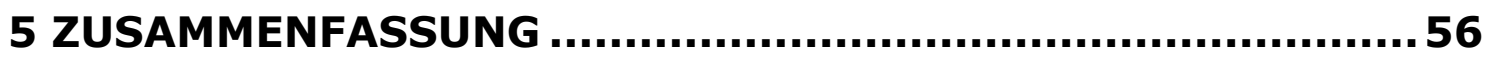

6 LITERATURVERZEICHNIS .............................................. 58 


\section{Abkürzungsverzeichnis}

ANCA antineutrophile zytoplasmatische Antikörper

Anti-CCP-Antikörper Antikörper gegen das cyclische citrullinierte Peptid

AUC Area under the Curve

BASDAI Bath Ankylosing Spondylitis Disease Activity Index

BSG Blutsenkungsgeschwindigkeit

CKD-EPI Chronic Kidney Disease Epidemiology Collaboration

CRP C-reaktives Protein

DAS-28 Disease Activity Score-28

DLE diskoider Lupus erythematodes eGFR estimated Glomerular Filtration Rate

EULAR European League against Rheumatism

FLK freie Leichtketten

HLA Human Leukocyte Antigen

KDIGO Kidney Disease Improving Global

Outcome

KI Konfidenzintervall
LK Leichtketten

MGUS monoklonale Gammopathie unklarer Signifikanz

MM multiples Myelom

MnEV Monate nach Erstvorstellung

MW Mittelwert

OR Odds Ratio

PCT Procalcitonin

pSS primäres Sjögren-Syndrom

RA rheumatoide Arthritis

RF Rheumafaktor

RG Risikogruppe

ROC Receiver Operating Characteristics

SA Standardabweichung

SLE systemischer Lupus erythematodes

SLEDAI Systemic Lupus Erythematosus Disease Activity Index

UMG Universitätsmedizin Göttingen

к kappa

$\lambda$ lambda 


\section{Abbildungsverzeichnis}

ABbILDUNG 1: ÜBERSiCht ÜBER DIE EINZELNEN PATIENTENKOLleKTIVE. ......................

ABBILDUNG 2: ANTEIL DER OBERGRUPPEN IM STUDIENKOLLEKTIV........................... 19

ABBILDUNG 3: BETEILIGUNG DER GRUNDERKRANKUNG AN INNEREN ORGANEN ALLGEMEIN, DER

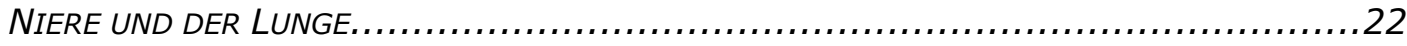

ABBILDUNG 4: EINTEILUNG IN CKD-RISIKOGRUPPEN INNERHALB DER OBERGRUPPEN. ..........23

ABBILDUNG 5: IMMUNSUPPRESSIVA IM STUDIENKOLLEKTIV. ................................. 24

ABBILDUNG 6: BOX PLOT FÜR KAPPA-LK, EINGETEILT IN DIE OBERGRUPPEN UND DIE

REFERENZGRUPPE GESUND; IM VERGLEICH ZUR REFERENZGRUPPE GESUND................28

ABBILDUNG 7: BOX PLOT FÜR LAMBDA-LK, EINGETEILT IN DIE OBERGRUPPEN UND DIE

REFERENZGRUPPE GESUND; IM VERGLEICH ZUR REFERENZGRUPPE GESUND................28

ABbildung 8: DARSTEllung der RELATIVEN ANZAHL PATIENTEN MIT ERHÖHTEN LEICHTKETtEN

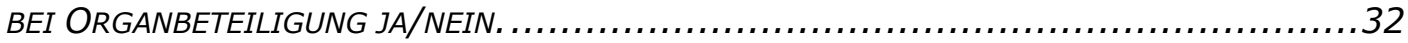

ABbilduNG 9: BOX PLOT FÜR KAPPA-LK IN DEN EINZELNEN KOLLEKTIVEN/UNTERGRUPPEN. ......36

ABBILDUNG 10: BOX PLOT FÜR LAMBDA-LK IN DEN EINZELNEN KOLLEKTIVEN/UNTERGRUPPEN. .36 


\section{Tabellenverzeichnis}

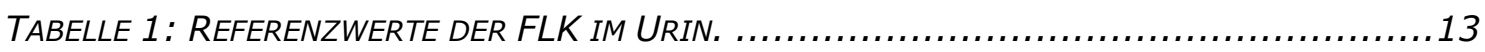

TABELLE 2: FORMEL ZUR BERECHNUNG DER EGFR NACH DER CKD-EPI-FORMEL AUS DER

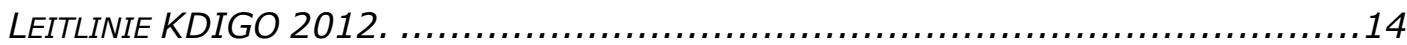

TABELLE 3: EINTEILUNG DER EGFR UND DER ALBUMINURIE NACH DER LEITLINIE KDIGO 2012.15

TABELLE 4: PROGNOSE DER CKD BEI DEN EINZELNEN EGFR- UND ALBUMINURIE-STADIEN. .....15

TABELLE 5: IMMUNSUPPRESSIVA DES STUDIENKOLLEKTIVS. ...............................

TABELLE 6: EPIDEMIOLOGISCHE DATEN DER EINZELNEN KOLLEKTIVE......................... 18

TABELLE 7: ÜBERSICHT ÜBER DIE RHEUMATISCHEN GRUNDERKRANKUNGEN IM STUDIENKOLLEKTIV.

TABELLE 8: ÜBERSICHT ÜBER DIE ENTZÜNDUNGSWERTE IM BLUT DES STUDIENKOLLEKTIVS. .....21

TABELLE 9: ÜBERSICHT ÜBER DIE NIERENWERTE IM STUDIENKOLLEKTIV.......................22

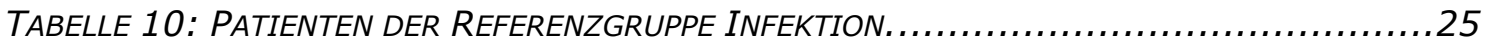

TABELLE 11: LEICHTKETTEN UND IHR QUOTIENT INNERHALB DER EINZELNEN

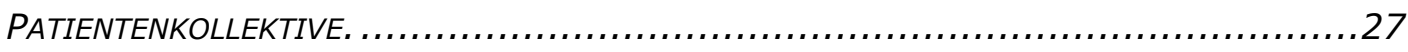

TABELLE 12: ZUSAMMENHANG ZWISCHEN ERHÖHTEN LEICHTKETTEN UND DEM VORHANDENSEIN EINER CHRONISCH ENTZÜNDLICHEN RHEUMATISCHEN ERKRANKUNG; IM VERGLEICH MIT DER

REFERENZGRUPPE GESUND. ....................................................... 29

TABELLE 13: KORRELATION DER AKTIVITÄT DER GRUNDERKRANKUNG ANHAND DER

ENTZÜNDUNGSPARAMETER IM BLUT MIT DEN LEICHTKETTEN IM URIN IM STUDIENKOLLEKTIV.

TABELLE 14: KORRELATION ZWISCHEN DEN LEICHTKETTEN IM URIN UND DEN

ENTZÜNDUNGSPARAMETERN IM BLUT IM STUDIENKOLLEKTIV........................... 31

TABELLE 15: BETEILIGUNG DER GRUNDERKRANKUNG AN INNEREN ORGANEN. ....................

TABELLE 16: LEICHTKETTEN IM URIN BEI EINNAHME/NICHT-EINNAHME VON IMMUNSUPPRESSIVA

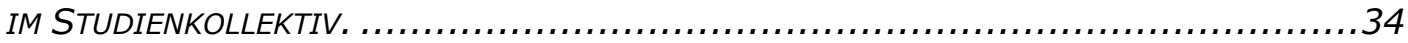

TABELLE 17: LEICHTKETTEN IM URIN IN DEN EINZELNEN KOLLEKTIVEN: VERGLEICH VON

PATIENTEN MIT ENTZÜNDUNG, VERURSACHT DURCH DIE GRUNDERKRANKUNG VS. PATIENTEN

MIT RHEUMATISCHER ERKRANKUNG UND ENTZÜNDUNG, VERURSACHT DURCH EINE

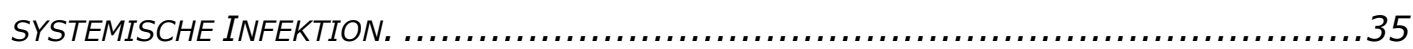

TABELLE 18: HÖHE DER FLK IN DEN UNTERGRUPPEN DER REFERENZGRUPPE INFEKTION. .........37

TABELLE 19: ASSOZIATION ZWISCHEN ERHÖHTEN FLK IM URIN UND INFEKTIONEN. ...............38

TABELLE 20: CHARAKTERISTIK DER EINZELNEN PARAMETER IM HINBLICK AUF IHRE PRÄDIKTIVE MÖGLICHKEIT ZUM VORHANDENSEIN EINER INFEKTION BEI CHRONISCH ENTZÜNDLICHEN RHEUMATISCHEN ERKRANKUNGEN. 


\section{Einleitung}

\subsection{Chronisch entzündliche rheumatische Erkrankungen}

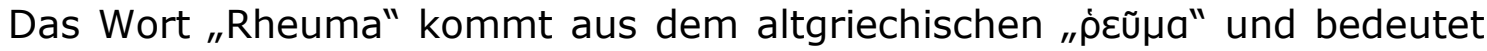
"Strömung, Fluss" (Pfeifer et al. 1997). Die Griechen in der Antike verstanden darunter ein Hinabfließen von Säften vom Gehirn in den Körper, welches ihrer Ansicht nach Krankheiten auslöste.

Die rheumatischen Erkrankungen sind in den westlichen Industrieländern ein häufiges Krankheitsbild und machen etwa $20 \%$ aller Diagnosen aus. Auch wenn sie in den Mortalitätsstatistiken sehr weit unten stehen $(0,5 \%$ aller Todesfälle), sollte ihre Auswirkung sowohl auf den einzelnen Patienten als auch volkswirtschaftlich nicht unterschätzt werden, da rheumatische Erkrankungen häufig zur Erwerbsunfähigkeit führen (Braun 2012).

Die rheumatischen Erkrankungen kann man nach pathogenetischen Gesichtspunkten in vier Gruppen unterteilen: die entzündlichen Systemerkrankungen sowie die nicht-entzündlichen Gelenkerkrankungen, die weichteilrheumatischen und die stoffwechselbedingten rheumatischen Erkrankungen. Im Folgenden wird nur auf die Gruppe der entzündlichen rheumatischen Erkrankungen eingegangen.

Bei den chronisch entzündlichen rheumatischen Erkrankungen handelt es sich mit wenigen Ausnahmen (z. B. Borreliose) um Autoimmunreaktionen, bei denen autoreaktive $B$ - und T-Lymphozyten in Erscheinung treten. Insbesondere den B-Zellen wurde in den letzten Jahren eine größere Bedeutung in der Pathogenese rheumatischer Erkrankungen beigemessen (Youinou et al. 2009). Die genaue Ätiologie hingegen ist meist unbekannt. Es wird angenommen, dass neben einer genetischen Prädisposition auch Umweltfaktoren (z. B. Rauchen, Infektionen, Medikamente) für den Ausbruch und Verlauf der Erkrankung entscheidend sein können (Herold 2017).

Neben dem Leitsymptom des Gelenkschmerzes kann es auch zu mannigfaltigen extraartikulären Manifestationen kommen, z. B. an der Haut, den Augen, der Lunge oder der Niere. Aber auch eine isolierte Manifestation an den inneren Organen ohne eine Gelenkbeteiligung ist möglich. 
Die chronisch entzündlichen rheumatischen Erkrankungen werden in vier große Gruppen eingeteilt: chronische Polyarthritiden, Kollagenosen, Spondyloarthritiden und Vaskulitiden. Für jede Gruppe gibt es spezielle Charakteristika, auf die im Verlauf noch genauer eingegangen wird.

Die Diagnostik ist bei allen Gruppen ähnlich: Die Anamnese und die klinische Untersuchung ergeben in mehr als $90 \%$ der Fälle die richtige Diagnose (Braun 2012). Ergänzt wird dies durch Laboruntersuchungen, bei denen die allgemeinen Entzündungsparameter (z. B. C-reaktives Protein (CRP), Blutsenkungsgeschwindigkeit (BSG)) und für die Differenzialdiagnostik die Autoantikörper bestimmt werden. Die Anzahl der verschiedenen Autoantikörper in der Diagnostik ist groß und wächst anhaltend. Auszugsweise genannt, da häufig bestimmt, seien hier der Rheumafaktor (RF), die antinukleären Antikörper (ANA) und bei Hinweisen auf eine Vaskulitis die antineutrophilen zytoplasmatischen Antikörper (ANCA). Zudem können weitere Laborparameter Hinweise auf eine mögliche Organbeteiligung (z. B. der Niere) liefern.

Sonographische und radiologische Untersuchungen dienen der Sicherung der Diagnose und können den Gelenkzustand zum Zeitpunkt der Erstdiagnose festhalten. Neben diesen Basismaßnahmen können weitere Bildgebungen (Magnetresonanztomographie, Skelettszintigraphie, u. a.) der Diagnosefindung oder Aktivitätseinschätzung dienen.

Im klinischen Alltag sind besonders die Kollagenosen und Vaskulitiden zum Teil nur schwer von Infektionen mit einer Lungen- oder sonstigen Organbeteiligung zu unterscheiden. Hierbei können sich der Auskultationsbefund, das Röntgen-Thorax und die erhöhten systemischen Entzündungsparameter von Patienten mit infektiösen Pneumonien und den selteneren Vaskulitiden und Kollagenosen gleichen und die Diagnostik und Therapieeinleitung verzögern. Auch im Verlauf bleibt bei erhöhten systemischen Entzündungsparametern häufig unklar, ob es sich um eine erhöhte Aktivität der Grunderkrankung oder um eine Infektion handelt. Dabei sollte man die Tatsache beachten, dass Patienten mit chronisch entzündlichen rheumatischen Erkrankungen häufig von Infektionen betroffen sind (Doran et al. 2002), insbesondere auch aufgrund ihrer immunsuppressiven Therapie (Komano et al. 2011; Germano et 
al. 2014). Zudem führen Infektionen bei dieser Patientenklientel vermehrt zur Hospitalisierung (Galloway et al. 2011), was mit erhöhten Kosten für das Gesundheitssystem einhergeht. Eine Unterscheidung zwischen Aktivität und Infektion ist aktuell anhand von Laborparametern nicht möglich, wenn man Procalcitonin (PCT) als Marker einer bakteriellen Sepsis ausnimmt.

Eine kausale Therapie ist für die meisten chronisch entzündlichen rheumatischen Erkrankungen nicht bekannt (Ausnahme Borreliose). Dabei besteht die Therapie aus drei Grundprinzipien: der Entzündungshemmung, der Immunsuppression und der physikalischen Therapie. Als besonders wertvoll in der Therapie haben sich die Biologika erwiesen. Diese rekombinant hergestellten Antikörper können gezielt in die immunologischen Vorgänge des Körpers intervenieren und haben die Behandlung rheumatischer Erkrankungen in den letzten Jahrzehnten deutlich verbessert.

Im Folgenden werden die wichtigsten Fakten zu den vier Gruppen der chronisch entzündlichen rheumatischen Erkrankungen genannt.

\subsubsection{Chronische Polyarthritiden}

In der Gruppe der chronischen Polyarthritiden kommt es überwiegend zu einer Beteiligung der Synovialis der Gelenke. Die rheumatoide Arthritis (RA) ist mit einer Prävalenz von $2 \%$ bei den über 55-Jährigen der größte Vertreter dieser Gruppe. Es handelt sich um eine chronisch entzündliche Systemerkrankung, die unbehandelt in eine Zerstörung der Gelenke mündet. Bei der RA liegt eine familiäre Häufung vor; insbesondere das Human Leukocyte Antigen (HLA) DR4 stellt einen Risikofaktor dar (bei ca. 70 \% der RA-Patienten positiv) (Herold 2017).

Als Autoantikörper dominieren der Rheumafaktor und Antikörper gegen das cyclische citrullinierte Peptid (Anti-CCP-Antikörper). Zudem kann begleitend eine Immunkomplexvaskulitis auftreten, die auch innere Organe befallen kann.

Die Diagnosestellung der RA erfolgt anhand der Kriterien des American College of Rheumatology (ACR) und der European League against Rheumatism 
(EULAR) aus dem Jahre 2010 (Aletaha et al. 2010). Zur Verlaufskontrolle und Aktivitätseinschätzung dient der Disease Activity Score-28 (DAS-28). Darin fließen die Anzahl der druckschmerzhaften und der geschwollenen Gelenke, die BSG und eine subjektive Einschätzung des Krankheitszustandes durch den Patienten ein (Prevoo et al. 1995).

Bei der Therapie der RA ist vor allem das Prinzip hit hard and early entscheidend, um einer Gelenkzerstörung frühzeitig entgegenzuwirken. Prognostisch ist die Lebenserwartung von RA-Patienten im Durchschnitt drei bis zehn Jahre geringer als in der Normalbevölkerung (Alamanos und Drosos 2005), da insbesondere ein erhöhtes Risiko für Herzinfarkte vorliegt (AvinaZubieta et al. 2012). Das kardiovaskuläre Risiko kann durch eine gute Einstellung der Grunderkrankung mit einem DAS-28 $\leq 3,2$ vermindert werden (Arts et al. 2017).

Als Sonderformen der chronischen Polyarthritis zählen unter anderem die juvenile idiopathische Arthritis, die late onset rheumatoid arthritis, das StillSyndrom und der Morbus Felty.

\subsubsection{Kollagenosen}

Die Kollagenosen sind systemische Erkrankungen, die sich vor allem am Bindegewebe manifestieren. Antinukleäre Antikörper findet man bei fast allen Vertretern dieser Gruppe. Beim systemischen Lupus erythematodes (SLE) kommt es häufig zu einem Befall innerer Organe wie z. B. der Lupusnephritis. Im Gegensatz dazu stehen lokale Formen des Lupus, wie z. B. der diskoide Lupus erythematodes (DLE). Für die Verlaufsbeurteilung des SLE gibt es mehrere Scores, einer davon ist der Systemic Lupus Erythematosus Disease Activity Index (SLEDAI) (Bombardier et al. 1992).

Neben den Lupus-Erkrankungen zählen auch die Poly-/ Dermatomyositiden, die Sklerodermie, das Sjögren-Syndrom und Mischkollagenosen zu der Gruppe der Kollagenosen. 


\subsubsection{Spondyloarthritiden}

Bei der Gruppe der Spondyloarthritiden handelt es sich um seronegative (Fehlen von Rheumafaktoren) chronisch entzündliche Erkrankungen, die häufig das Achsenskelett betreffen und mit dem HLA-B27 assoziiert sind. Die Prävalenz liegt in Europa bei etwa 1 \% (Herold 2017). Zu den Spondyloarthritiden zählen die Spondylitis ankylosans (ehemals Morbus Bechterew; 90 \% HLA-B27 positiv), die Psoriasisarthritis, die enteropathische Arthritis und die undifferenzierte Spondyloarthritis. Als Einschätzung der Aktivität der Spondylitis ankylosans dient der Bath Ankylosing Spondylitis Disease Activity Index (BASDAI), ein Fragebogen über den klinischen Zustand des Patienten, der von diesem selbst ausgefüllt wird (Garrett et al. 1994).

\subsubsection{Vaskulitiden}

Bei den Vaskulitiden handelt es sich um autoimmunologisch bedingte chronisch entzündliche Systemerkrankungen der Gefäße mit konsekutiver Schädigung der betroffenen Organe. Man unterscheidet die primären von den sekundären Vaskulitiden, die z. B. im Rahmen anderer rheumatischer Erkrankungen auftreten können. Die Primären wurden 1994 auf der Chapel Hill Consensus Conference in die Vaskulitiden kleiner, mittlerer und großer Gefäße unterteilt (Jennette et al. 1994). In einem erneuten Konsens 2012 wurde die Einteilung um eine vierte Gruppe für Vaskulitiden variabler Größe ergänzt (Jennette et al. 2013). Bei den Vaskulitiden kleiner Gefäße dominiert die Untergruppe der ANCA-assoziierten Vaskulitiden, einer Gruppe von Erkrankungen, bei denen antineutrophile zytoplasmatische Antikörper produziert werden.

\subsection{Leichtketten}

Leichtketten (LK) sind Proteine, die bei der Produktion von Immunglobulinen (Antikörpern) durch Plasmazellen entstehen. Die Immunglobuline bestehen aus je zwei identischen leichten und zwei identischen schweren Ketten, die über Disulfidbrücken miteinander verbunden sind und zusammen eine tetramere Struktur formen (Hutchison et al. 2008; Brebner und Stockley 2013). 
Da mehr leichte als schwere Ketten produziert werden, werden nur $60 \%$ der Leichtketten in die Immunglobuline eingebaut; die restlichen $40 \%$ befinden sich als freie Leichtketten (FLK) im Serum (Waldmann et al. 1972).

Es werden zwei Isotypen unterschieden, kappa ( $\mathrm{k}$ ) und lambda $(\lambda)$, die als Monomere oder Dimere vorliegen können. Schätzungsweise werden pro Tag etwa 500 mg LK vom Lymphsystem produziert (van der Heijden et al. 2006). Beide Typen haben eine sehr kurze Halbwertszeit von 2-4 h für k-LK und 3-6 h für $\lambda$-LK (Draborg et al. 2015). Zum Vergleich, das intakte Immunglobulin IgG hat eine Halbwertszeit von etwa drei Wochen (Herold 2017).

Die FLK werden in der Niere von den Glomeruli gefiltert und in den proximalen Tubuli wieder resorbiert und metabolisiert. Bei gesunden Menschen sind daher nur sehr geringe Konzentrationen im Urin (1-10 mg im 24h-Sammelurin) nachweisbar (Zhang et al. 2013).

Bei höheren Konzentrationen im Urin können zwei Pathomechanismen ursächlich sein: Entweder liegt eine erhöhte Produktion der FLK vor, die die Kapazität der Resorption im proximalen Tubulus übersteigt, oder das proximale Tubulussystem der Nieren ist geschädigt, weshalb keine effiziente Resorption stattfinden kann (Zhang et al. 2013; Stokes et al. 2016).

\subsubsection{Bedeutung der freien Leichtketten in der Medizin}

Erhöhte FLK werden meistens mit dem multiplen Myelom (MM) assoziiert, bei dem es durch entartete Plasmazellen zur vermehrten Produktion von monoklonalen Immunglobulinen oder nur freier LK kommt mit pathologischem $\mathrm{k} / \lambda$ Quotienten (Nakano et al. 2004). Die nachgewiesenen FLK im Urin bezeichnet man nach ihrem Erstbeschreiber Dr. H. Bence Jones, der 1847 erstmals das Auftreten von Leichtketten im Urin bei einem Patienten mit mollities ossium entdeckte (Bence Jones 1847), als Bence-Jones-Proteine.

Eine Frühform des multiplen Myeloms ist die monoklonale Gammopathie unklarer Signifikanz (MGUS). Studien zur MGUS zeigten, dass ein erhöhter $\kappa / \lambda$-Quotient mit einer erhöhten Wahrscheinlichkeit des Übergangs in ein MM assoziiert ist (Rajkumar et al. 2005). Beim multiplen Myelom kann es auch 
zu einer AL (amyloid-light chain)-Amyloidose kommen. Dabei kommt es durch eine Fehlfaltung der Proteine zur Umwandlung der FLK in nicht lösliche fibrilläre Aggregate, die sich im Interstitium ablagern (=Amyloid), bevorzugt in den Nieren und dem Herzen (Herold 2017). Ebenso treten Amyloidosen sekundär im Rahmen von chronischen Erkrankungen auf, wie z. B. bei der rheumatoiden Arthritis (Giraudeau et al. 2000).

Die FLK-Bestimmung im Urin war das erste diagnostische Mittel in der Diagnostik des multiplen Myeloms (Bradwell 2005). Seit 2001 steht mit der Nephelometrie eine schnellere und zuverlässigere Methode zur Bestimmung der FLK zur Verfügung (Bradwell et al. 2001), weshalb es vermehrt Studien gab, die das Auftreten von erhöhten FLK bei verschiedenen anderen Erkrankungen untersucht haben.

So wurde entdeckt, dass erhöhte FLK im Serum bei bestimmten Infektionen wie Helicobacter pylori, Pneumonie oder Endokarditis vorkommen (Hopper et al. 2000; Mastroianni-Kirsztajn et al. 2008; Girón und Shah 2013). Durch die erhöhten LK schließt man auf eine erhöhte B-Zell-Aktivität im Serum, wie es bei einer Infektion mit Antikörperbildung typisch ist (Hopper und Papagiannes 1986).

Leichtketten können auch in anderen Körperflüssigkeiten bestimmt werden. So können sie im Liquor zerebrospinalis erhöht sein, beispielsweise bei Meningitis oder multipler Sklerose (Fagnart et al. 1988; Presslauer et al. 2016). Bereits 1968 entdeckten Cooper und Bluestone zudem erhöhte FLK in der Synovialflüssigkeit von Patienten mit RA.

\subsubsection{Freie Leichtketten bei chronisch entzündlichen rheumatischen Erkrankungen}

Mehrere Studien haben herausgefunden, dass die FLK bei chronisch entzündlichen rheumatischen Erkrankungen erhöht sind. Bereits in den sechziger Jahren gab es erste Studien zu Patienten mit Kollagenosen und RA. Dabei wurden erhöhte Leichtketten im Serum und der Synovialflüssigkeit gefunden (Epstein und Tan 1966; Cooper und Bluestone 1968). Epstein vermutete 
1973 anhand einer Einzelfallbeschreibung zudem, dass die FLK im Urin eine erhöhte Aktivität beim SLE vorhersagen könnten.

Seit der Methodenumstellung zur Bestimmung der FLK im Jahre 2001 (Bradwell et al. 2001), bei der mittels Nephelometrie eine gute Möglichkeit zur Routinediagnostik gegeben ist, konnten die Ergebnisse vorheriger Studien bestätigt werden.

Gottenberg und Mitarbeiter (2007 \& 2009) beschrieben erhöhte FLK im Serum bei Patienten mit (früher) rheumatoider Arthritis und primärem SjögrenSyndrom ( $p S S$ ). Weitere Studien beschrieben erhöhte FLK bei Patienten mit RA im Serum (Ye et al. 2013; Deng et al. 2015) und der Synovialflüssigkeit (Kormelink et al. 2010).

Auch bei Patienten mit systemischem Lupus erythematodes konnten erhöhte FLK im Serum entdeckt werden (Aggarwal et al. 2011; Draborg et al. 2015). Wenige Studien gab es bislang zum Auftreten von FLK im Urin bei chronisch entzündlichen rheumatischen Erkrankungen. Dabei wurden die meisten Untersuchungen bei Patienten mit Kollagenosen, insbesondere mit einem SLE, durchgeführt (Hopper et al. 2000; Aggarwal 2013; Hanaoka et al. 2013).

\section{Freie Leichtketten und Krankheitsaktivität}

Aggarwal und Mitarbeiter beschrieben 2011 eine starke Korrelation zwischen der Krankheitsaktivität des SLE und der Höhe der FLK im Serum. Der Grund hierfür kann darin liegen, dass die Aktivität des Lupus eng mit der B-ZellAktivität zusammenhängt (Jasin und Ziff 1975; Blaese et al. 1980). Eine weitere Studie bestätigte eine Korrelation zwischen den FLK und der Krankheitsaktivität beim SLE: Draborg und Mitarbeiter (2015) konnten anhand von Daten von 45 Patienten zeigen, dass die Serum-FLK mit dem SLEDAI-Score und anderen Serum-Aktivitätsparametern wie der Anti-ds-DNA oder dem CRP korrelierten.

Auch bei Patienten mit RA konnten die FLK als Aktivitätsparameter identifiziert werden: So wurde bei 50 Patienten mit RA eine Korrelation zwischen 
dem DAS-28 und den Serum-LK bestätigt. In derselben Studie konnte auch eine positive Korrelation zwischen den FLK und 139 Patienten mit primärem Sjögren-Syndrom gesehen werden (Gottenberg et al. 2007).

Eine weitere Studie beschäftigte sich mit Patienten mit RA, die mit Rituximab behandelt wurden. Dabei wurden die FLK in der Synovialflüssigkeit, dem Synovialgewebe und dem Serum bestimmt. Die Werte der FLK korrelierten mit dem DAS-28 und der Höhe der Antikörper (RF und Anti-CCP). Auch wurde ein Rückgang der FLK unter Rituximab-Therapie gesehen. Die Autoren schlussfolgerten, dass die FLK als Biomarker für das Ansprechen von Rituximab gesehen werden können (Kormelink et al. 2010).

Auch beim SLE wurde eine Normalisierung der FLK im Serum unter einer Therapie mit Rituximab beschrieben (Chiche et al. 2011).

\section{Freie Leichtketten und Infektion}

Ob die Höhe der FLK bei Patienten mit chronisch entzündlicher rheumatischer Erkrankung zwischen einer vermehrten Aktivität der Grunderkrankung und einer akuten Infektion unterscheiden kann, wurde bislang wenig untersucht. Mastroianni-Kirsztajn und Mitarbeiter (2008) untersuchten die FLK im Urin bei Patienten mit SLE mit und ohne Infektion und verglichen die Werte mit Patienten ohne SLE aber mit Infektion. Dabei zeigte sich, dass die Patienten ohne SLE aber mit Infektion ( $n=14)$ höhere FLK-Werte hatten als die Patientengruppe mit SLE ( $n=43)$. Im Vergleich zu der Gruppe "SLE ohne Infektion aber aktiver Grunderkrankung" zeigten sich ähnliche Werte. Die Autoren kamen zu dem Schluss, dass die FLK im Urin nicht zur Differenzierung zwischen Infektion und aktiver Grunderkrankung geeignet seien.

\subsection{Fragestellung}

Die vorliegende Promotion befasst sich mit der Bedeutung freier Leichtketten im Urin von Patienten mit chronisch entzündlichen rheumatischen Erkrankungen. Ziel der Arbeit war es, den Stellenwert der FLK im Urin in der Diagnostik, 
Aktivitätsbestimmung und Therapie rheumatischer Erkrankungen zu analysieren. Zudem sollte herausgearbeitet werden, ob Infektionen in diesem Patientenkollektiv mithilfe der FLK früher identifiziert werden können.

Zur Beantwortung der folgenden Hypothesen wurde eine monozentrische retrospektive Studie mit 1500 Patienten durchgeführt, bei denen die freien Leichtketten kappa und lambda im Urin bestimmt worden waren.

Folgende Hypothesen galt es anhand der Daten zu untersuchen:

1. Patienten mit chronisch entzündlichen rheumatischen Erkrankungen haben erhöhte FLK im Urin.

2. Hiervon abgeleitet: Erhöhte Leichtketten können zur Diagnosestellung rheumatischer Erkrankungen beitragen und ermöglichen die Abgrenzung von Infektionserkrankungen mit vergleichbaren Symptomen (Pneumonie vs. Vaskulitis).

3. Die FLK im Urin können die Aktivität von chronisch entzündlichen rheumatischen Erkrankungen anzeigen.

4. Die FLK können den Verlauf und die Effektivität einer immunsuppressiven Therapie anzeigen.

5. Die FLK im Urin können bei Patienten mit chronisch entzündlichen rheumatischen Erkrankungen zwischen einer erhöhten Aktivität der Grunderkrankung und einer Infektion unterscheiden. 


\section{Patienten und Methoden}

\subsection{Patienten}

In der vorliegenden Studie wurde die Bedeutung von freien Leichtketten im Urin bei Patienten mit rheumatischen Erkrankungen untersucht. Diese Untersuchungen erfolgten im Rahmen einer monozentrischen retrospektiven Studie. Die EDV-Abteilung der Universitätsmedizin Göttingen (UMG) identifizierte alle Patienten der UMG, bei denen im Zeitraum von Januar 2011 bis einschließlich Dezember 2013 eine Bestimmung der kappa- und lambdaLeichtketten im Urin sowie ihres Quotienten vorgenommen wurde. Insgesamt waren dies 1526 Patienten.

Zu 1500 Patienten gab es eine ausführliche Dokumentation bezüglich ihrer Krankheitsgeschichte, die ich aus den elektronischen Akten herausgearbeitet habe. Diese 1500 Patienten (=Gesamtkollektiv) wurden in einer separaten Tabelle zusammengefasst, in der neben dem Geschlecht, dem Alter und den Leichtketten im Urin auch die Diagnosen aufgeführt wurden.

Im Gesamtkollektiv litten 401 Patienten an einer chronisch entzündlichen rheumatischen Erkrankung. Um Störfaktoren auf die Höhe der LK auszuschließen, wurden 19 Patienten mit einem akuten Malignom, einem multiplen Myelom, einer MGUS oder einer Amyloidose ausgeschlossen.

Das Studienkollektiv bestand folglich aus 382 Patienten, zu denen folgende epidemiologische Daten erhoben wurden: Geschlecht [m/w], Alter [Jahre], Gewicht [kg], Größe [cm], Datum der Erstvorstellung [TT.MM.JJJJ] und der weiteren Vorstellungen im Verlauf.

Außerdem wurden aus dem Gesamtkollektiv noch zwei Vergleichsgruppen gebildet: die Referenzgruppe Gesund ( $\mathrm{N}=140)$, bestehend aus Patienten ohne Autoimmunerkrankungen, Infektionen, Nieren- oder Lebererkrankungen oder hämatologischen/onkologischen Erkrankungen, und die Referenzgruppe Infektion ( $\mathrm{N}=219)$, bestehend aus Patienten mit systemischer Infektion oder Sepsis. Patienten mit lokalen Infekten der Haut, der ableitenden Harnwege oder Verdachtsdiagnosen wurden von dieser Gruppe ausgeschlossen. 
Für einzelne Untersuchungen wurde das Studienkollektiv in weitere kleinere Kollektive unterteilt (Abbildung 1).

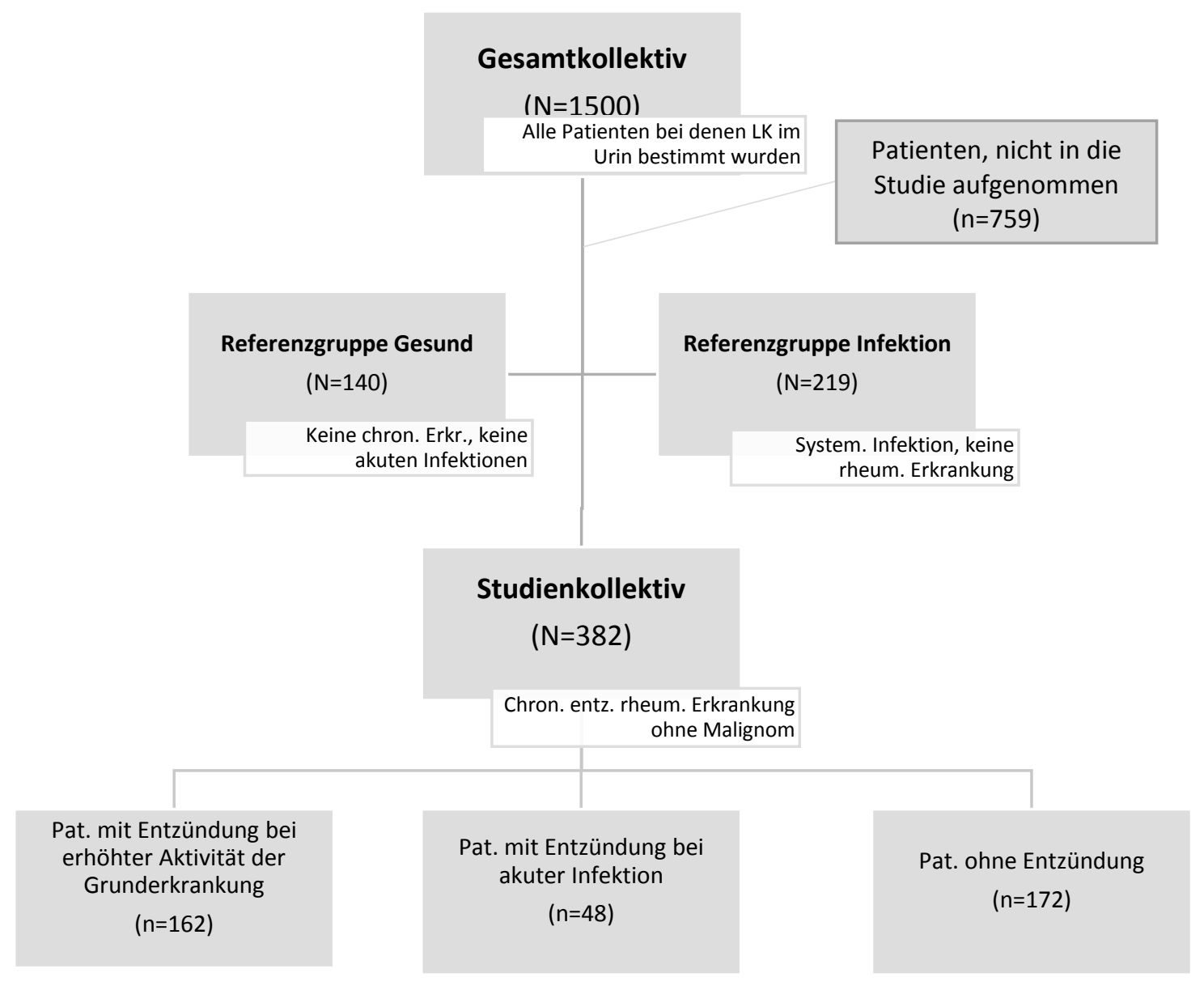

\section{Abbildung 1: Übersicht über die einzelnen Patientenkollektive.}

Bei den Patienten, die nicht in die Studie aufgenommen wurden, handelt es sich um Patienten, die weder an einer chronisch entzündlichen rheumatischen Erkrankung noch an einer akuten Infektion litten oder in die Referenzgruppe Gesund passten. Hierzu gehörten beispielsweise Patienten mit Leber- oder Niereninsuffizienz oder akutem Malignom.

Das Studiendesign wurde der Ethikkommission vorgelegt und genehmigt (Referenznummer 11/2/14). Aufgrund des retrospektiven Designs sowie der fehlenden Konsequenzen jeglicher Art für die Patienten war keine gesonderte Aufklärung einzelner Patienten notwendig. 


\subsection{Leichtketten}

Die Bestimmung der $\mathrm{k}$ - und $\lambda$-Leichtketten im Urin war Voraussetzung für die Aufnahme in diese Studie. Die Quantifizierung der Leichtketten erfolgte durch Nephelometrie mit dem BN ProSpec (Siemens, Marburg) mittels eines Nephelometrie test kit (Siemens Diagnostics, Marburg), das standardmäßig an der UMG verwendet wird. Neben den kappa- und lambda-Leichtketten [mg/l] wurde auch der kappa-lambda-Quotient berechnet (Tabelle 1).

Tabelle 1: Referenzwerte der FLK im Urin.

\begin{tabular}{l|l} 
Freie Leichtketten im Urin & Referenzwerte \\
\hline $\mathrm{K}$-FLK $(\mathrm{mg} / \mathrm{l})$ & $<6,8$ \\
$\lambda$-FLK $(\mathrm{mg} / \mathrm{l})$ & $<3,7$ \\
$\mathrm{~K} / \lambda$-Quotient & $>1,0$ bis $<5,2$
\end{tabular}

\subsection{Krankheitsaktivität: Scores und Entzündungswerte}

Die Aktivität der Grunderkrankung wurde je nach Dokumentation mithilfe der Aktivitätsscores oder anhand des CRP/ der BSG eingeteilt.

Der DAS-28 zur Beurteilung der Krankheitsaktivität bei der RA wurde anhand der international geltenden Klassifikation in leichte $(2,6$ bis $<3,2)$, mittlere $(\geq 3,2$ bis $<5,1)$ und hohe $(\geq 5,1)$ Aktivität eingeteilt. Werte $<2,6$ galten als Remission. Zudem wurden auch Scores zur Bestimmung der Aktivität des SLE (SLEDAI) und der Spondylitis ankylosans (BASDAI) aufgezeichnet.

Einschränkend muss gesagt werden, dass die Anzahl dieser im Arztbrief dokumentierten Scores niedrig war, so dass bei der Beurteilung eher auf die systemische Entzündungsaktivität zurückgegriffen werden musste. Hierzu wurden die CRP-Werte $[\mathrm{mg} / \mathrm{l}]$ und die BSG $[\mathrm{mm} / \mathrm{h} \mathrm{n}$. W.] genutzt.

Als weitere Entzündungswerte wurden die Leukozyten [ / $\mathrm{nl}$ ], die Lymphozyten [\% der Leukozyten] und das Procalcitonin $[\mathrm{ng} / \mathrm{ml}]$ dokumentiert.

Die Ätiologie der Entzündung wurde anhand der Krankengeschichte und Anamnese, der Aktivität der Grunderkrankung inklusive der Entzündungsfaktoren und dem PCT festgelegt. Dabei folgte eine Einteilung in drei Gruppen: 
$0=$ keine syst. Entzündung, $1=$ syst. Entzündung durch erhöhte Aktivität der Grunderkrankung und 2 = syst. Entzündung durch akute Infektion unterschieden.

In der Referenzgruppe Infektion wurde zudem auch der Fokus der Infektion notiert.

\subsection{Organbeteiligung}

Bezogen auf die rheumatische Grunderkrankung wurden die Arztbriefe im Hinblick auf eine Organbeteiligung durchgesehen. Dazu zählten eine Beteiligung der inneren Organe (Niere, Lunge, Gastrointestinaltrakt, Herz, Serosa, Knochenmark, Leber, Milz) und weiterer Organsysteme (Haut, Auge, HalsNase-Ohren).

Aufgrund der besonderen Bedeutung der Nierenfunktion im Hinblick auf die LK-Ausscheidung im Urin wurde diese genauer in der Promotion beschrieben. Im Urin wurden neben den kappa- und lambda-Leichtketten $[\mathrm{mg} / \mathrm{I}]$ und dem kappa-lambda-Quotienten noch Kreatinin [mg/dl], Albumin [mg/l], a-1Mikroglobulin [mg/l] und die Proteine [mg/l] bestimmt. Zudem wurden zur verbesserten Vergleichbarkeit die Albumin-, die a-1-Mikroglobulin- und die Proteinwerte in mg/g Kreatinin umgerechnet (=Albuminurie; a-1-Mikroglubulinurie; Proteinurie).

Als weiterer Parameter der Nierenfunktion diente das Serum-Kreatinin. Mithilfe der Chronic Kidney Disease Epidemiology Collaboration (CKD-EPI)Formel, die Alter, Geschlecht, Hautfarbe (es wurde nicht-schwarz für alle Patienten angenommen) und Serum-Kreatinin berücksichtigt, wurde die estimated Glomerular Filtration Rate (eGFR) bestimmt (Tabelle 2).

Tabelle 2: Formel zur Berechnung der eGFR nach der CKD-EPI-Formel aus der Leitlinie KDIGO 2012.

\begin{tabular}{|c|c|c|}
\hline Geschlecht & Serum-Kreatinin (SKr) (mg/dl) & Formel für eGFR $\left(\mathrm{ml} / \mathrm{min} / 1,73 \mathrm{~m}^{2}\right)$ \\
\hline weiblich & $\leq 0,7$ & $144 \times(\mathrm{SKr} / 0,7)^{-0,329} \times 0,993^{\text {Alter }}$ \\
\hline weiblich & $>0,7$ & $144 \mathrm{x}(\mathrm{SKr} / 0,7)^{-1,209} \times 0,993^{\text {Alter }}$ \\
\hline männlich & $\leq 0,9$ & $141 \times(\mathrm{SKr} / 0,9)^{-0,329} \times 0,993^{\text {Alter }}$ \\
\hline männlich & $>0,9$ & $141 \times(\mathrm{SKr} / 0,9)^{-1,209} \times 0,993^{\text {Alter }}$ \\
\hline
\end{tabular}


Nach der Leitlinie KDIGO 2012 wurden die eGFR und Albuminurie in verschiedene Stadien eingeteilt (Tabelle 3).

Tabelle 3: Einteilung der eGFR und der Albuminurie nach der Leitlinie KDIGO 2012.

\begin{tabular}{l|l|l|l} 
Stadium & $\begin{array}{l}\text { eGFR } \\
\text { (ml/min/1,732) }\end{array}$ & Stadium & $\begin{array}{l}\text { Albuminurie } \\
\text { (mg/g Kreatinin) }\end{array}$ \\
\hline G1 (normal/hoch) & $\geq 90$ & A1 (normal-leicht erhöht) & $<30$ \\
\hline G2 (leicht erniedrigt) & $60-89$ & A2 (mittelgradig erhöht) & $30-300$ \\
\hline G3a (leicht/mittelgradig erniedrigt) & $45-59$ & A3 (stark erhöht) & $>300$ \\
\hline G3b mittelgradig/stark erniedrigt) & $30-44$ & & \\
\hline G4 (stark erniedrigt) & $15-29$ & & \\
\hline G5 (Nierenversagen) & $<15$ & &
\end{tabular}

Aus den eingeteilten Stadien konnte man schließlich verschiedene Risikogruppen bilden, die das Risiko für die Entwicklung einer chronischen Niereninsuffizienz anzeigen (Tabelle 4).

Tabelle 4: Prognose der CKD bei den einzelnen eGFR- und Albuminurie-Stadien.

\begin{tabular}{|c|c|c|c|c|c|}
\hline & & & \multicolumn{3}{|c|}{$\begin{array}{l}\text { Albuminurie-Stadium } \\
\text { (mg/g Kreatinin) }\end{array}$} \\
\hline & & & A1 & A2 & A3 \\
\hline & & & $\begin{array}{c}\text { normal bis } \\
\text { leicht er- } \\
\text { höht }\end{array}$ & $\begin{array}{l}\text { mittelgra- } \\
\text { dig erhöht }\end{array}$ & stark erhöht \\
\hline \multirow{6}{*}{ 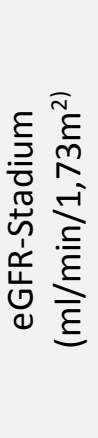 } & G1 & normal/hoch & \multirow{2}{*}{1} & \multirow{2}{*}{2} & \multirow{2}{*}{3} \\
\hline & $\mathbf{G 2}$ & leicht erniedrigt & & & \\
\hline & G3a & leicht/mittelgradig erniedrigt & 2 & 3 & \multirow{4}{*}{4} \\
\hline & G3b & mittelgradig/stark erniedrigt & 3 & \multirow{3}{*}{4} & \\
\hline & G4 & stark erniedrigt & \multirow{2}{*}{4} & & \\
\hline & G5 & Nierenversagen & & & \\
\hline
\end{tabular}

1: geringes Risiko; 2: leicht erhöhtes Risiko; 3: hohes Risiko; 4: sehr hohes Risiko (Einteilung erfolgte nach der Leitlinie KDIGO 2012). 


\subsection{Immunsuppression}

Des Weiteren wurden den Patientenakten Informationen bezüglich der Immunsuppression entnommen. Dabei wurden Medikamente gleicher Wirkstoffgruppen teilweise zusammengeführt (z. B. TNF-alpha-Blocker). Die einzelnen Medikamente können Tabelle 5 entnommen werden.

Tabelle 5: Immunsuppressiva des Studienkollektivs.

\begin{tabular}{l|l} 
Immunsuppressiva & Wirkstoffe \\
\hline Glukokortikoide & $\begin{array}{l}\text { Prednisolon (\& Dosisäquivalente) } \\
\text { Methotrexat } \\
\text { Methotrexat }\end{array}$ \\
\hline Antimetabolite & $\begin{array}{l}\text { Adalimumab, Certolizumab, Etanercept, Golimumab, } \\
\text { Infliximab }\end{array}$ \\
\hline TNF-alpha-Blocker & $\begin{array}{l}\text { Rituximab } \\
\text { Cyclophosphamid }\end{array}$ \\
\hline MabThera &
\end{tabular}

\subsection{Parameter im Verlauf}

Um die Qualität der einzelnen Parameter hinsichtlich ihrer prädiktiven Aussagekraft einschätzen zu können, wurden zu jedem Patienten, der sich im Zeitraum von Januar 2011 bis einschließlich Februar 2015 mehrmals vorstellte, die einzelnen Parameter der Vorstellungen in die Datentabelle aufgenommen. Dabei wurden eine sehr kurzfristige $(0,1-3,0$ Monate nach Erstvorstellung (MnEV)), eine kurzfristige (3,1 - 6,0 MnEV), eine mittelfristige $(6,1$ - 12,0 MnEV), eine langfristige $(12,1$ - 24,0 MnEV) und eine sehr langfristige ( $>24$ MnEV) Wiedervorstellung unterschieden.

Für den Fall dass ein Patient in einem Zeitfenster mehrmals vorstellig wurde, wurde das Datum ausgewählt, das dem Median des jeweiligen Zeitfensters am nächsten war. 


\subsection{Statistische Auswertung und graphische Darstellung}

Die statistische Auswertung und graphische Darstellung der Daten erfolgte mit Microsoft Office Excel 2013, STATISTICA 12.0 und SPSS Statistics 23.0. Die Tabellen sowie einige Abbildungen wurden mit Microsoft Office Word 2013 erstellt.

Die statistische Analyse wurde nach einem Vorgespräch über die Auswertung und mit Hilfe von Herrn PD Dr. K. Jung (Abteilung medizinische Statistik der Georg-August-Universität Göttingen) durchgeführt. Zudem erfolgte eine Unterstützung durch das Institut für Pharmakologie und Präventive Medizin in Cloppenburg (Frau Dr. C. Deutsch).

Der gesamte Datensatz wurde deskriptiv ausgewertet und mittels Häufigkeitstabellen und Graphiken dargestellt.

Zum Vergleich zwischen zwei Gruppen wurde der t-Test bzw. der MannWhitney-U-Test für kontinuierliche Variablen verwendet. Für kategoriale Variablen wurde der $\mathrm{X}^{2}$-Test bzw. der Fisher's Exakt-Test angewandt. Um eine mögliche Korrelation zu erkennen, wurden die Pearson- oder SpearmanKorrelation durchgeführt.

Ein $\mathrm{p}$-Wert $<0,05$ wurde als statistisch signifikant angesehen.

Receiver operating characteristics (ROC) Kurven in Verbindung mit dem Youden's Index wurden zur Bestimmung des cut-off Wertes der einzelnen Parameter zur Festlegung der Sensitivität, der Spezifität und der positiven Likelihood Ratio genommen. 


\section{Ergebnisse}

\subsection{Patientenkollektiv}

Das Gesamtkollektiv bestand aus 1526 Patienten, von denen 1500 Patienten aufgrund der vorliegenden Daten ausgewertet wurden (43,2 \% weiblich (648/1500)). Aus diesen 1500 Patienten wurden verschiedene Kollektive gebildet, um einzelne Gruppen miteinander vergleichen zu können (siehe Abbildung 1). Von den 1500 Patienten litten 401 Patienten an einer chronisch entzündlichen rheumatischen Grunderkrankung. Um mögliche Einflussfaktoren auf die Höhe der Leichtketten im Urin auszuschließen, wurden 19 Patienten mit akutem Malignom, multiplen Myelom, MGUS oder Amyloidose ausgeschlossen.

Dieses Studienkollektiv ( $N=382)$ setzte sich aus 213 weiblichen $(55,8 \%)$ und 169 männlichen Patienten zusammen. Das mittlere Alter lag bei $56,8 \pm 16,7$ Jahren (Tabelle 6). Aus dem mittleren Gewicht $(62,5 \pm 19,5 \mathrm{~kg})$ und der Größe $(161,5 \pm 10,6 \mathrm{~cm})$ ergab sich ein errechneter BMI von 23,8 \pm $6,1 \cdot \mathrm{kg} / \mathrm{m}^{2}$.

Aus dem Gesamtkollektiv entstanden zudem zwei Referenzgruppen:

a) die Referenzgruppe Gesund $(\mathrm{N}=140)$; bestehend aus Patienten ohne Autoimmunerkrankungen, Infektionen, Nieren- oder Lebererkrankungen oder hämato-/onkologischen Erkrankungen. Die meisten dieser Patienten waren wegen einer arteriellen Hypertonie, einer dermatologischen Erkrankung oder eines Apoplex in Behandlung.

b) die Referenzgruppe Infektion ( $\mathrm{N}=219)$; bestehend aus Patienten mit systemischer Infektion oder Sepsis, wobei lokale Infekte der Haut, Harnwegsinfekte oder Verdachtsdiagnosen ausgeschlossen wurden.

Tabelle 6: Epidemiologische Daten der einzelnen Kollektive.

\begin{tabular}{l|l|l|l|l} 
& Gesamtkollektiv & Studienkollektiv & $\begin{array}{l}\text { Referenzgruppe } \\
\text { Gesund }\end{array}$ & $\begin{array}{l}\text { Referenzgruppe } \\
\text { Infektion }\end{array}$ \\
\hline $\begin{array}{l}\text { Geschlecht } \\
\text { (\% weiblich) }\end{array}$ & $648 / 1500(43,2)$ & $213 / 382(55,8)$ & $53 / 140(37,9)$ & $83 / 219(37,9)$ \\
Alter (Jahren) & $58,5 \pm 20,3$ & $56,8 \pm 16,7$ & $49,1 \pm 22,9$ & $64,2 \pm 19,1$
\end{tabular}

Werte in Mittelwert (MW) \pm Standardabweichung (SA) oder $n / N(\%)$. 


\subsection{Studienkollektiv}

\subsubsection{Rheumatische Grunderkrankungen}

Als Einschlusskriterium in die Studie galt das Vorhandensein einer chronisch entzündlichen rheumatischen Grunderkrankung bei Abwesenheit von hämato-/ onkologischen Erkrankungen und/oder einer Amyloidose. Die rheumatischen Erkrankungen wurden in verschiedene Ober- und Untergruppen eingeteilt:

Die Obergruppen setzten sich aus den chronischen Polyarthritiden (40,1\%), den Kollagenosen (21,2 \%), den Spondyloarthritiden (18,6\%), den Vaskulitiden $(15,7 \%)$ und den sonstigen rheumatischen Erkrankungen $(4,5 \%)$ zusammen (Abbildung 2).

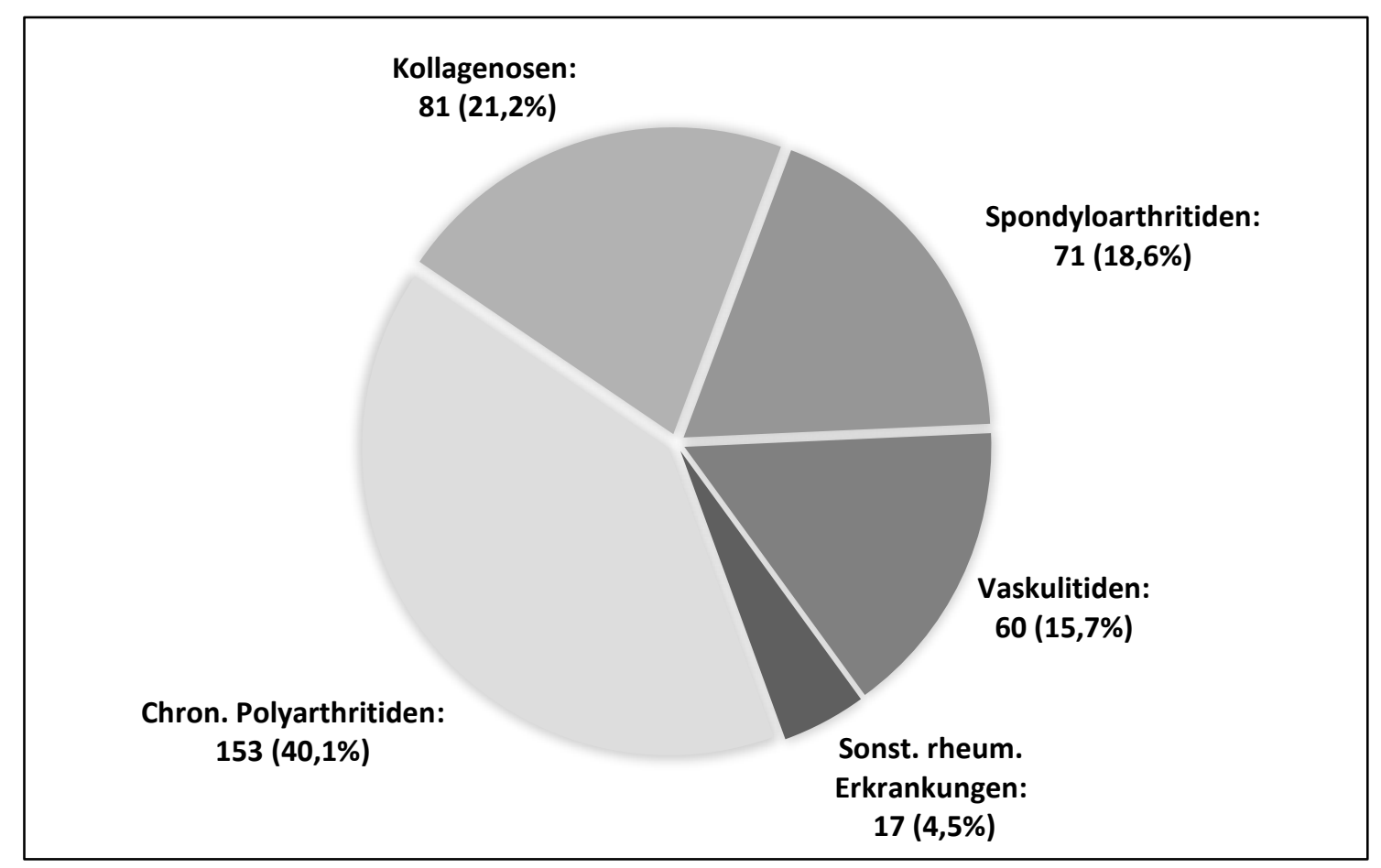

Abbildung 2: Anteil der Obergruppen im Studienkollektiv.

Die jeweils größten Untergruppen können der Tabelle 7 entnommen werden. Aufgeführt wurden die häufigsten Erkrankungen. Sehr seltene Erkrankungen wurden nicht gesondert in ihrer Häufigkeit aufgelistet, sind aber in der Legende erwähnt. 
Tabelle 7: Übersicht über die rheumatischen Grunderkrankungen im Studienkollektiv.

\begin{tabular}{l|ll} 
Obergruppe: $\mathbf{n} / \mathbf{N}(\%)$ & Untergruppe: & n/N (\%) \\
\hline $\begin{array}{l}\text { Chronische Polyarthritiden: } \\
\text { 153/382 (40,1) }\end{array}$ & $\begin{array}{l}\text { Rheumatoide Arthritis } \\
\text { Sonstige Polyarthritiden }\end{array}$ & $\begin{array}{l}148 / 382(38,7) \\
5 / 382(1,3)\end{array}$ \\
\hline K1/lagenosen: & Systemischer Lupus erythematodes & $34 / 382(8,9)$ \\
& (Limitierte) syst. Sklerodermie & $12 / 382(3,1)$ \\
& Diskoider Lupus erythematodes & $8 / 382(2,1)$ \\
& Mischkollagenosen & $7 / 382(1,8)$ \\
& Sjögren-Syndrom & $6 / 382(1,6)$ \\
& Sonstige Kollagenosen & $14 / 382(3,7)$ \\
\hline Spondyloarthritiden: & Psoriasisarthritis & $31 / 382(8,1)$ \\
$71 / 382(18,6)$ & Spondylitis ankylosans & $26 / 382(6,8)$ \\
& Sonstige Spondyloarthritiden & $14 / 382(3,7)$ \\
\hline Vaskulitiden: & & \\
$60 / 382(15,7)$ & ANCA-assoziierte Vaskulitiden & $26 / 382(6,8)$ \\
& Leukozytoklastische Vaskulitiden & $12 / 382(3,1)$ \\
& Polymyalgia rheumatica & $8 / 382(2,1)$ \\
& Aortitis & $3 / 382(0,8)$ \\
& Sonstige Vaskulitiden & $11 / 382(2,9)$ \\
\hline Sonstige Erkrankungen: & Sarkoidose & $13 / 382(3,4)$ \\
$17 / 382(4,5)$ & Reaktive Arthritis & $3 / 382(0,8)$ \\
& M. Behçet & $1 / 382(0,3)$
\end{tabular}

Bei den Obergruppen ergab sich rundungsbedingt eine Prozentzahl von 100,1\%. Unter den "Sonstigen Polyarthritiden" wurden der Morbus Still $(n=3)$ und die juvenile idiopathische Arthritis $(n=2)$ zusammengefasst. Zu den "Sonstigen Kollagenosen" wurden die Dermatomyositis ( $n=6)$, undifferenzierte Kollagenosen ( $n=3)$, das Jo1-Antikörper-Syndrom ( $n=2)$, die eosinophile Fasziitis $(n=2)$ und die okuläre Myositis ( $n=1)$ gezählt. Bei den "Sonstigen Spondyloarthritiden" handelte es sich um undifferenzierte Spondyloarthritiden $(n=12)$ und um enteropathisch-assoziierte Spondyloarthritiden ( $n=2)$. Unter den "Sonstigen Vaskulitiden" wurden die undifferenzierte Vaskulitis $(n=4)$, die Arteriitis temporalis $(n=2)$, die Panarteriitis nodosa $(n=2)$, das Kawasaki-Syndrom $(n=1)$, die Purpura Schoenlein-Henoch ( $n=1)$ und die Großgefäßvaskulitis $(n=1)$ zusammengefasst.

\subsubsection{Krankheitsaktivität und Entzündungswerte}

Eine Darstellung der Entzündungsaktivität anhand von Scores erfolgte nur für den DAS-28 als Marker für die Krankheitsaktivität der rheumatoiden Arthritis. Dieser wurde bei 51 Patienten mit der Grunderkrankung bestimmt und zeigte eine mittlere Aktivität der Grunderkrankung (DAS-28: MW \pm SA: 4,1 $\pm 1,6$ ) an. Leider wurden die krankheitsspezifischen Scores sowie die hierzu notwendigen Parameter für die weiteren Erkrankungen zu selten oder gar nicht 
erhoben, so dass keine weitere Auswertung erfolgte. Beispielhaft soll hier die Erhebung des BASDAI $(n=5)$ und des SLEDAI $(n=0)$ genannt sein.

Einen Überblick über die Entzündungswerte im Blut des Studienkollektivs liefert Tabelle 8. Im Mittel ist die Entzündung als leicht bis mittelgradig einzustufen. Hierbei bestehen jedoch zwischen den Patienten große Unterschiede, welches sich insbesondere beim CRP und der BSG nach 1 Stunde in einer großen Standardabweichung ausdrückt. Hierbei umfasst die Studie Patienten mit einem CRP von 0,2 mg/l bis zu einem maximalen Wert von $363,8 \mathrm{mg} / \mathrm{l}$. Einen ebenso breiten Umfang findet man für die BSG (1h) mit min. Werten von $1 \mathrm{~mm} / \mathrm{h} \mathrm{n}$. W. und max. Werten von $125 \mathrm{~mm} / \mathrm{h} \mathrm{n}$. W..

Tabelle 8: Übersicht über die Entzündungswerte im Blut des Studienkollektivs.

\begin{tabular}{|l|l|l} 
Entzündungsparameter im Blut & MW \pm SA & Minimum - Maximum \\
\hline CRP $(m g / I)(n=358)$ & $30,2 \pm 56,6$ & $0,2-363,8$ \\
\hline BSG $\mathbf{1 h}(\mathrm{mm} / \mathrm{h} n$. W.) $(n=156)$ & $23,9 \pm 26,1$ & $1-125$ \\
Procalcitonin $(\mu \mathrm{g} / \mathrm{l})(n=38)$ & $0,65 \pm 2,0$ & $0,05-11,1$ \\
\hline Leukozyten $(/ \mathrm{nl})(n=373)$ & $8,7 \pm 4,4$ & $1,8-64,5$ \\
\hline Lymphozyten (\% der Leukozyten) (n=103) & $21,7 \pm 9,9$ & $5,7-50,8$
\end{tabular}

Dieser weite Bereich an unterschiedlichen Entzündungsparametern stellt eine ideale Voraussetzung für die weiteren Untersuchungen dar, bei denen die Entzündung mit den Leichtketten im Urin korreliert werden soll. Diese Zusammenhänge finden sich ausführlich in Kapitel 3.4.

\subsubsection{Organbeteiligung}

Bei der Beteiligung der Grunderkrankung an den Organen zeigte sich, dass bei 81 Patienten $(21,2 \%)$ innere Organe befallen waren; davon war die Niere in 52 Fällen $(13,6 \%)$ beteiligt. Zudem waren folgende Organsysteme in absteigender Frequenz beteiligt: Haut (21,2 \%), Auge (7,3\%), Lunge $(6,8 \%)$, Hals-Nasen-Ohren $(4,7 \%)$, Knochenmark $(4,2 \%)$.

Am häufigsten zeigte sich eine Beteiligung der inneren Organe bei den Kollagenosen (43/81 (53,1\%)) und den Vaskulitiden (27/60 (45,0\%)). Bei 
beiden war insbesondere die Niere von der Grunderkrankung befallen (Kollagenosen: 26/81 (32,1\%); Vaskulitiden: 22/60 (36,7 \%)) (Abbildung 3).

Patienten mit einer chronischen Polyarthritis oder einer Spondyloarthritis litten erwartungsgemäß nur selten an einem Befall der inneren Organe.

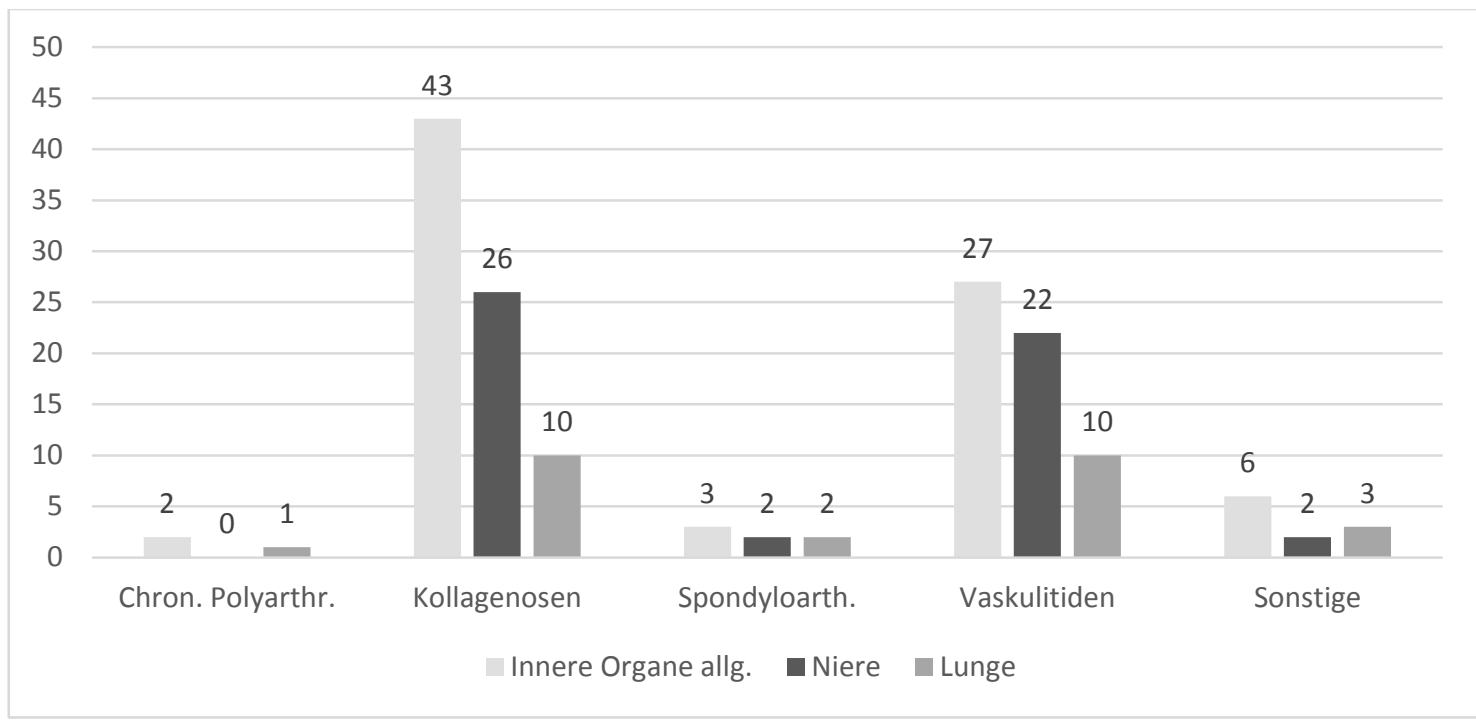

Abbildung 3: Beteiligung der Grunderkrankung an inneren Organen allgemein, der Niere und der Lunge. Absolute Zahlenwerte.

Die Auswertung der Nierenfunktionsparameter im Studienkollektiv zeigte für die eGFR einen Median von $80,3 \mathrm{ml} / \mathrm{min} / 1,73 \mathrm{~m}^{2}$, was dem Stadium G2 entspricht (Tabelle 9).

Tabelle 9: Übersicht über die Nierenwerte im Studienkollektiv.

\begin{tabular}{|l|l} 
Nierenfunktionsparameter & Median (1./3. Quartile) \\
\hline eGFR (ml/min/1,73m²) & $80,3(53,0 / 98,5)$ \\
\hline Proteinurie (mg/g Kreatinin) & $159,3(100,7 / 319,2)$ \\
\hline Albuminurie (mg/g Kreatinin) & $12,3(7,5 / 31,8)$ \\
\hline alpha-1-Mikroglobulinurie (mg/g Kreatinin) & $17,7(10,2 / 33,2)$
\end{tabular}

Bei fehlender Normalverteilung wurde hier der Median verwendet.

In Bezug auf das Risiko einer chronischen Niereninsuffizienz, bemessen anhand der CKD-Risikogruppierung, zeigte sich für die Mehrheit der Patien- 
ten ein geringes Risiko. Die Risikogruppe-1 (RG-1) mit einer eGFR $\geq 60$ $\mathrm{ml} / \mathrm{min} / 1,73 \mathrm{~m}^{2}$ machte 58,1 \% des Studienkollektivs aus. Etwa ebenso hoch war der Anteil der RG-1 bei Patienten mit chronischer Polyarthritis (66,0 \%). Anders war es bei den Vaskulitiden: Dort zeigte sich bei etwa einem Drittel der Patienten ein sehr hohes Risiko für die Entwicklung einer chronischen Niereninsuffizienz (RG-4 / eGFR $<30$ ml/min/1,73m² und/oder Albuminurie: 35,0 \%). Die Patienten der Kollagenosen waren zu 27,1 \% der RG-3 oder -4 angehörig (Abbildung 4).

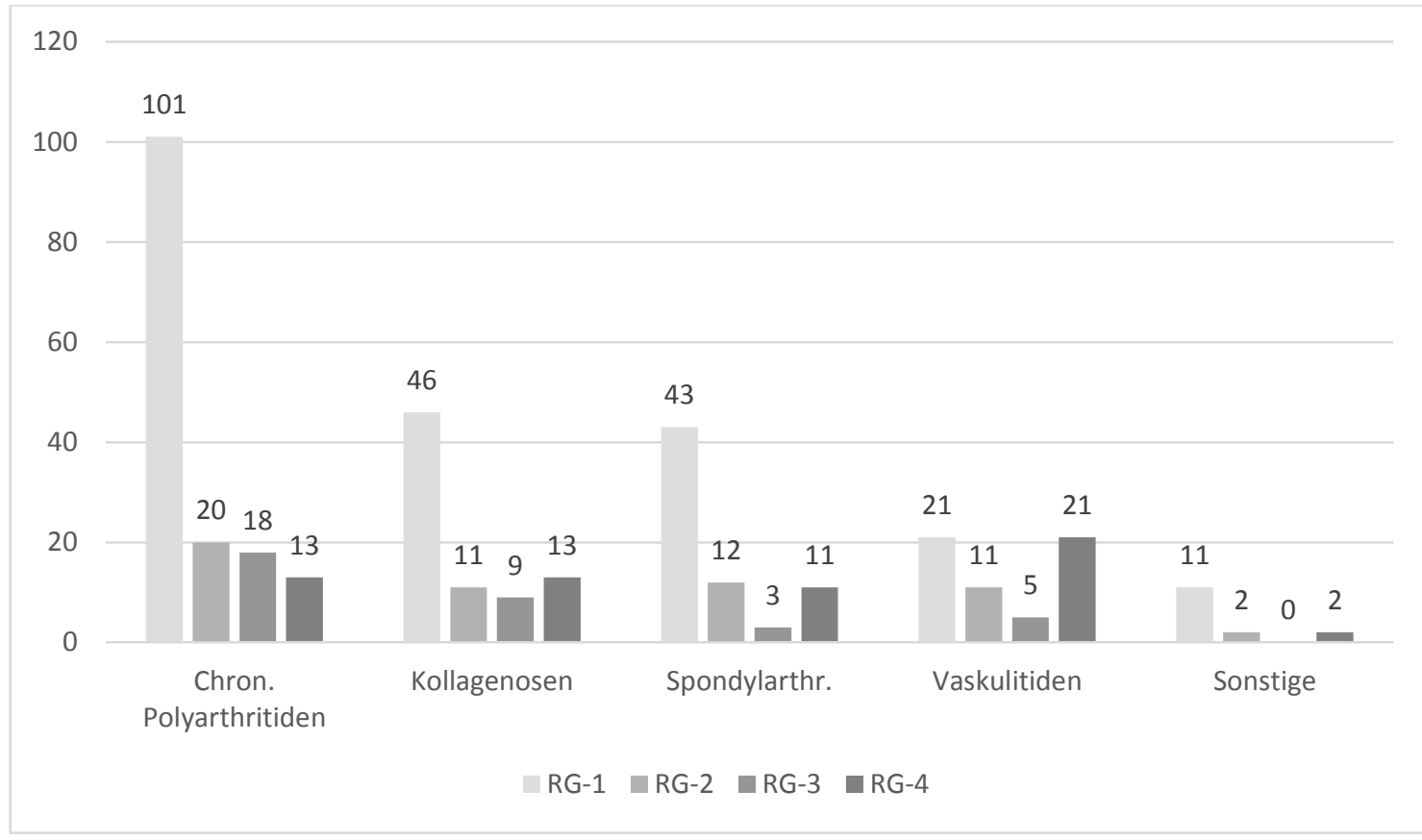

Abbildung 4: Einteilung in CKD-Risikogruppen innerhalb der Obergruppen.

Absolute Zahlenwerte. RG-1: eGFR $\geq 60 \mathrm{ml} / \mathrm{min} / 1,73^{2}$ und Albuminurie $<30 \mathrm{mg} / \mathrm{g} ; R G-2$ : eGFR $\geq 45$ $\mathrm{ml} / \mathrm{min} / 1,73^{2}$ und Albuminurie $<30 \mathrm{mg} / \mathrm{g}$ oder eGFR $\geq 60 \mathrm{ml} / \mathrm{min} / 1,73^{2}$ und Albuminurie $30-300$ $\mathrm{mg} / \mathrm{g}$; RG-3: eGFR $\geq 30 \mathrm{ml} / \mathrm{min} / 1,73^{2}$ und Albuminurie $<30 \mathrm{mg} / \mathrm{g}$ oder eGFR $\geq 45 \mathrm{ml} / \mathrm{min} / 1,73^{2}$ und Albuminurie $30-300 \mathrm{mg} / \mathrm{g}$ oder eGFR $\geq 60 \mathrm{ml} / \mathrm{min} / 1,73^{2}$ und Albuminurie $>300 \mathrm{mg} / \mathrm{g} ; \mathrm{RG}-4$ : eGFR $<30 \mathrm{ml} / \mathrm{min} / 1,73^{2}$ oder eGFR $<45 \mathrm{ml} / \mathrm{min} / 1,73^{2}$ und Albuminurie $30-300 \mathrm{mg} / \mathrm{g}$ oder eGFR $<60 \mathrm{ml} / \mathrm{min} / 1,73^{2}$ und Albuminurie $>300 \mathrm{mg} / \mathrm{g}$. Siehe auch Tabelle 3 und 4 .

\subsubsection{Immunsuppression}

Insgesamt 286 Patienten (74,7 \%) nahmen ein oder mehrere Immunsuppressiva ein (1,2 $\pm 0,95$ Immunsuppressiva / Patient).

Den größten Anteil an der Gesamtheit der eingenommenen Immunsuppressiva hatte dabei das Prednisolon, das in unterschiedlichen Dosierungen 
insgesamt von 221 Patienten (55,5\%) eingenommen wurde. Den monoklonalen CD-20-Antikörper Rituximab erhielten 16 Patienten (4,2 \%) (Abbildung $5)$.

Hierbei erfolgte die Einnahmehäufigkeit in Abhängigkeit von der zugrunde liegenden Grunderkrankung. Dabei wurde MXT zu 71,2 \% von Patienten mit chronischer Polyarthritis eingenommen, die Antimetabolite vorwiegend von solchen mit Kollagenose $(50,0 \%)$ und Cyclophosphamid von solchen mit Vaskulitiden $(70,0 \%)$.

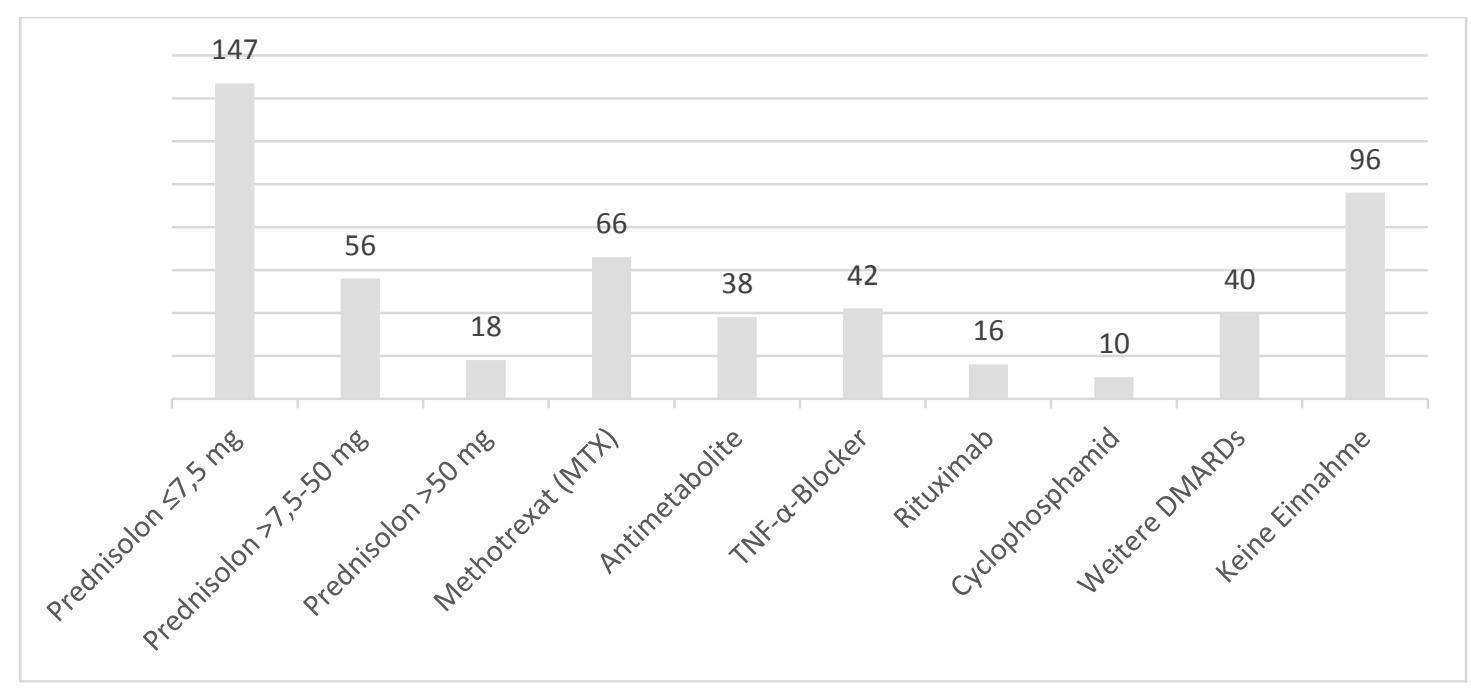

Abbildung 5: Immunsuppressiva im Studienkollektiv. Absolute Zahlenwerte.

\subsection{Charakterisierung der Referenzgruppen}

Die Referenzgruppe Gesund bestand aus 140 Patienten mit unauffälliger systemischer Entzündungsaktivität bei dermatologischen Krankheitsbildern, arterieller Hypertonie oder neurologischen Symptomen. Ausgeschlossen wurden Patienten mit Autoimmunerkrankungen, Infektionen, Nieren- oder Lebererkrankungen oder hämato-/onkologischen Erkrankungen.

Patienten der Referenzgruppe Infektion litten zu 54,8 \% an einer pulmonalen Infektion, die zumeist durch eine (septische) Pneumonie bedingt war. Es folgten in absteigender Reihenfolge sonstige Infektionen (18,7 \%), gastrointestinale $(11,9 \%)$, urogenitale $(10,5 \%)$ und zuletzt eine kleine Gruppe von 
Patienten mit Endokarditis (4,1 \%). Es wurden vornehmlich bakterielle Infekte, aber auch solche mit einer viralen Genese eingeschlossen. Eine genauere Beschreibung der einzelnen Krankheiten findet sich in Tabelle 10.

Tabelle 10: Patienten der Referenzgruppe Infektion.

\begin{tabular}{|c|c|c|}
\hline $\begin{array}{l}\text { Referenzgruppe Infektion } \\
(\mathrm{N}=219)\end{array}$ & Art der Infektion & $n / N(\%)$ \\
\hline Pulmonal $(n=120)$ & $\begin{array}{l}\text { Pneumonie } \\
\text { Pneumonie mit Sepsis } \\
\text { Bronchitis/infektexacerbierte COPD }\end{array}$ & $\begin{array}{l}58 / 219(26,5) \\
46 / 219(21,0) \\
16 / 219(7,3)\end{array}$ \\
\hline Gastrointestinal $(n=26)$ & $\begin{array}{l}\text { Gastroenteritis } \\
\text { Cholezystitis/Cholangitis } \\
\text { Bakterielle Peritonitis } \\
\text { Pankreatitis }\end{array}$ & $\begin{array}{l}12 / 219(5,5) \\
6 / 219(2,7) \\
5 / 219(2,3) \\
3 / 219(1,4)\end{array}$ \\
\hline Urogenital $(n=23)$ & $\begin{array}{l}\text { Harnwegsinfekt mit Sepsis } \\
\text { Pyelonephritis }\end{array}$ & $\begin{array}{l}21 / 219(9,6) \\
2 / 219(0,9)\end{array}$ \\
\hline Endokarditis $(n=9)$ & $\begin{array}{l}\text { Mit Sepsis } \\
\text { Ohne Sepsis }\end{array}$ & $\begin{array}{l}5 / 219(2,3) \\
4 / 219(1,8)\end{array}$ \\
\hline Sonstige $(n=41)$ & $\begin{array}{l}\text { Sepsis unklarer Fokus } \\
\text { Sepsis bei Weichteilinfektion } \\
\text { Infekt mit unklarem Fokus } \\
\text { Sepsis bei Fremdkörperinfektion } \\
\text { Virale Infektion (EBV, CMV, HPV) }\end{array}$ & $\begin{array}{l}15 / 219(6,8) \\
7 / 219(3,2) \\
7 / 219(3,2) \\
6 / 219(2,7) \\
6 / 219(2,7)\end{array}$ \\
\hline
\end{tabular}

Rundungsbedingt ergab sich eine Prozentzahl von 99,9\%.

\subsection{Leichtketten und kappa-lambda-Quotient im Urin}

In diesem Kapitel werden die Leichtketten, ihr Quotient und mögliche Einflussfaktoren auf dessen Höhe beschrieben.

Die durchschnittliche Höhe der $\mathrm{K}$ - und $\lambda$-LK im Studienkollektiv lag bei 26,5 \pm 41,7 mg/l (Norm: <6,8 mg/l) und 10,3 $\pm 22,3 \mathrm{mg} / \mathrm{l}$ (Norm: <3,7 mg/l). Hierbei hatten Patienten mit einer Kollagenose ( $\mathrm{K}: 44,6 \pm 70,8 \mathrm{mg} / \mathrm{l} ; \lambda: 18,1$ $\pm 41,8 \mathrm{mg} / \mathrm{l})$ und insbesondere mit einem systemischen Lupus erythematodes ( $\mathrm{K}: 57,2 \pm 86,5 \mathrm{mg} / \mathrm{l} ; \lambda: 28,2 \pm 60,5 \mathrm{mg} / \mathrm{l}$ ) durchschnittlich die höchsten Werte (Tabelle 11). Gefolgt wurden die Kollagenosen von Patienten mit ANCA-assoziierten Vaskulitiden und Spondyloarthritiden. Die niedrigsten Werte zeigten sich für Patienten mit chronischer Polyarthritis, wobei Patienten mit rheumatoider Arthritis die niedrigsten Werte präsentierten ( $: 18,9 \pm$ 
$26,8 \mathrm{mg} / \mathrm{l} ; \lambda: 7,1 \pm 11,6 \mathrm{mg} / \mathrm{l})$. Bezogen auf pathologisch erhöhte Leichtketten im Urin oberhalb der Norm zeigte sich, dass im Studienkollektiv insgesamt $84,0 \%$ erhöhte $\kappa$-Werte und 60,5 \% erhöhte $\lambda$-Werte aufwiesen.

Bei allen Obergruppen und den meisten Untergruppen waren die FLK im Vergleich zur Referenzgruppe Gesund signifikant erhöht. Ausnahmen bildeten hiervon nur die Untergruppe „Psoriasisarthritis" sowie Patienten mit einem diskoiden Lupus erythematodes (DLE) (Tabelle 11).

Bei der Bewertung der einzelnen Gruppen sollte die große Spannbreite beachtet werden. Ein Beispiel hierfür sind Patienten mit SLE und DLE in der Gruppe der Kollagenosen: Hier hatten Patienten der SLE-Gruppe deutlich höhere Werte als die der DLE-Gruppe (Tabelle 11).

Stellt man alle drei verschiedenen Patientenkollektive nebeneinander, so stellt man fest, dass die Referenzgruppe Infektion die höchsten Leichtketten aufwies ( $\mathrm{k}: 96,3 \pm 117,9 \mathrm{mg} / \mathrm{l} ; \lambda: 43,1 \pm 61,7 \mathrm{mg} / \mathrm{l}$ ), gefolgt von dem Studienkollektiv und zuletzt der Referenzgruppe Gesund ( $\mathrm{k}:$ 10,9 \pm 6,2 mg/; $\lambda: 4,4 \pm 2,7 \mathrm{mg} / \mathrm{l})$. Dieselbe Reihenfolge gilt auch für die Prävalenzen pathologisch erhöhter Leichtketten. Hier zeigte die Referenzgruppe Infektion bei 97,7 \% erhöhte א-FLK und bei 96,8 \% der Patienten erhöhte $\lambda$-FLK. Auffällig ist auch, dass die Referenzgruppe Gesund ebenfalls erhöhte FLK aufwies (Tabelle 11).

Weniger auffällig waren der Quotient aus $\mathrm{k}$ und $\lambda$ (Norm: <5,2). Zu erwähnen ist der niedrigste Wert bei der Referenzgruppe Gesund sowie ein dazu signifikant erhöhter Wert bei den Kollagenosen $(p<0,001)$, den Spondyloarthritiden $(p<0,05)$ und den sonstigen rheumatischen Erkrankungen $(p<0,01)$. Ansonsten zeigten sich zwischen den Gruppen keine signifikanten Unterschiede. Zur Wahrung der Übersichtlichkeit wurde sich in der Tabelle 11 auf die freien Leichtketten beschränkt und der Quotient nicht dargestellt. 
Tabelle 11: Leichtketten und ihr Quotient innerhalb der einzelnen Patientenkollektive.

\begin{tabular}{|c|c|c|c|c|}
\hline & $\begin{array}{l}\mathbf{k}(\mathbf{m g} / \mathrm{l}) \\
\mathrm{MW} \pm \mathrm{SA}\end{array}$ & $\begin{array}{l}\kappa \geq 6,8 \mathrm{mg} / \mathrm{l} \\
\mathrm{n} / \mathrm{N}(\%)\end{array}$ & $\begin{array}{l}\lambda(\mathrm{mg} / \mathrm{l}) \\
\mathrm{MW} \pm \mathrm{SA}\end{array}$ & $\begin{array}{l}\lambda \geq 3,7 \mathrm{mg} / \mathrm{l} \\
\mathrm{n} / \mathrm{N}(\%)\end{array}$ \\
\hline $\begin{array}{l}\text { Referenzgruppe Gesund } \\
(\mathrm{N}=140)\end{array}$ & $10,9 \pm 6,2$ & $95 / 140(67,9)$ & $4,4 \pm 2,7$ & $57 / 140(40,7)$ \\
\hline $\begin{array}{l}\text { Referenzgruppe Infektion } \\
(\mathrm{N}=219)\end{array}$ & $96,3 \pm 117,9 * * *$ & $214 / 219(97,7)$ & $43,1 \pm 61,7 * * *$ & $212 / 219(96,8)$ \\
\hline Studienkollektiv ( $\mathrm{N}=382$ ) & $26,5 \pm 41,7 * * *$ & $321 / 382(84,0)$ & $10,3 \pm 22,3 * * *$ & $231 / 382(60,5)$ \\
\hline Chron. Polyarthritis ( $n=153)$ & $19,8 \pm 27,3^{* * *}$ & $121 / 153(79,1)$ & $7,3 \pm 11,5^{* *}$ & $83 / 153(54,2)$ \\
\hline Rheumatoide Arthritis ( $n=148$ ) & $18,9 \pm 26,8^{* *}$ & $115 / 146(78,8)$ & $7,1 \pm 11,6 * *$ & $77 / 146(52,7)$ \\
\hline Spondyloarthritis $(n=71)$ & $23,0 \pm 25,0 * * *$ & $61 / 71(85,9)$ & $8,5 \pm 10,3^{* *}$ & $44 / 71(62,0)$ \\
\hline Spondylitis ankylosans $(n=26)$ & $25,5 \pm 26,7 *$ & $22 / 25(88,0)$ & $10,2 \pm 13,6^{*}$ & $17 / 25(68,0)$ \\
\hline Psoriasisarthritis $(n=31)$ & $19,3 \pm 24,7$ & $25 / 31(80,6)$ & $6,5 \pm 5,7^{*}$ & $17 / 31(54,8)$ \\
\hline Kollagenose $(n=81)$ & $44,6 \pm 70,8^{* * *}$ & $70 / 81(86,4)$ & $18,1 \pm 41,8^{* *}$ & $54 / 81(66,7)$ \\
\hline SLE $(n=34)$ & $57,2 \pm 86,5^{* *}$ & $30 / 34(88,2)$ & $28,2 \pm 60,5^{*}$ & $28 / 34(82,4)$ \\
\hline $\operatorname{DLE}(n=8)$ & $24,2 \pm 23,7$ & $6 / 7(85,7)$ & $10,6 \pm 15,1$ & $2 / 7(28,6)$ \\
\hline Vaskulitis $(n=60)$ & $23,6 \pm 32,1 * *$ & $54 / 60(90,0)$ & $10,0 \pm 15,7^{* *}$ & $40 / 60(66,7)$ \\
\hline ANCA-assoz. Vaskulitis $(n=26)$ & $25,2 \pm 29,9 *$ & $24 / 26(92,3)$ & $9,9 \pm 12,3^{*}$ & $16 / 26(61,5)$ \\
\hline $\begin{array}{l}\text { Sonstige rheum. Erkrankungen } \\
(n=17)\end{array}$ & $25,8 \pm 24,9 *$ & $15 / 17(88,2)$ & $7,7 \pm 6,0^{*}$ & $10 / 17(58,8)$ \\
\hline
\end{tabular}

Die $p$-Werte beziehen sich auf den Vergleich zur Referenzgruppe Gesund: ${ }^{*} p<0,05 ;{ }^{* *} p<0,01$; $* * * p<0,001$.

In den folgenden Abbildungen soll der Unterschied zwischen den Obergruppen und der Referenzgruppe Gesund sowie die große Spannbreite innerhalb der Gruppen noch einmal bildlich dargestellt werden (Abbildung 6 und 7). 


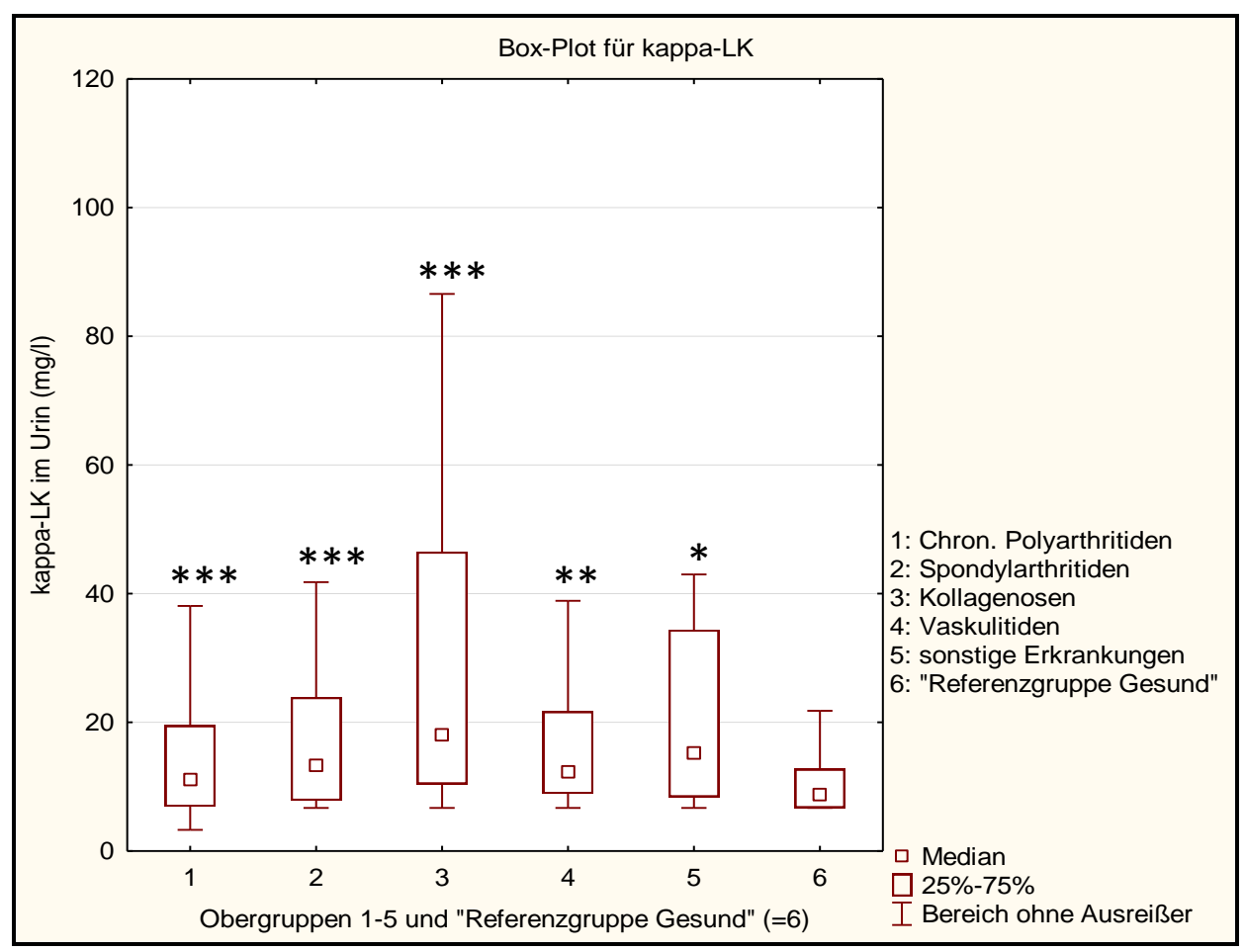

Abbildung 6: Box Plot für kappa-LK, eingeteilt in die Obergruppen und die Referenzgruppe Gesund; im Vergleich zur Referenzgruppe Gesund: ${ }^{*} p<0,05 ;{ }^{* *} p<0,01$; $* * * p<0,001$.

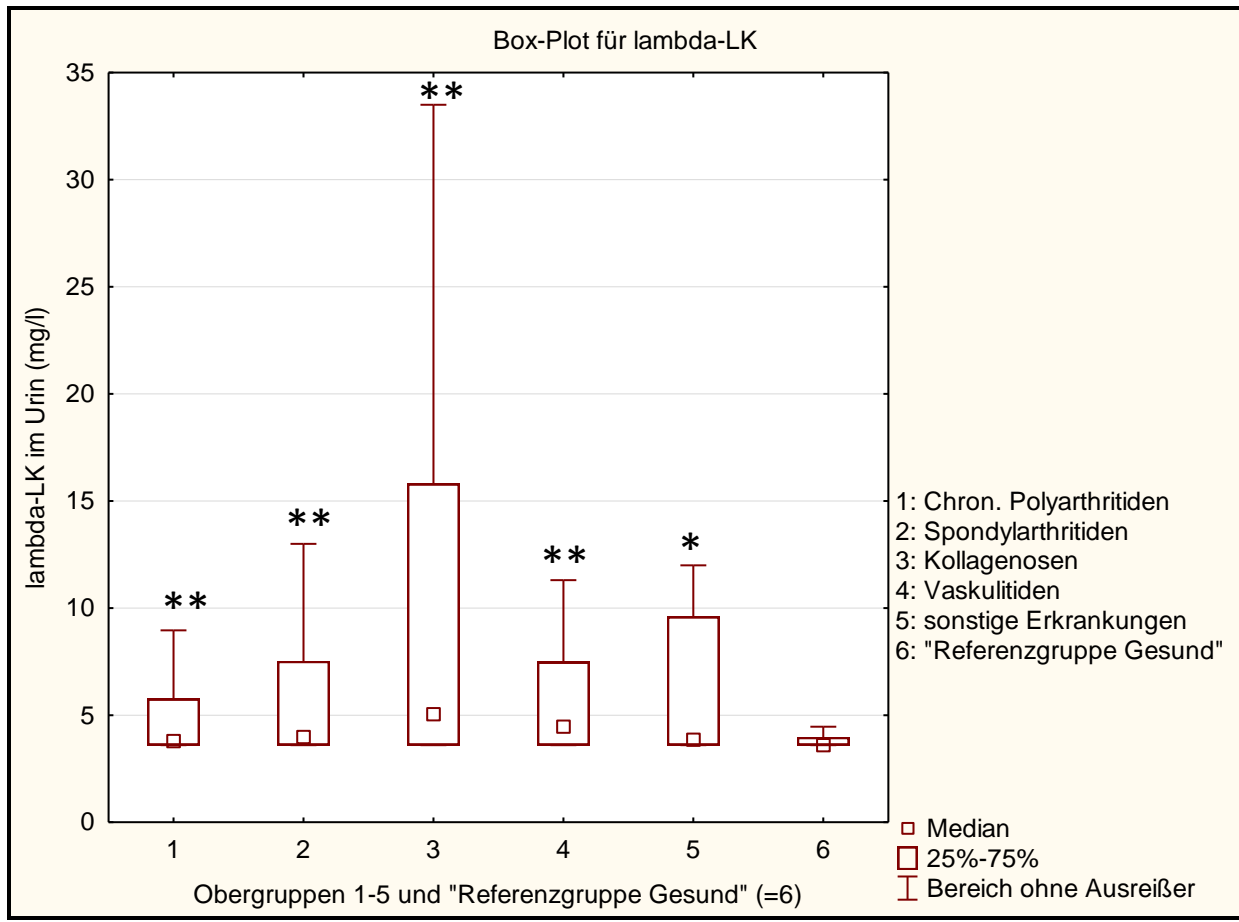

Abbildung 7: Box Plot für lambda-LK, eingeteilt in die Obergruppen und die Referenzgruppe Gesund; im Vergleich zur Referenzgruppe Gesund: ${ }^{*} p<0,05 ;{ }^{* *} p<0,01$; ${ }^{* * *} p<0,001$. 


\subsubsection{Prädiktiver Wert der Leichtketten auf rheumatische Erkrankun- gen}

Untersucht werden sollte, ob die FLK im Urin das Vorhandensein einer rheumatischen Erkrankung vorhersagen können. Dieses konnte für einen K-Wert über $6,8 \mathrm{mg} / \mathrm{I}$ nachgewiesen werden. Die hierfür berechnete Odds Ratio für die Gruppe Studienkollektiv vs. Referenzgruppe Gesund lag bei 2,49 (95 \%-KI: 1,59 - 3,90). Dieser Zusammenhang bestand nicht nur für das gesamte Studienkollektiv, sondern auch für jede einzelne Obergruppe.

Zudem nahmen auch die $\lambda$-Werte über $3,7 \mathrm{mg} / \mathrm{l}$ eine prädiktive Stellung ein. Auch hier lagen die Odds Ratio im Studienkollektiv und in allen Obergruppen in Gegenüberstellung zu der Referenzgruppe Gesund bei $>1$. Besonders stark war diese Assoziation in der Gruppe der Vaskulitiden ( $k>6,8 \mathrm{mg} / \mathrm{l}$ : OR 4,26; $95 \%$ KI 1,71-10,6; $p=0,001 ; \lambda>3,7$ mg/l: OR 2,91; $95 \%$ KI 1,55-5,49; $p=0,001)$.

Beim $\kappa / \lambda$-Quotienten über 5,2 zeigte sich nur in der Gruppe der Kollagenosen ein signifikanter Wert $(K / \lambda>5,2$ : OR 9,15; $95 \%$ KI 1,05-79,71; $p=0,026)$ (Tabelle 12).

Tabelle 12: Zusammenhang zwischen erhöhten Leichtketten und dem Vorhandensein einer chronisch entzündlichen rheumatischen Erkrankung; im Vergleich mit der Referenzgruppe Gesund.

\begin{tabular}{|c|c|c|c|c|c|c|}
\hline & $\mathrm{K}(\mathrm{mg} / \mathrm{l})$ & & $\lambda(\mathrm{mg} / \mathrm{l})$ & & $\kappa / \lambda$ & \\
\hline & OR (95 \% KI) & p-Wert & OR (95 \% KI) & $p$-Wert & OR (95 \% KI) & p-Wert \\
\hline Studienkollektiv & $2,49(1,59-3,90)$ & $<0,001$ & $2,23(1,50-3,31)$ & $<0,001$ & $6,47(0,85-49,11$ & 0,054 \\
\hline Chron. Polyarthritis & $1,79(1,06-3,03)$ & 0,029 & $1,73(1,09-2,75)$ & 0,021 & $6,66(0,81-54,87)$ & 0,069 \\
\hline Spondyloarthritis & $2,89(1,36-6,16)$ & 0,005 & $2,37(1,32-4,26)$ & 0,003 & $6,13(0,63-60,06)$ & 0,112 \\
\hline Kollagenose & $3,01(1,46-6,24)$ & 0,002 & $2,91(1,64-5,16)$ & $<0,001$ & $9,15(1,05-79,71)$ & 0,026 \\
\hline Vaskulitis & $4,26(1,71-10,64)$ & 0,001 & $2,91(1,55-5,49)$ & 0,001 & $4,79(0,43-53,90)$ & 0,215 \\
\hline
\end{tabular}

OR: Odds Ratio. KI: Konfidenzintervall. 


\subsubsection{Einfluss der Krankheitsaktivität und Entzündungswerte}

Im Folgenden sollte untersucht werden, ob die Erkrankungsaktivität mit der Höhe der Leichtketten korreliert. Für die einzelnen Erkrankungen liegen hierfür verschiedene spezifische Scores vor, die Befunde der Klinik mit der systemischen Entzündungsaktivität kombinieren. Wie oben beschrieben, lagen leider nur für den DAS-28 als Aktivitätsparameter der RA ausreichend Daten aus der retrospektiven Studie vor (51/148 (34,5 \%)). Zwischen dem DAS-28 und den Leichtketten bestand keine Korrelation (Tabelle 13).

Soweit Infektionen ausgeschlossen wurden, spiegeln auch die systemischen Entzündungsparameter (CRP und BSG) bei Patienten mit chronisch entzündlichen rheumatischen Erkrankungen die Krankheitsaktivität wider. Für die Berechnung wurden daher Patienten, die an einer akuten Infektion litten, aus dieser Berechnung herausgenommen.

Im Studienkollektiv korrelierte die Aktivität der Grunderkrankung, gemessen anhand der Entzündungsparameter CRP und BSG nach $1 \mathrm{~h}$ im Blut, leicht mit den $k$ - und $\lambda$-Leichtketten ( $p$ jeweils $\leq 0,001$ ) (Tabelle 13).

Die Korrelation ist jedoch unterschiedlich und zeigte sich besonders in der Obergruppe der Vaskulitiden. Hier wies das CRP eine starke Korrelation mit den $\mathrm{K}$-LK $(r=0,578 ; p<0.001)$ und den $\lambda$-LK $(r=0,514 ; p<0.001)$ auf.

Eine weitere Korrelation wurde für die große Gruppe der Patienten mit rheumatoider Arthritis festgestellt. Im Gegensatz zum DAS-28 (s. o.) ergab sich eine gute Korrelation zwischen den $k$ - und $\lambda$-Leichtketten sowie dem CRP ( $k: r=0,368 ; p<0,001 ; \lambda: r=0,398 ; p<0,001)$ als auch der BSG ( $k: r=0,692$; $p<0,001 ; \lambda: r=0,612 ; p<0,001$ ) (Tabelle 13).

Keine Korrelation zeigte sich für Patienten mit den weiteren Erkrankungen. Auch gab es in keiner Gruppe eine Korrelation zwischen der Aktivität der Grunderkrankung und dem $\mathrm{k} / \lambda$-Quotienten (Tabelle 13). 
Tabelle 13: Korrelation der Aktivität der Grunderkrankung anhand der Entzündungsparameter im Blut mit den Leichtketten im Urin im Studienkollektiv.

\begin{tabular}{|c|c|c|c|c|c|c|}
\hline & & $\mathrm{g} / \mathrm{ll}$ & & $\mathrm{g} / \mathrm{l})$ & & $/ \lambda$ \\
\hline & $r$ & $\mathrm{p}$ & $r$ & $\mathrm{p}$ & $r$ & $p$ \\
\hline Studienkollektiv ( $n$ & & & & & & \\
\hline $\operatorname{CRP}(n=312)$ & 0,208 & $<0,001$ & 0,190 & 0,001 & 0,044 & 0,436 \\
\hline BSG $1 \mathrm{~h}(\mathrm{n}=151)$ & 0,480 & $<0,001$ & 0,454 & $<0,001$ & 0,090 & 0,272 \\
\hline Rheumatoide Arthr & & & & & & \\
\hline $\operatorname{CRP}(n=129)$ & 0,368 & $<0,001$ & 0,398 & $<0,001$ & 0,084 & 0,346 \\
\hline BSG $1 \mathrm{~h}(\mathrm{n}=72)$ & 0,692 & $<0,001$ & 0,612 & $<0,001$ & 0,318 & 0,006 \\
\hline DAS-28 $(n=51)$ & 0,123 & 0,388 & 0,123 & 0,390 & 0,763 & 0,763 \\
\hline Spondyloarthritis & & & & & & \\
\hline $\operatorname{CRP}(n=64)$ & 0,132 & 0,299 & 0,178 & 0,160 & 0,127 & 0,318 \\
\hline BSG $1 \mathrm{~h}(\mathrm{n}=30)$ & 0,156 & 0,409 & 0,251 & 0,181 & $-0,245$ & 0,192 \\
\hline SLE & & & & & & \\
\hline $\operatorname{CRP}(n=24)$ & 0,397 & 0,055 & 0,088 & 0,684 & 0,393 & 0,057 \\
\hline BSG $1 \mathrm{~h}(n=8)$ & 0,653 & 0,079 & 0,649 & 0,082 & $-0,388$ & 0,342 \\
\hline Vaskulitis & & & & & & \\
\hline $\operatorname{CRP}(n=42)$ & 0,578 & $<0,001$ & 0,514 & $<0,001$ & 0,170 & 0,282 \\
\hline BSG 1 h (n=17) & 0,362 & 0,154 & 0,641 & 0,006 & $-0,163$ & 0,533 \\
\hline
\end{tabular}

Patienten mit akuter Infektion waren bei diesen Berechnungen ausgeschlossen.

Ebenso wurden keine Korrelationen zwischen den Leukozyten, den Lymphozyten und dem Procalcitonin und den Leichtketten oder ihrem Quotienten festgestellt (Tabelle 14).

Tabelle 14: Korrelation zwischen den Leichtketten im Urin und den Entzündungsparametern im Blut im Studienkollektiv.

\begin{tabular}{|c|c|c|c|c|c|c|}
\hline & \multicolumn{2}{|c|}{ K (mg/l) } & \multicolumn{2}{|c|}{$\lambda(\mathrm{mg} / \mathrm{l})$} & \multicolumn{2}{|c|}{$\kappa / \lambda$} \\
\hline & $r$ & $\mathrm{p}$ & $r$ & $\mathrm{p}$ & $r$ & $\mathrm{p}$ \\
\hline Procalcitonin $(n=38)$ & $-0,02$ & 0,898 & 0,04 & 0,794 & $-0,34$ & 0,038 \\
\hline Leukozyten $(n=373)$ & 0,02 & 0,715 & $-0,03$ & 0,579 & 0,00 & 0,997 \\
\hline Lymphozyten $(n=103)$ & $-0,11$ & 0,256 & $-0,10$ & 0,336 & 0,09 & 0,352 \\
\hline
\end{tabular}




\subsubsection{Einfluss der Organbeteiligung}

Bei den Patienten, bei denen die Grunderkrankung auch innere Organe geschädigt hat, fiel auf, dass diese im Durchschnitt höhere Leichtketten im Urin aufwiesen. Beispielhaft sei hier der große Unterschied zwischen dem systemischen LE ( $\kappa: 57,2 \pm 86,5 \mathrm{mg} / \mathrm{l} ; \lambda: 28,2 \pm 60,5 \mathrm{mg} / \mathrm{l})$ und dem diskoiden LE ( $\mathrm{K}: 24,2 \pm 23,7 \mathrm{mg} / \mathrm{l} ; \lambda: 10,6 \pm 15,1 \mathrm{mg} / \mathrm{l}$ ) oder auch die niedrigen Leichtkettenwerte bei den Patienten mit rheumatoider Arthritis oder Psoriasisarthritis genannt (siehe Tabelle 11).

Der Unterschied bei einem Befall der inneren Organe erwies sich als hoch signifikant (Innere Organe: $\mathrm{k}: 39,3 \pm 61,8 \mathrm{mg} / \mathrm{l} ; \lambda: 16,6 \pm 38,2 \mathrm{vs}$. Ohne Innere Organe: $k: 23,0 \pm 33,7 ; \lambda: 8,6 \pm 15,0 ; p$-Werte: $\kappa: p<0,001$; $\lambda: p<0,001)$. Auch die Patienten mit Befall der Niere zeigten höhere LK-Werte als Patienten ohne Nierenbefall der Grunderkrankung (Niere: $\kappa: 39,5 \pm 65,3$; $\lambda: 17,6 \pm 45,2$ vs. Ohne Niere: $k: 24,4 \pm 36,4 ; \lambda: 9,1 \pm 15,7 ; p$-Werte: $\kappa: p<0,01 ; \lambda: p<0,01)$. Die Auswertung ergab zudem, dass der prozentuale Anteil an pathologisch erhöhten Leichtkettenwerten erhöht war, wenn die inneren Organe oder nur die Niere von der Grunderkrankung befallen waren (Abbildung 8 und Tabelle 15).

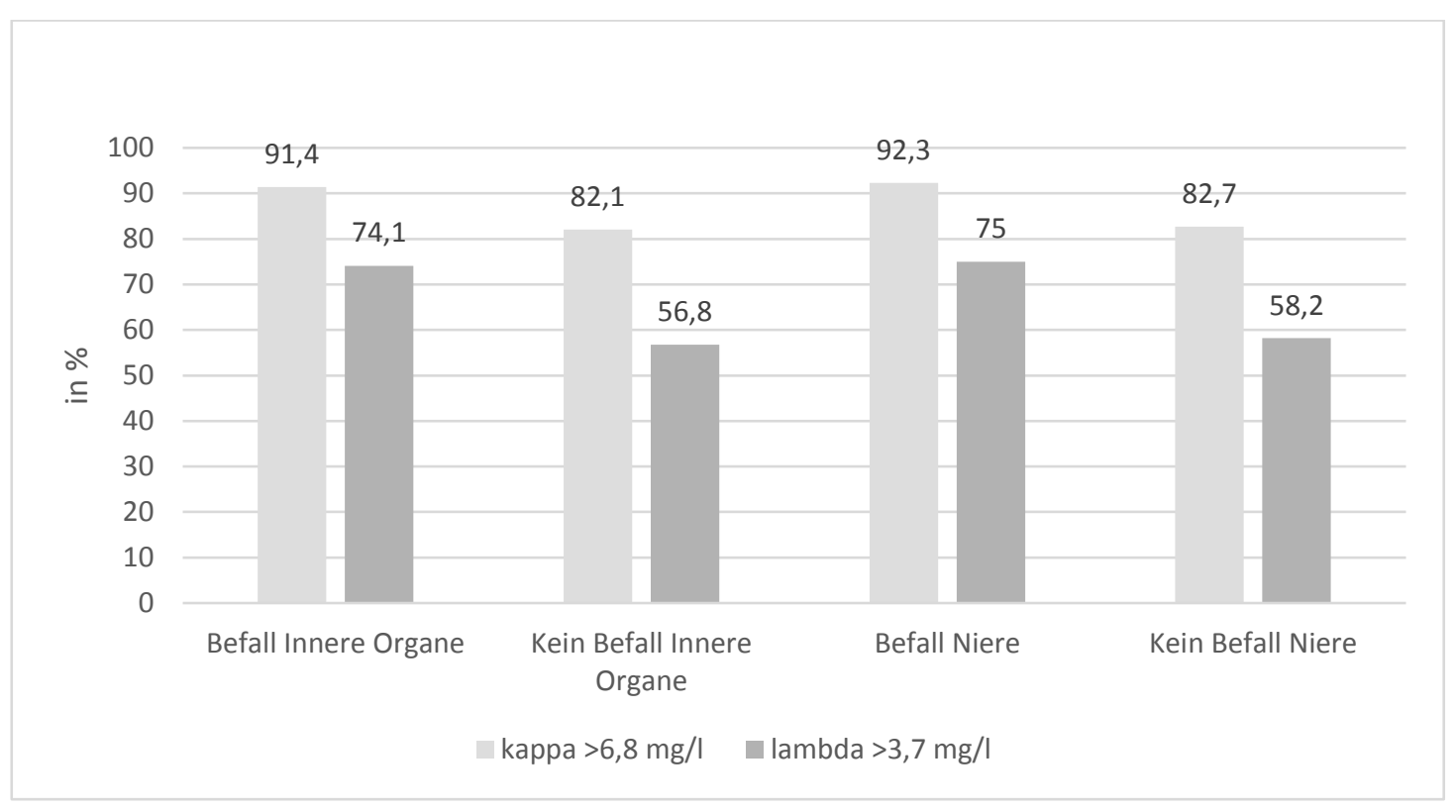

Abbildung 8: Darstellung der relativen Anzahl Patienten mit erhöhten Leichtketten bei Organbeteiligung ja/nein. 
Tabelle 15: Beteiligung der Grunderkrankung an inneren Organen.

\begin{tabular}{|c|c|c|c|c|c|c|}
\hline & $\begin{array}{l}\mathrm{k}(\mathrm{mg} / \mathrm{l}) \\
\mathrm{MW} \pm \mathrm{SA}\end{array}$ & $\begin{array}{l}\kappa \geq 6,8 \mathrm{mg} / \mathrm{l} \\
\mathrm{n} / \mathrm{N}(\%)\end{array}$ & $p$-Wert & $\begin{array}{l}\lambda(\mathrm{mg} / \mathrm{l}) \\
\mathrm{MW} \pm \mathrm{SA}\end{array}$ & $\begin{array}{l}\lambda \geq 3,7 \mathrm{mg} / \mathrm{l} \\
\mathrm{n} / \mathrm{N}(\%)\end{array}$ & p-Wert \\
\hline \multicolumn{7}{|l|}{$\begin{array}{l}\text { Beteiligung } \\
\text { Innere Organe }\end{array}$} \\
\hline ja $(n=81)$ & $39,3 \pm 61,8$ & $74 / 81(91,4)$ & \multirow{2}{*}{$p<0,001$} & $16,6 \pm 38,2$ & $60 / 81(74,1)$ & \multirow{2}{*}{$p<0,001$} \\
\hline nein $(n=301)$ & $23,0 \pm 33,7$ & $247 / 301(82,1)$ & & $8,6 \pm 15,0$ & $171 / 301(56,8)$ & \\
\hline \multicolumn{7}{|l|}{$\begin{array}{l}\text { Beteiligung } \\
\text { Niere }\end{array}$} \\
\hline ja $(n=52)$ & $39,5 \pm 65,3$ & $48 / 52(92,3)$ & \multirow{2}{*}{$p<0,01$} & $17,6 \pm 45,2$ & $39 / 52(75,0)$ & \multirow{2}{*}{$p<0,01$} \\
\hline nein $(n=330)$ & $24,4 \pm 36,4$ & $273 / 330(82,7)$ & & $9,1 \pm 15,7$ & $192 / 330(58,2)$ & \\
\hline \multicolumn{7}{|l|}{$\begin{array}{l}\text { Beteiligung } \\
\text { Lunge }\end{array}$} \\
\hline $\mathrm{ja}(\mathrm{n}=26)$ & $39,7 \pm 60,5$ & $24 / 26(92,3)$ & \multirow{2}{*}{$p=0,646$} & $12,3 \pm 18,5$ & $19 / 26(73,1)$ & \multirow{2}{*}{$p=0,695$} \\
\hline nein $(n=356)$ & $25,5 \pm 40,0$ & $297 / 356(83,4)$ & & $10,1 \pm 22,5$ & $212 / 356(59,6)$ & \\
\hline
\end{tabular}

Der Nierenbefall ist von besonderem Interesse, und es ist naheliegend, dass eine Niereninsuffizienz oder eine Proteinurie mit einer erhöhten Ausscheidung von Leichtketten einhergeht. Aufgrund dessen wurde eine Subanalyse mit den einzelnen Nierenfunktionsparametern durchgeführt. Bei den Parametern der Nierenfunktion zeigte sich, dass eine Proteinurie keinen signifikanten Einfluss auf die FLK oder ihren Quotienten hat $(k: p=0,097 ; \lambda: p=0,148 ; \kappa / \lambda$ : $p=0,193)$. Die eGFR, die Albuminurie und die a1-Mikroglobulinurie hingegen hatten einen signifikanten Einfluss auf die Höhe der FLK (für $\mathrm{K}$ : alle: $p<0,001$; für $\lambda$ : eGFR/a-1-Mikroglobulinurie: $p<0,001$, Albuminurie: $p=0,002$ ).

\subsubsection{Einfluss der Immunsuppression}

Bei der Einnahme eines oder mehrerer Immunsuppressiva zeigte sich, dass Patienten bei Einnahme niedrigere Leichtkettenwerte im Urin aufwiesen als bei Nicht-Einnahme. Jedoch war der Unterschied nicht signifikant ( $\mathrm{k}: \mathrm{p}=0,107 ; \lambda: p=0,583)$.

Im Gegensatz zu den meisten Immunsuppressiva erwies sich durch die Gabe von Rituximab ( $n=16$ (4,2 \%)) eine erheblich verminderte Ausscheidung von Leichtketten (Tabelle 16). Der Unterschied zur Gruppe der Patienten ohne Rituximab erwies sich hierbei als hoch-signifikant $(\kappa: p<0,01 ; \lambda: p<0,01)$. 
Für alle weiteren Einzelpräparate inklusive der Glukokortikoide konnte ein solcher Effekt nicht gesehen werden.

Tabelle 16: Leichtketten im Urin bei Einnahme/Nicht-Einnahme von Immunsuppressiva im Studienkollektiv.

\begin{tabular}{|c|c|c|c|c|c|c|}
\hline Studienkollektiv & $\begin{array}{l}\mathbf{k}(\mathbf{m g} / \mathrm{l}) \\
\mathrm{MW} \pm \mathrm{SA}\end{array}$ & $\begin{array}{c}\kappa \geq 6,8 \mathrm{mg} / \mathrm{l} \\
\mathrm{n} / \mathrm{N}(\%)\end{array}$ & p-Wert & $\begin{array}{c}\lambda(\mathrm{mg} / \mathrm{l}) \\
\mathrm{MW} \pm \mathrm{SA}\end{array}$ & $\begin{array}{c}\lambda \geq 3,7 \mathrm{mg} / \mathrm{l} \\
\mathrm{n} / \mathrm{N}(\%)\end{array}$ & p-Wert \\
\hline $\begin{array}{l}\text { Mit Immunsuppression } \\
(\mathrm{n}=286)\end{array}$ & $24,8 \pm 42,7$ & $238 / 286(83,2)$ & \multirow{2}{*}{0,107} & $10,2 \pm 24,3$ & $174 / 286(60,8)$ & \multirow{2}{*}{0,583} \\
\hline $\begin{array}{l}\text { Ohne Immunsuppression } \\
(n=96)\end{array}$ & $31,4 \pm 38,6$ & $83 / 96(86,5)$ & & $10,5 \pm 14,9$ & $57 / 96(59,4)$ & \\
\hline Mit Rituximab $(n=16)$ & $12,6 \pm 16,4$ & $9 / 16(56,3)$ & \multirow{2}{*}{$<0,01$} & $6,2 \pm 9,6$ & $4 / 16(25,0)$ & \multirow{2}{*}{$<0,01$} \\
\hline Ohne Rituximab $(n=366)$ & $27,1 \pm 42,4$ & $312 / 366(85,2)$ & & $10,4 \pm 22,6$ & $227 / 366(62,0)$ & \\
\hline
\end{tabular}

\subsubsection{Einfluss einer Infektion}

Basierend auf der Beobachtung, dass erhöhte systemische Entzündungsparameter mit den Leichtketten korrelieren, wurde im Folgenden der Frage nachgegangen, ob LK im Urin einen Hinweis auf die Ätiologie erhöhter Entzündungsparameter geben können. Diese Frage tritt in der Klinik häufig auf, wenn es darum geht, ob ein erhöhtes CRP oder eine erhöhte BSG durch die rheumatische Grunderkrankung selbst oder durch eine Infektion des immunsupprimierten Patienten verursacht wird.

Für die Untersuchung wurde das Studienkollektiv in weitere Unterkollektive eingeteilt, abhängig davon, ob eine Entzündung vorlag und wenn ja, ob sie durch eine erhöhte Aktivität der Grunderkrankung oder eine akute systemische Infektion bedingt war (Abbildung 1).

Folgende Feststellungen konnten aus den Daten herausgearbeitet werden. Dabei wird im Folgenden eine Reihenfolge gebildet je nach Höhe der Leichtketten im Urin, beginnend mit den Gruppen mit den geringsten Leichtketten (Tabelle 17): 
a) Patienten mit einer rheumatischen Erkrankung, aber ohne eine akute Entzündung (, in Remission") hatten die niedrigsten FLK Werte ( $\mathrm{n}=172$; $\mathrm{K}: 18,2 \pm 28,4 \mathrm{mg} / \mathrm{l} ; \lambda: 6,4 \pm 9,7 \mathrm{mg} / \mathrm{l})$.

b) Anschließend kamen die Patienten mit einer rheumatischen Erkrankung und erhöhten syst. Entzündungsparametern bedingt durch die Grunderkrankung ( $\mathrm{n}=162 ; \mathrm{k}: 22,7 \pm 26,3 \mathrm{mg} / \mathrm{l} ; \lambda: 8,1 \pm 9,1 \mathrm{mg} / \mathrm{l}$ ).

c) Patienten mit einer rheumatischen Erkrankung und erhöhten systemischen Entzündungsparametern bedingt durch einen zusätzlichen Infekt hatten wiederum noch höhere Werte $(\mathrm{n}=48 ; \mathrm{k}: 68,8 \pm 81,8 \mathrm{mg} / \mathrm{l}$; $\lambda: 31,4 \pm 53,5 \mathrm{mg} / \mathrm{l})$. Zwischen der Gruppe „bedingt durch aktive Grunderkrankung (b)" und „bedingt durch akute systemische Infektion (c)" bestand ein signifikanter Unterschied ( $\mathrm{k}: \mathrm{p}<0,001 ; \lambda: p=0,004)$.

d) Noch höhere Werte gab es in der Referenzgruppe Infektion ( $\mathrm{N}=219$; K: $96,3 \pm 117,9 \mathrm{mg} / \mathrm{l} ; \lambda$ : 43,1 $\pm 61,7 \mathrm{mg} / \mathrm{l})$. Dieser Unterschied wird insbesondere in den Box Plots deutlich (Abbildung 9 und 10).

Tabelle 17: Leichtketten im Urin in den einzelnen Kollektiven: Vergleich von Patienten mit Entzündung, verursacht durch die Grunderkrankung vs. Patienten mit rheumatischer Erkrankung und Entzündung, verursacht durch eine systemische Infektion.

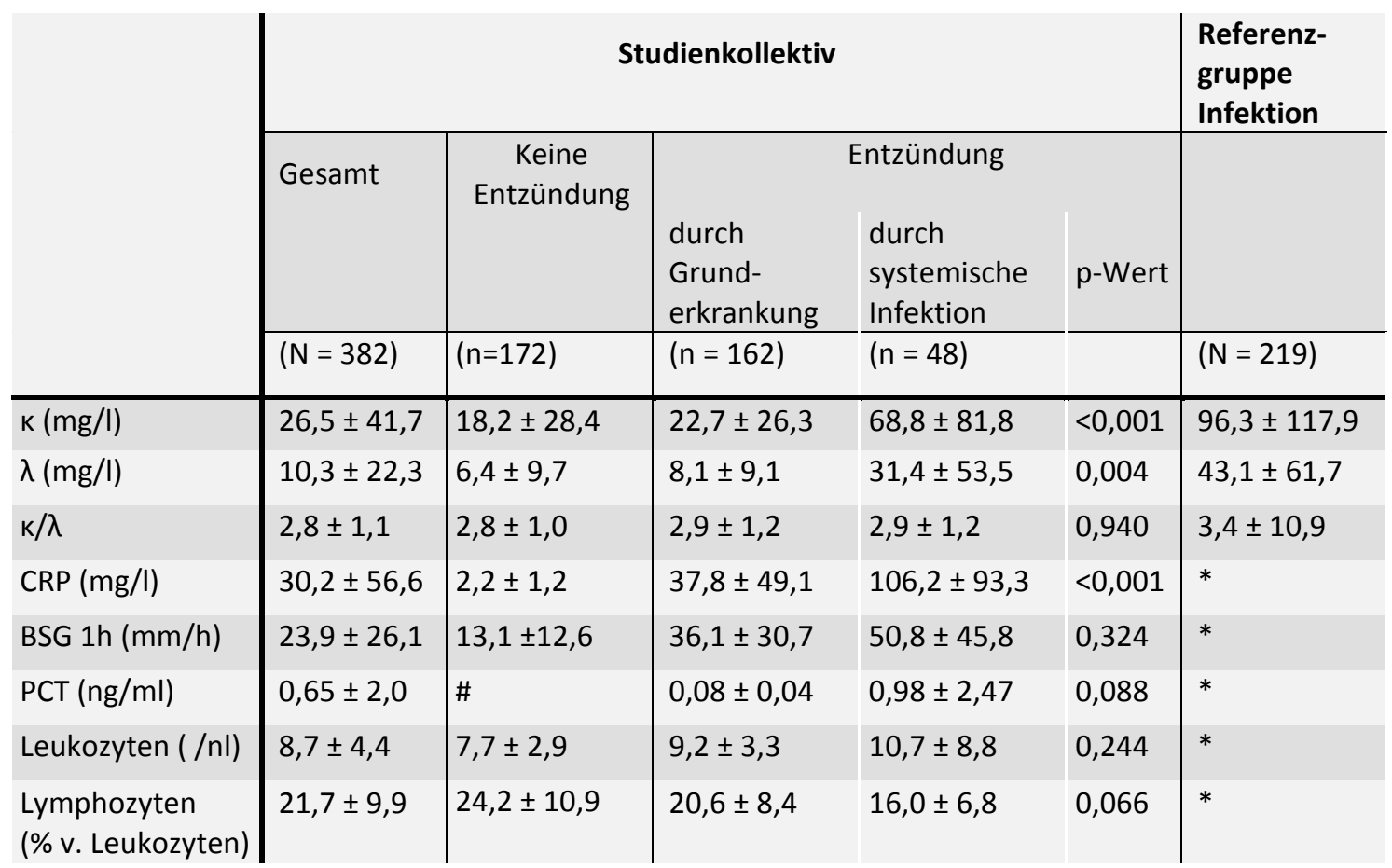

Angaben in $M W \pm S A$. *Daten nicht verfügbar; \#Fallzahl $n<5$. 


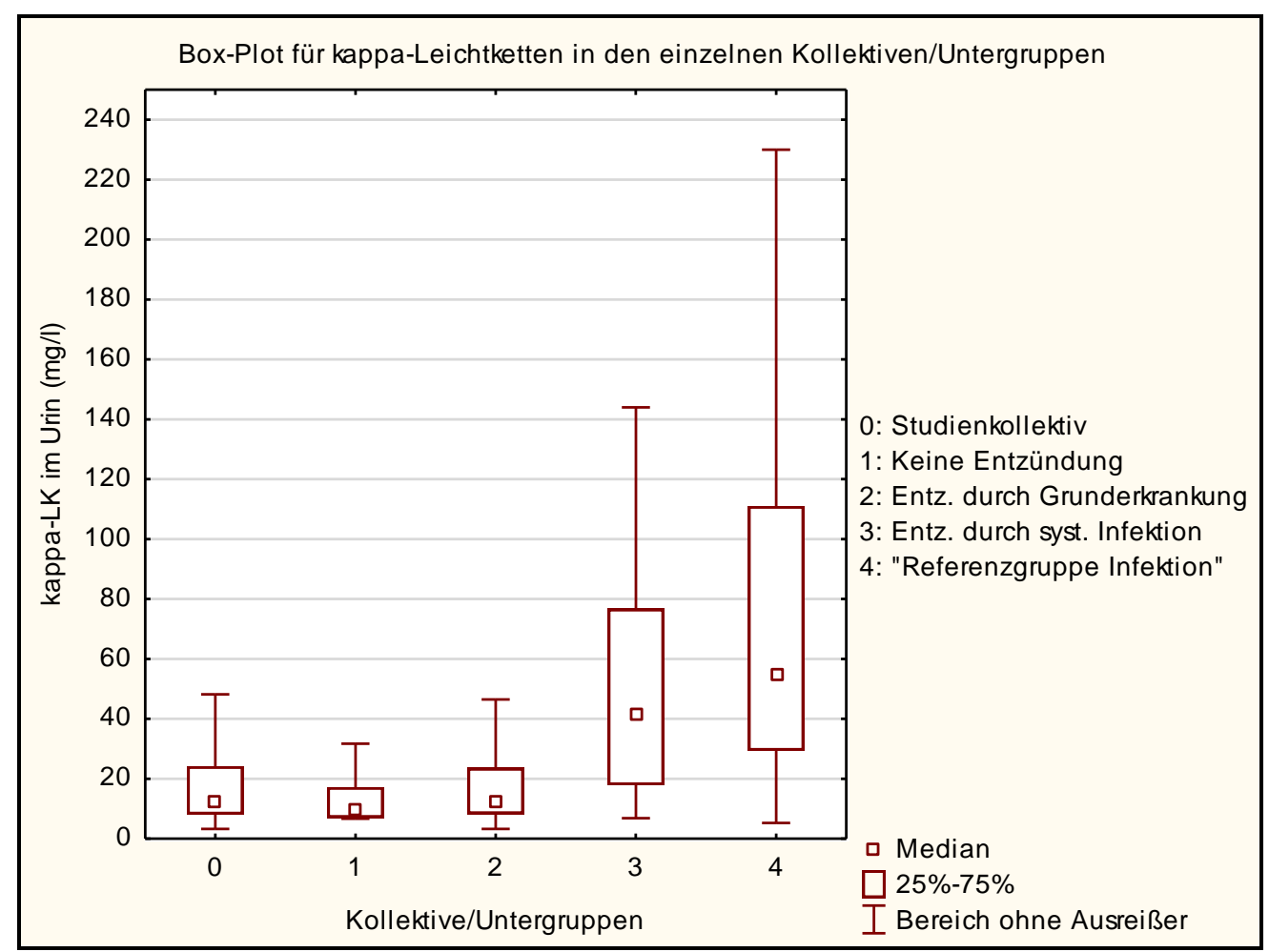

Abbildung 9: Box Plot für kappa-LK in den einzelnen Kollektiven/Untergruppen.

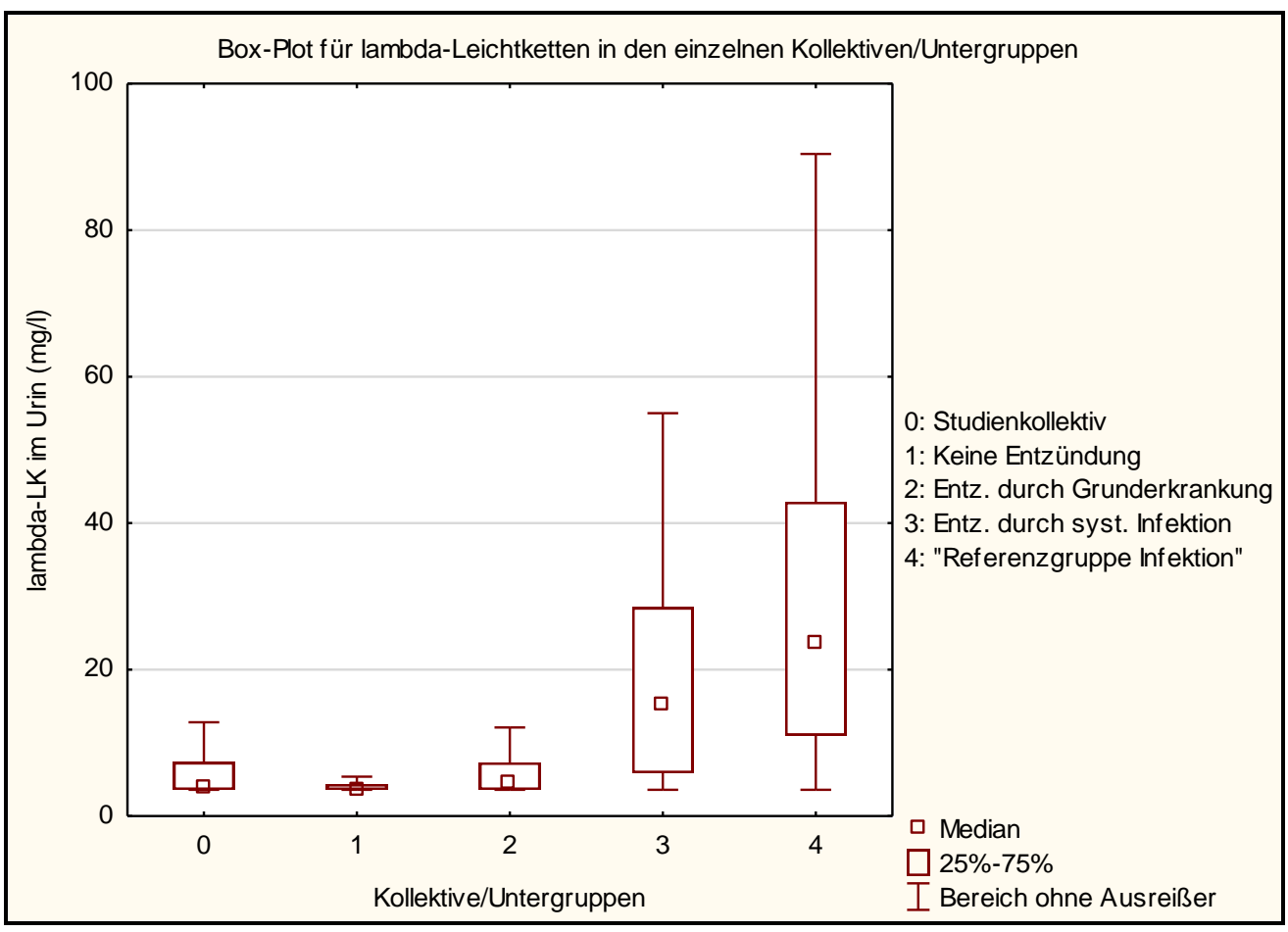

Abbildung 10: Box Plot für lambda-LK in den einzelnen Kollektiven/Untergruppen. 
In der Referenzgruppe Infektion zeigten sich insbesondere die Patienten mit Endokarditis mit stark erhöhten Leichtkettenwerten ( $n=9 ; \kappa: 157,4 \pm 135,5$ $\mathrm{mg} / \mathrm{l} ; \lambda: 77,5 \pm 88,5 \mathrm{mg} / \mathrm{l})$, jedoch war diese Gruppe mit nur neun Patienten schwach vertreten. Die Untergruppen der pulmonalen und urogenitalen Infektionen hatten hingegen die niedrigsten Werte (Tabelle 18).

Tabelle 18: Höhe der FLK in den Untergruppen der Referenzgruppe Infektion.

\begin{tabular}{|c|c|c|c|c|}
\hline & $\begin{array}{l}\mathrm{k}(\mathrm{mg} / \mathrm{l}) \\
\mathrm{MW} \pm \mathrm{SA}\end{array}$ & $\begin{array}{c}\mathrm{K} \geq 6,8 \mathrm{mg} / \mathrm{l} \\
\mathrm{n} / \mathrm{N}(\%)\end{array}$ & $\begin{array}{l}\lambda(\mathrm{mg} / \mathrm{l}) \\
\mathrm{MW} \pm \mathrm{SA}\end{array}$ & $\begin{array}{c}\lambda \geq 3,7 \mathrm{mg} / \mathrm{l} \\
\mathrm{n} / \mathrm{N}(\%)\end{array}$ \\
\hline $\begin{array}{l}\text { Referenzgruppe Infektion } \\
(\mathrm{N}=219)\end{array}$ & $96,3 \pm 117,9$ & $214 / 219(97,7)$ & $43,1 \pm 61,7$ & $212 / 219(96,8)$ \\
\hline Pulmonal $(N=120)$ & $79,7 \pm 100,8$ & $117 / 120(97,5)$ & $35,0 \pm 51,7$ & $115 / 120(95,8)$ \\
\hline Gastrointestinal $(N=26)$ & $124,8 \pm 161,2$ & $25 / 26(96,2)$ & $48,6 \pm 60,4$ & $26 / 26(100,0)$ \\
\hline Urogenital $(\mathrm{N}=23)$ & $73,0 \pm 47,4$ & $23 / 23(100,0)$ & $34,7 \pm 26,8$ & $23 / 23(100,0)$ \\
\hline Endokarditis $(\mathrm{N}=9)$ & $157,4 \pm 135,5$ & $9 / 9(100,0)$ & $77,5 \pm 88,5$ & $9 / 9(100,0)$ \\
\hline $\begin{array}{l}\text { Andere/Unbekannte } \\
(\mathrm{N}=41)\end{array}$ & $126,3 \pm 144,8$ & $40 / 41(97,6)$ & $60,5 \pm 88,0$ & $39 / 41(95,1)$ \\
\hline
\end{tabular}

Basierend auf den oben genannten Ergebnissen konnte festgestellt werden, dass bei Patienten mit rheumatischen Erkrankungen ("Studienkollektiv") mit systemischer Entzündung $(n=210)$ und erhöhten FLK die Wahrscheinlichkeit erhöht ist, dass diese durch eine Infektion bedingt ist (Tabelle 19).

Dieser Zusammenhang galt auch für die Obergruppe der chronischen Polyarthritiden, obgleich die Odds Ratio im Vergleich geringer war (Tabelle 19). Für die K-LK konnte keine Odds Ratio berechnet werden, da in der Gruppe mit akuter Infektion bei je 100,0 \% erhöhte $\mathrm{k}$-LK vorlagen. 
Tabelle 19: Assoziation zwischen erhöhten FLK im Urin und Infektionen.

\begin{tabular}{|c|c|c|c|c|}
\hline $\begin{array}{l}\text { Studienkollektiv mit } \\
\text { Entzündung ( } n=210)\end{array}$ & Mit Infektion & Ohne Infektion & OR (95 \% KI) & p-Wert \\
\hline \multicolumn{5}{|l|}{ Gesamt } \\
\hline $\mathrm{K}>6,8 \mathrm{mg} / \mathrm{l}$ & $48 / 48(100,0)$ & $134 / 162(82,7)$ & n. e. & 0,002 \\
\hline$\Lambda>3,7 \mathrm{mg} / \mathrm{l}$ & $47 / 48(97,9)$ & $105 / 162(64,8)$ & $25,51(3,43-189,81)$ & $<0,001$ \\
\hline $\mathrm{K} / \lambda>5,2$ & $2 / 48(4,2)$ & $9 / 162(5,6)$ & $0,74(0,15-3,54)$ & 1,000 \\
\hline \multicolumn{5}{|l|}{ Mit Immunsuppression } \\
\hline $\mathrm{K}>6,8 \mathrm{mg} / \mathrm{l}$ & $35 / 35(100,0)$ & $100 / 122(64,8)$ & n. e. & 0,004 \\
\hline$\wedge>3,7 \mathrm{mg} / \mathrm{l}$ & $34 / 35(97,1)$ & $79 / 122(5,7)$ & $18,51(2,45-139,92)$ & $<0,001$ \\
\hline$\kappa / \lambda>5,2$ & $1 / 35(2,9)$ & $7 / 122(5,7)$ & $0,48(0,06-4,07)$ & 0,685 \\
\hline \multicolumn{5}{|l|}{ Chron. Polyarthritis } \\
\hline $\mathrm{K}>6,8 \mathrm{mg} / \mathrm{l}$ & $14 / 14(100,0)$ & $54 / 71(76,1)$ & n. e. & 0,062 \\
\hline$\Lambda>3,7 \mathrm{mg} / \mathrm{l}$ & $13 / 14(92,9)$ & $38 / 71(53,5)$ & $11,29(1,40-90,98)$ & 0,006 \\
\hline $\mathrm{K} / \lambda>5,2$ & $0 / 14(0,0)$ & $5 / 71(7,0)$ & n. e. & 0,585 \\
\hline Gesamtkollektiv & $\begin{array}{l}\text { Referenzgruppe } \\
\text { Infektion }\end{array}$ & Studienkollektiv & OR (95 \% KI) & p-Wert \\
\hline $\mathrm{K}>6,8 \mathrm{mg} / \mathrm{l}$ & $214 / 219(97,7)$ & $321 / 382(84,0)$ & $8,13(3,22-20,57)$ & $<0,001$ \\
\hline$\wedge>3,7 \mathrm{mg} / \mathrm{l}$ & $212 / 219(96,8)$ & $231 / 382(60,5)$ & $19,80(9,07-43,20)$ & $<0,001$ \\
\hline$\kappa / \lambda>5,2$ & $9 / 219(4,1)$ & $17 / 382(4,5)$ & $0,92(0,40-2,10)$ & 0,843 \\
\hline
\end{tabular}

Aus dem ursprünglichen Gesamtkollektiv ( $N=1500)$ wurden das Studienkollektiv und die Referenzgruppe Infektion gebildet. n. e.: nicht errechenbar.

Die gute prädiktive Eigenschaft der K-Leichtketten in Bezug auf eine Infektion zeigte sich auch in einer moderaten Sensitivität von $63 \%$, einer Spezifität von $84 \%$ und einer "Area under the Curve" (AUC) von 0,78 (95\% KI 0,710,$85 ; p<0,001$ ). Ähnliche Werte präsentierten auch die $\lambda$-LK (Sensitivität: 65 \%; Spezifität: $81 \%$; AUC: 0,80 (95 \% KI 0,74-0,87; p<0,001)). Der $k / \lambda$ Quotient hingegen wies auch in diesen Berechnungen keine Bedeutung als prädiktiver Parameter auf (Tabelle 20).

Die höchste positive Likelihood Ratio hatten das $\operatorname{CRP}(5,1)$ und das PCT $(5,5)$. Beide wiesen hohe Spezifitäten auf, jedoch nur geringe Sensitivitäten. 
Tabelle 20: Charakteristik der einzelnen Parameter im Hinblick auf ihre prädiktive Möglichkeit zum Vorhandensein einer Infektion bei chronisch entzündlichen rheumatischen Erkrankungen.

\begin{tabular}{|c|c|c|c|c|c|c|c|}
\hline Parameter & $\mathbf{N}$ & $\begin{array}{l}\text { Sensitivität } \\
\text { (\%) }\end{array}$ & $\begin{array}{l}\text { Spezifität } \\
(\%)\end{array}$ & AUC (95 \% KI) & $\begin{array}{l}\text { Optimaler } \\
\text { cut-off } \\
\text { MW }\end{array}$ & $\begin{array}{l}\text { Positive } \\
\text { Likelihood } \\
\text { Ratio }\end{array}$ & p-Wert \\
\hline $\mathrm{K}(\mathrm{mg} / \mathrm{l})$ & $\begin{array}{l}\text { Infektion=48 } \\
\text { Ohne Infektion=148 }\end{array}$ & 63 & 84 & $0,78(0,71-0,85)$ & 32,15 & 3,9 & $<0,0001$ \\
\hline$\lambda(\mathrm{mg} / \mathrm{l})$ & $\begin{array}{l}\text { Infektion=48 } \\
\text { Ohne Infektion=162 }\end{array}$ & 65 & 81 & $0,80(0,74-0,87)$ & 9,53 & 3,5 & $<0,0001$ \\
\hline $\mathrm{k} / \lambda$ & $\begin{array}{l}\text { Infektion }=48 \\
\text { Ohne Infektion = } 162\end{array}$ & 83 & 29 & $0,51(0,42-0,61)$ & 1,87 & 1,2 & 0,790 \\
\hline $\mathrm{CRP}(\mathrm{mg} / \mathrm{l})$ & $\begin{array}{l}\text { Infektion=46 } \\
\text { Ohne Infektion = } 146\end{array}$ & 63 & 88 & $0,74(0,65-0,84)$ & 63,1 & 5,1 & $<0,001$ \\
\hline BSG $(\mathrm{mm} / \mathrm{h})$ & $\begin{array}{l}\text { Infektion }=5 \\
\text { Ohne Infektion }=65\end{array}$ & 40 & 92 & $0,58(0,29-0,87)$ & 84,0 & 5,2 & 0,550 \\
\hline РCT (ng/ml) & $\begin{array}{l}\text { Infektion=24 } \\
\text { Ohne Infektion=11 }\end{array}$ & 50 & 91 & $0,83(0,68-0,97)$ & 0,15 & 5,5 & 0,002 \\
\hline $\begin{array}{l}\text { Leukozyten } \\
\text { (/nl) }\end{array}$ & $\begin{array}{l}\text { Infektion=48 } \\
\text { Ohne Infektion=158 }\end{array}$ & 38 & 79 & $0,53(0,43-0,64)$ & 11,3 & 1,8 & 0,460 \\
\hline
\end{tabular}

Der optimale cut-off Mittelwert, der Basis für die Berechnungen der Sensitivität, Spezifität und der positiven Likelihood Ratio waren, wurde mittels Youden's Index berechnet.

\subsection{Einzelne Verläufe}

In der primären Erhebung wurden alle Bestimmungen in der UMG eingeschlossen. Dies beinhaltete auch Doppelbestimmungen bei einzelnen Patienten. Geplant war die Auswertung dieser Verlaufsdaten, um eine Aussage über die Assoziation der Leichtketten mit der Krankheitsaktivität auch im Verlauf zu bekommen. Diese primär vorgesehene Auswertung war jedoch aufgrund der unregelmäßigen Frequenzen der Wiedervorstellungen der einzelnen Patienten nicht möglich. Die Frequenz der Vorstellungen hing dabei wesentlich von der Krankheitsaktivität bei den einzelnen Patienten ab. Berechnungen mit den Daten hätten eine Fehlaussage in der Beurteilung ergeben, weshalb sie hier nicht aufgeführt werden.

Der Verlauf der Leichtketten soll daher im Folgenden nur an einzelnen Beispielen exemplarisch erläutert werden. 


\section{Beispiel 1: Patient mit rheumatoider Arthritis}

Ein Patient (22 Jahre) litt an einer seronegativen rheumatoiden Arthritis. Bei Erstvorstellung zeigte sich eine erhöhte Krankheitsaktivität mit einem DAS28 von 3,8 (mittlere Aktivität) sowie einem CRP von 7,6 mg/l ohne Hinweise auf eine Infektion. Zu diesem Zeitpunkt waren die Leichtketten im Urin erhöht ( $\mathrm{k:} 23,4 \mathrm{mg} / \mathrm{l} ; \lambda: 13,0 \mathrm{mg} / \mathrm{l}$ ).

Aufgrund der erhöhten Krankheitsaktivität erfolgte die Eskalation der immunsuppressiven Therapie von einer Monotherapie mit Methotrexat auf eine Kombination von Methotrexat mit Sulfasalazin. Etwa fünf Monate später stellte sich der Patient erneut vor. Diesmal war er beschwerdefrei, und es ergab sich ein DAS-28 von $<2,6$ („Remission") und ein normwertiges CRP von $1,0 \mathrm{mg} / \mathrm{l}$. Passend hierzu zeigten sich deutlich gesunkene Leichtketten im Urin ( $\mathrm{k}: 8,8 \mathrm{mg} / \mathrm{l} ; \lambda: 3,6 \mathrm{mg} / \mathrm{l})$.

\section{Beispiel 2: Patientin mit Gabe von Rituximab}

Bei einer Patientin (74 Jahre) wurde bei ihrer Erstvorstellung eine Granulomatose mit Polyangiitis mit Beteiligung der Lunge und der Niere nachgewiesen. Zu diesem Zeitpunkt hatte sie sehr hohe Leichtkettenwerte im Urin ( $\mathrm{k}: 143,0 \mathrm{mg} / \mathrm{l} ; \lambda: 49,0 \mathrm{mg} / \mathrm{l}$ ). Sie war noch nicht immunsuppressiv eingestellt, hatte eine eGFR von $57,7 \mathrm{ml} / \mathrm{min} / 1,73 \mathrm{~m}^{2}$ und ein CRP von $125,1 \mathrm{mg} / \mathrm{l}$, was auf die hohe Aktivität der Grunderkrankung zurückgeführt wurde.

Als sie sich 4,6 Monate später wieder vorstellte, hatte sie zwischenzeitlich neun Stöße Cyclophosphamid erhalten und ihre Leichtkettenwerte waren darunter deutlich gesunken ( $\mathrm{k}: 17,4 \mathrm{mg} / \mathrm{l} ; \lambda: 5,8 \mathrm{mg} / \mathrm{l}$ ).

Über ein Jahr später war die Patientin mit zwei Zyklen Rituximab behandelt worden und stellte sich nun 18,1 Monate nach der Erstvorstellung erneut vor. Die Leichtkettenwerte waren wiederum gesunken ( $\mathrm{k}: 9,2 \mathrm{mg} / \mathrm{l} ; \lambda: 3,9 \mathrm{mg} / \mathrm{l}$ ) und die Patientin zeigte sich weitestgehend beschwerdefrei. Auch die Entzündungsparameter lagen fast im Normbereich (CRP: 3,9 mg/l) bei in etwa konstant gebliebener eGFR $\left(51,3 \mathrm{ml} / \mathrm{min} / 1,73 \mathrm{~m}^{2}\right)$. 
Beispiel 3: Patientin mit Infektion und akutem Nierenversagen

Diese Patientin (73 Jahre) litt an einer ANCA-assoziierten Vaskulitis. Bei Erstvorstellung wies sie stark erhöhte Entzündungsparameter (CRP: 242,9 mg/l; Procalcitonin: $11,1 \mathrm{ng} / \mathrm{ml}$ ) auf, die auf eine Urosepsis zurückzuführen waren. In diesem Rahmen bestand ein akut auf chronisches Nierenversagen mit einer deutlich verminderten eGFR $\left(15,3 \mathrm{ml} / \mathrm{min} / 1,73 \mathrm{~m}^{2}\right)$. Die Leichtketten im Urin zeigten sich zu diesem Zeitpunkt deutlich erhöht ( $\mathrm{k}: 48,8 \mathrm{mg} / \mathrm{l} ; \lambda: 34,3 \mathrm{mg} / \mathrm{l}$ ).

Bei einer erneuten Vorstellung nach 13,8 Monaten lagen keine erhöhten systemischen Entzündungsparameter im Blut vor. Zudem präsentierte sich die Patientin mit einer verbesserten Nierenfunktion (eGFR 51,6 ml/min/1,73m²). Die Leichtketten im Urin waren diesmal niedriger als bei Erstvorstellung ( $\mathrm{\kappa :} 31,1 \mathrm{mg} / \mathrm{l} ; \lambda: 12,6 \mathrm{mg} / \mathrm{l}$ ). 


\section{Diskussion}

In dieser Studie wurde die Bedeutung der freien Leichtketten im Urin bei chronisch entzündlichen rheumatischen Erkrankungen untersucht. Dafür wurden die Daten von 1500 Patienten der Universitätsmedizin Göttingen analysiert, bei denen die FLK im Urin zwischen den Jahren 2011 und 2013 bestimmt worden waren.

Es zeigte sich, dass die FLK $(\kappa \& \lambda)$ bei den Patienten mit rheumatischen Erkrankungen im Vergleich zu der Referenzgruppe Gesund signifikant erhöht waren. Bei der größten Gruppe, der rheumatoiden Arthritis, korrelierten die FLK zudem mit den systemischen Entzündungsparametern (CRP \& BSG), so dass die Leichtketten im Urin als einfach zu bestimmender Aktivitätsparameter fungieren könnten. Des Weiteren zeigte sich ein Abfall der FLK unter einer Depletion der B-Zellen mittels Rituximab.

Erhöhte Leichtketten sind jedoch auch mit dem Vorhandensein von Infekten assoziiert. Abhängig von der Höhe der LK kann man vorhersagen, ob erhöhte systemische Entzündungsparameter bei Patienten mit chronisch entzündlichen rheumatischen Erkrankungen durch die Grunderkrankung oder eine Infektion bedingt sind.

\subsection{Diskussion der Methoden}

Für die vorliegende Studie wurden die Daten von 1500 Patienten ausgewertet und einzelne Patientenkollektive gebildet. Das Studienkollektiv, bestehend aus Patienten mit chronisch entzündlichen rheumatischen Erkrankungen, umfasste 382 Patienten. Im Vergleich zu vorherigen Untersuchungen, die die Bedeutung der Leichtketten bei Patienten mit rheumatischen Erkrankungen vornehmlich im Serum untersuchten, liegt in der aktuellen Promotion eine große Fallzahl vor. Damit konnte vor allem das Ziel erreicht werden, die FLK aus einem einfach zu gewinnenden Material (Urin) als generellen Marker für die Aktivität einer rheumatischen Erkrankung gleich welcher Entität einer großen Kohorte zu untersuchen. 
Um eine möglichst große Fallzahl zu haben, wurden nur wenige Ausschlusskriterien benannt; allein Patienten mit Amyloidose oder Malignomen sowie insbesondere einem multiplen Myelom wurden ausgeschlossen, da diese die Höhe der FLK beeinflussen (Gottenberg et al. 2007). Um eine möglichst generelle Aussage treffen zu können, wurden auch die häufig begleitenden Nierenerkrankungen nicht ausgeschlossen, obgleich diese die Höhe der Leichtketten im Urin beeinflussen können und daher bei anderen Studien ausgeschlossen wurden (Chiche et al. 2011; Draborg et al. 2015).

Nachteil der Studie war das retrospektive Design, so dass die Aussagekraft in einigen Bereichen eingeschränkt ist. Hierzu gehört, dass einzelne Krankheitsgruppen nur in geringer Anzahl vertreten waren, so dass hier keine ausreichend valide statistische Aussage getroffen werden konnte.

Zudem lagen keine Daten zu den FLK im Serum vor, die mit den FLK im Urin hätten verglichen werden können. In einer Studie von Hutchison und Mitarbeitern (2008) wurde jedoch entdeckt, dass die FLK im Urin mit denen im Serum korrelierten. Auch wurde bereits beschrieben, dass eine Einmalprobe von Urin mit Ergebnissen einer 24h-Urinprobe korreliere (Hanaoka et al. 2013).

Weiter nachteilig war die geringe Anzahl von krankheitsspezifischen Scores bei unserer Patientengruppe. Lediglich der DAS-28 zur Abschätzung der Krankheitsaktivität bei Patienten mit rheumatoider Arthritis wurde gehäuft verwendet und war daher auswertbar. Die Anzahl der weiteren Scores war in der Anzahl so gering, dass hier eine Auswertung nicht möglich war. Zur Abschätzung der Aktivität der Grunderkrankung wurden daher der laborchemische Entzündungsparameter CRP und die BSG verwendet. Diese Vorgehensweise spiegelt jedoch auch den klinischen Alltag wider, da die einzelnen Aktivitätsscores sehr aufwendig zu erheben sind und zur Beurteilung der Aktivität zumeist auf die Entzündungsparameter zurückgegriffen wird.

In Bezug auf die Referenzgruppen sollte erwähnt werden, dass die Referenzgruppe Gesund vermutlich nicht aus gänzlich gesunden Patienten bestand. 
Alle Patienten stellten sich wegen verschiedener Beschwerden in der Universitätsklinik Göttingen vor. Auch wenn eine Beteiligung innerer Organe laut Dokumentation nicht gegeben war, konnte eine Beeinflussung der FLK nicht komplett ausgeschlossen werden. Dies erklärt vermutlich, dass 67,9 \% bzw. 40,7 \% der Referenzgruppe Gesund erhöhte K- bzw. $\lambda$-LK aufwiesen. In anderen Studien hingegen zeigte das gesunde Vergleichskollektiv teilweise keine oder nur vereinzelt erhöhte LK (Gottenberg et al. 2007; Draborg et al. 2015). Es ist daher anzunehmen, dass die herausgearbeiteten Unterschiede die tatsächlichen Verhältnisse unterschätzen und die Unterschiede zu unserem Studienkollektiv noch größer ausfallen könnten.

Die Referenzgruppe Infektion war aus Patienten mit den verschiedensten Infektionen zusammengesetzt, die sich auch in der Ausprägung sehr unterschieden. Auch hierdurch sollte eine Aussage zur Alltagstauglichkeit der FLK im Urin getroffen werden. Die Ursachen der Infektionen sind detailliert im Ergebnisteil aufgeführt und umfassten bakterielle sowie virale Infektionen.

Die Auswertung der Verlaufsdaten schien uns statistisch nicht vertretbar. In den einzelnen festgelegten Zeiträumen waren insgesamt zu wenig Patienten der einzelnen Gruppen vorstellig gewesen. Zudem war aufgrund des retrospektiven Designs die Vermutung naheliegend, dass Patienten mit einer hohen Krankheitsaktivität deutlich häufiger im Verlauf auftraten als solche mit einer moderaten Erkrankungsaktivität oder gar solche in Remission. Um eine Abschätzung zu geben, in welchen Bereichen die FLK im Urin als Verlaufsparameter eine klinische Bedeutung haben könnten, wurden im Ergebnisteil einige typische Beispiele erwähnt.

Aufgrund der Daten ist eine Kontrolle der Werte in einer prospektiven Studie angedacht.

\subsection{Diskussion der Ergebnisse}

Folgende Hypothesen galt es anhand der Daten zu untersuchen:

1. Patienten mit chronisch entzündlichen rheumatischen Erkrankungen haben erhöhte FLK im Urin (Kapitel 4.2.1). 
2. Hiervon abgeleitet: Erhöhte Leichtketten können zur Diagnosestellung rheumatischer Erkrankungen beitragen und ermöglichen die Abgrenzung von Infektionserkrankungen mit vergleichbaren Symptomen (Pneumonie vs. Vaskulitis) (Kapitel 4.2.1).

3. Die FLK im Urin können die Aktivität von chronisch entzündlichen rheumatischen Erkrankungen anzeigen (Kapitel 4.2.2).

4. Die FLK können den Verlauf und die Effektivität einer immunsuppressiven Therapie anzeigen (Kapitel 4.2.4).

5. Die FLK im Urin können bei Patienten mit chronisch entzündlichen rheumatischen Erkrankungen zwischen einer erhöhten Aktivität der Grunderkrankung und einer Infektion unterscheiden (Kapitel 4.2.5).

\subsubsection{Leichtketten und rheumatische Erkrankungen}

Die FLK $(\kappa \& \lambda)$ im Urin zeigten sich im Studienkollektiv im Vergleich zu der Referenzgruppe Gesund signifikant erhöht. Somit wurden Studien, die erhöhte FLK bei einzelnen Krankheiten wie der RA oder dem SLE nachgewiesen haben, in unserem großen Kollektiv aller chronisch entzündlichen rheumatischen Erkrankungen bestätigt.

Innerhalb des Studienkollektivs präsentierten sich die Kollagenosen mit den höchsten Werten an FLK im Urin. Dabei lagen die Werte signifikant über denen der gesunden Referenzgruppe. Diese Ergebnisse stehen im Einklang zu früheren Untersuchungen über FLK im Urin bei Patienten mit SLE (Hopper et al. 2000; Aggarwal 2013; Hanaoka et al. 2013). Dabei scheinen die FLK im Urin die Konzentration der Leichtketten im Serum widerzuspiegeln, zieht man die beschriebene Korrelation zwischen den FLK im Urin und denen im Serum in Betracht (Hutchison et al. 2008). Dazu passend wurde auch bereits eine Erhöhung der FLK im Serum von Patienten mit SLE (Aggarwal et al. 2011; Chiche et al. 2011; Jolly et al. 2014; Draborg et al. 2015) und mit primärem Sjögren-Syndrom gefunden (Gottenberg et al. 2007).

Den Kollagenosen folgend zeigten sich die zweithöchsten Werte der FLK im Urin für die systemischen Vaskulitiden. Hier liegen bisher noch keine Untersuchungen im Urin vor. Im Serum stehen die Daten aber im Einklang 
mit denen von Burmeister und Mitarbeitern (2014), die unter anderem bei Vaskulitispatienten erhöhte Leichtketten im Serum fanden.

Bei den Spondyloarthritiden mit den dritthöchsten Spiegeln an FLK im Urin lagen bisher weder Studien im Urin noch im Serum vor. Die Daten zeigten jedoch die Übertragbarkeit der Aussagekraft der FLK auch auf die Gruppe der Spondyloarthritiden. Die Leichtketten könnten daher auch in dieser Gruppe zur Beurteilung des Krankheitsverlaufes herangezogen werden.

Verglichen mit den oben genannten Krankheitsbildern lagen bei den chronischen Polyarthritiden eher niedrigere FLK Spiegel im Urin vor, wenn auch hier ebenfalls eine signifikante Erhöhung verglichen mit der gesunden Referenzgruppe bestand. Bei der größten und möglicherweise klinisch bedeutsamsten Untergruppe, den Patienten mit rheumatoider Arthritis, konnten somit erhöhte FLK nun auch im Urin nachgewiesen werden, während bisherige Studien vor allem die FLK im Serum (Gottenberg et al. 2007; Gottenberg et al. 2009; Ye et al. 2013; Deng et al. 2015) oder der Synovialflüssigkeit (Kormelink et al. 2010) untersuchten. Diese Feststellung ist insbesondere daher interessant, da es sich bei einer Urinprobe um ein nicht-invasives Diagnostikum handelt und die Probe somit leicht zu gewinnen ist.

Die obige Auflistung nach der Höhe der FLK im Urin legt nahe, dass die Höhe wesentlich durch den systemischen Charakter und/oder den Befall der inneren Organe bei den einzelnen Erkrankungen determiniert wird (siehe Kapitel 4.2.3). Dies spiegelt sich auch durch die Streubreite zwischen den einzelnen Untergruppen wider, wobei hier beispielhaft die Diskrepanz zwischen dem diskoiden und systemischen Lupus erythematodes genannt sei.

Die signifikante Erhöhung der FLK im Urin im gesamten Studienkollektiv, aber auch für alle Obergruppen im Vergleich zur gesunden Referenzgruppe führt uns zur zweiten Hypothese, in der die FLK als Diagnosemarker von chronisch entzündlichen rheumatischen Erkrankungen Verwendung finden können. Die Hypothese ist nach den vorliegenden Daten nicht haltbar. Gegen die FLK im Urin als Diagnosekriterium sprechen die großen Unterschiede zwischen, aber auch innerhalb der Untergruppen. Wie oben beschrieben, scheint die Höhe 
der FLK stark von der systemischen Ausbreitung der Erkrankung, dem Organbefall (z. B. Nierenbefall) und begleitenden anderweitigen Erkrankungen, vor allem Infektionen, abzuhängen (s.u.). Die FLK sollten demnach eher als Ergänzung in der Diagnostik verstanden werden. Bei sehr hohen Leichtketten oberhalb der in dieser Studie errechneten cut-off-Werte (siehe Kapitel 3.4.5) ist die Wahrscheinlichkeit hoch, dass den Symptomen eine Infektion zugrunde liegt. In Abhängigkeit der weiteren Untersuchungsergebnisse (v. a. Autoimmun-Diagnostik, Histologie) bei Verdacht auf eine rheumatische Systemerkrankung sollte bei hohen LK im Urin daher parallel die Suche nach einem Infektfokus als alternativer Ursache intensiviert werden (z. B. Bildgebung, Blutkulturen).

Der $\mathrm{K} / \lambda$-Quotient war in dieser Studie weder im Studienkollektiv noch in den beiden Referenzgruppen im Durchschnitt erhöht und stimmte somit mit früheren Studien überein (Gottenberg et al. 2007; Chiche et al. 2011; Ye et al. 2013). Ursächlich für den fehlenden Unterschied könnte sein, dass bei den chronisch entzündlichen rheumatischen Erkrankungen eher eine generelle Überaktivität der B-Zellen besteht (polyklonal) und keine monoklonale Produktion der Leichtketten (Bradwell 2005).

\subsubsection{Leichtketten als Aktivitätsparameter}

Die erhöhten FLK im Urin von Patienten mit rheumatischen Erkrankungen lassen auch an die Verwendung dieser Laborparameter als Aktivitätsparameter denken. Die frühzeitige Erkennung einer erhöhten Krankheitsaktivität der schubweise verlaufenden rheumatischen Erkrankung ist von enormer Wichtigkeit. Die darauf basierende Therapieumstellung oder -intensivierung bringt nicht nur eine Symptomlinderung für den Patienten, sondern verhindert auch ein schnelles Voranschreiten der Erkrankung mit konsekutiver Organschädigung. Die gute Einstellung der Grunderkrankung mit einer möglichst niedrigen Aktivität sollte auch zur Vermeidung weiterer Begleiterkrankungen erfolgen. Zu nennen seien hier ein erhöhtes Risiko für Lymphome (Kassan 1978; Wolfe und Michaud 2004; Bernatsky et al. 2005) und kardiovaskuläre Erkrankungen (Ogdie et al. 2015). 
Aufgrund der unzureichenden Anzahl dokumentierter krankheitsspezifischer Scores wurde in dieser Studie auf die klinisch häufig gebräuchlicheren systemischen Entzündungsparameter CRP und BSG zurückgegriffen. Dabei zeigte sich im Studienkollektiv der Patienten mit rheumatischen Erkrankungen eine Korrelation zwischen den FLK im Urin und den Entzündungsparametern CRP und BSG.

Untersucht man die Ober- und Untergruppen gesondert bezüglich dieser Korrelation, so fällt auf, dass der Zusammenhang vornehmlich in den Gruppen mit einer großen Anzahl an Patienten bestätigt werden konnte. Hierzu gehört insbesondere die Gruppe der Patienten mit einer rheumatoiden Arthritis, bei der eine starke Korrelation sowohl des CRP als auch der BSG mit den FLK festgestellt wurde. Die erhöhten Leichtketten könnten demnach als Aktivitätsparameter dienen. Auch andere Studien konnten diesen Zusammenhang bestätigen: So wurden Korrelationen zwischen den FLK im Serum und dem CRP, der BSG, aber auch dem DAS-28 gesehen (Gottenberg et al. 2007; Kormelink et al. 2010; Ye et al. 2013). Im Gegensatz zu den bisherigen Studien korrelierte in dieser Studie der DAS-28 nicht mit den FLK, was vermutlich an der zu geringen Anzahl von Patienten mit verfügbarem Score $(n=51)$ lag; ein Nachteil des retrospektiven Designs. Ob sich eine Korrelation der FLK im Urin mit dem DAS-28 bei einer größeren Gruppe an Patienten zeigen würde, unterliegt der Spekulation und sollte Gegenstand einer prospektiven Studie sein.

Ebenso zeigte sich eine starke Korrelation zwischen den FLK und dem CRP bei den Vaskulitiden. Dies steht im Einklang mit einer Studie von Burmeister und Mitarbeitern (2014), die eine Korrelation zwischen dem CRP und den FLK im Serum finden konnten. Da das CRP mit der Höhe der Krankheitsaktivität korreliert (Booth et al. 2004), könnten die FLK im Urin eine einfach Möglichkeit der Aktivitätseinschätzung darstellen.

Interessanterweise konnten bei Patienten mit einem SLE keine signifikanten Korrelationen zwischen den systemischen Entzündungsparametern und den FLK im Urin gesehen werden. Dieses steht vordergründig im Kontrast zu Untersuchungen, die eine Korrelation der FLK im Serum mit der Krank- 
heitsaktivität, gemessen an krankheitsspezifischen Scores (z. B. SLEDAI), aufzeigen konnten (Aggarwal et al. 2011; Chiche et al. 2011; Jolly et al. 2014; Draborg et al. 2015). Diese Diskrepanz ist jedoch durch den deutlich unterschiedlichen Organbefall erklärbar. Scores wie der SLEDAI beziehen die Art und Ausprägung des Organbefalls in die Gesamtsumme mit ein und spiegeln damit deutlich besser die Krankheitsaktivität wider als das CRP oder die BSG. Dass die FLK im Urin nicht so stark mit der Krankheitsaktivität korrelierten, könnte auch durch die lokale Entzündung in den Nieren begründet sein (Hanaoka et al. 2013). Hierzu passt auch die gute Korrelation zwischen den FLK und dem CPR/ der BSG bei der rheumatoiden Arthritis, bei der die Organbeteiligung in der Regel keine Bedeutung hat.

Bei den Spondyloarthritiden zeigte sich in dieser Studie keine Korrelation zwischen den FLK im Urin und der Aktivität der Grunderkrankung. Dies könnte an der Tatsache liegen, dass generell nur etwa 50-70 \% der Patienten mit Spondyloarthritis erhöhte CRP- und BSG-Werte aufweisen (Sieper et al. 2002). Dennoch konnten einige Studien eine leichte Korrelation zwischen den Entzündungswerten und der Aktivität der Spondyloarthritis feststellen (Ruof und Stucki 1999). Da 85,9 bzw. 62,0 \% der Patienten mit Spondyloarthritis in dieser Studie erhöhte $\mathrm{K}$ - bzw. $\lambda$-LK aufwiesen, sollte ihr Potential als Aktivitätsparameter bei diesen Patienten in weiteren Studien genauer analysiert werden.

Zusammenfassend kann man für die Krankheitsaktivität sagen, dass die FLK im Urin durchaus als Aktivitätsparameter dienen können. Dieser Zusammenhang wurde insbesondere bei Patienten mit rheumatoider Arthritis gesehen, bei denen die stärkste Korrelation vorlag, was am ehesten durch eine fehlende Organbeteiligung zu erklären ist.

\subsubsection{Leichtketten und Organbefall}

In dieser Studie wurde zudem die Bedeutung einer Beteiligung der Grunderkrankung an inneren Organen, insbesondere der Nieren und der Lunge, herausgearbeitet. So zeigte sich, dass Patienten mit Befall der inneren Organe oder nur der Niere allein signifikant höhere FLK im Urin aufwiesen als 
Patienten ohne Beteiligung. Die Fallzahlen waren mit $81(21,2 \%)$ für den Befall innerer Organe bzw. 52 (13,6 \%) der Niere allein recht groß. Die Ergebnisse stimmten mit denen von Gottenberg und Mitarbeitern (2007) überein, die erhöhte FLK im Serum bei pSS-Patienten mit systemischer Beteiligung sahen.

Des Weiteren zeigte die Auswertung der Nierenfunktion, dass die eGFR, die Albuminurie und die a-1-Mikroglobulinurie einen signifikanten Einfluss auf die FLK im Urin hatten. Der Zusammenhang wurde durch die Einteilung der Nierenbeteiligung gemäß der aktuellen KDIGO Leitlinie näher untersucht. Die Einteilung erfolgt nach dem Grad der eGFR Einschränkung und der Höhe der Albuminurie und spiegelt den Grad der Nierenfunktionseinschränkung zum Zeitpunkt der Datenerhebung wider. Hierbei gehörten Patienten mit chronischer Polyarthritis zu 66,0 \% der CKD-RG-1 mit einer geringen Einschränkung der Nierenfunktion an (eGFR $\geq 60 \mathrm{ml} / \mathrm{min} / 1,73^{2}$ ). Diese Feststellung könnte ein möglicher Grund für die niedrigen Leichtkettenwerte in dieser Gruppe sein: Studien diesbezüglich zeigten nämlich, dass die CKD-Einteilung mit der Höhe der Leichtketten korreliert (Hutchison et al. 2008; Burmeister et al. 2014). Das bedeutet, dass Patienten aus einer höheren CKD-Risikogruppe auch vermehrt erhöhte Leichtketten aufweisen. Ein Beispiel aus dieser Studie ist die Gruppe der Kollagenosen mit einem hohen Anteil (27,1 \%) an Patienten aus den Risikogruppen- 3 und -4 (eGFR $<45 \mathrm{ml} / \mathrm{min} / 1,73 \mathrm{~m}^{2}$ und/oder stark erhöhte Albuminurie), die im Vergleich zu den anderen Gruppen die höchsten FLK-Werte hatten. Bei der Bewertung der FLK im Urin sollte daher immer auch die Nierenfunktion des Patienten beachtet werden, um mögliche Störfaktoren mit einzukalkulieren. Diese Feststellung erklärt vermutlich die stark erhöhten LK-Werte bei Patienten mit systemischem Lupus erythematodes und den Vaskulitiden. Besonders viele Daten und Studien liegen hierbei für den SLE vor, eine Krankheit, die sehr häufig mit einer Nierenbeteiligung einhergeht und so zu einer Nierenfunktionsverschlechterung führt (Yokoyama et al. 2011). Die FLK im Urin könnten folglich Hinweise auf eine Lupusnephritis oder gar über ihren Verlauf geben. Zu derselben Schlussfolgerung kamen auch Hanaoka und Mitarbeiter (2013), die die FLK im Urin als mögliche Biomarker für die Aktivität der Lupusnephritis sahen, da es ihrer Theorie nach 
durch eine vermehrte Plasmazellinfiltration in der Niere zur lokalen Inflammation und LK-Produktion komme. Im Gegensatz dazu steht die Aussage von Hopper und Mitarbeitern (2000), die die erhöhten FLK im Urin eher auf eine erhöhte Produktion im Serum deuteten und nicht auf ein lokales Entzündungsgeschehen in den Nieren. Eine Kombination dieser Meinungen lieferte der Autor Aggarwal (2013), der vorherige Studien so deutete, dass FLK im Urin vor allem als organspezifische Biomarker für die Lupusnephritis dienen könnten, während er die FLK im Serum eher als Parameter für die allgemeine Aktivität des SLE sah. Diese Studie zeigte jedoch, dass die FLK im Urin bei Krankheiten, die selten mit einem Organbefall einhergehen (z. B. RA), durchaus eine gute Option zur Beurteilung der Krankheitsaktivität darstellen.

Im Gegensatz zu den hohen Werten bei Patienten mit SLE stehen die niedrigen Werte der DLE-Gruppe. Dies könnte dadurch erklärt sein, dass es beim DLE nur in $5 \%$ der Fälle zu einer extradermalen Manifestation kommt (Herold 2017) und die systemische Entzündungsreaktion und folglich die LKProduktion demnach gering ausfallen.

Die Ergebnisse bzgl. einer pulmonalen Beteiligung im Studienkollektiv zeigten keinen signifikanten Unterschied. Dies liegt vermutlich an der geringen Anzahl an Patienten mit Lungenbeteiligung $(n=26)$. Insbesondere war nur ein Patient mit RA von einem Lungenbefall betroffen, was ohnehin eher eine Rarität bei der RA ist. Andere Studien hingegen zeigten jedoch erhöhte FLK im Serum bei Patienten mit RA und pulmonaler Beteiligung (Deng et al. 2015).

Da eine systemische Beteiligung bei Patienten mit chronisch entzündlicher rheumatischer Erkrankung frühzeitig erkannt werden sollte, sollten weitere Studien bzgl. der Bedeutung freier Leichtketten als Hinweis für eine Organbeteiligung durchgeführt werden. Unseren Daten folgend besteht die größte Aussagekraft der FLK im Urin hinsichtlich der Aktivität rheumatischer Erkrankungen bei solchen, die keine Nieren- oder anderweitige Organbeteiligung aufweisen. Beispiel hierfür sind die Patienten mit RA, bei denen selten eine Organbeteiligung vorhanden ist. Hierzu passend ist auch, dass in dieser Gruppe die besten Korrelationen zwischen dem CRP/ der BSG und den Leichtketten gefunden wurden. 


\subsubsection{Leichtketten bei immunsuppressiver Therapie und im Verlauf}

In der vorliegenden Studie hatten 74,7 \% des Studienkollektivs Immunsuppressiva eingenommen. Die Konzentration freier LK lag bei diesen Patienten im Durchschnitt niedriger als bei den Patienten ohne immunsuppressive Therapie, obgleich der Unterschied zwischen beiden Gruppen nicht signifikant war. Auch Hanaoka und Mitarbeiter (2013) beobachteten in ihrer Studie zu SLE-Patienten mit Lupusnephritis Klasse III/IV einen Rückgang der LK-Werte im Urin nach Therapiebeginn.

Insbesondere die Patienten mit Rituximab-Therapie zeigten in dieser Studie signifikant erniedrigte LK-Werte im Vergleich zu Patienten ohne Rituximab. Dabei sollte jedoch die geringe Fallzahl dieser Gruppe $(n=16)$ beachtet werden. Diese Studie bestätigte somit bisherige Studien, die einen Rückgang der FLK im Serum (Kormelink et al. 2010; Chiche et al. 2011) unter RituximabTherapie gesehen haben.

Rituximab ist ein monoklonaler Antikörper gegen CD20, ein Antigen, das sich auf der Oberfläche von B-Zellen befindet. Die Wirkung von Rituximab liegt in einer Depletion der B-Zellen, die in der Pathogenese der rheumatischen Erkrankungen von Bedeutung sind (Herold 2017). Mehrere Studien konnten zeigen, dass es unter Rituximab bei chronisch entzündlichen rheumatischen Erkrankungen zu einem Rückgang der Beschwerdesymptomatik gekommen ist, unter anderem bei Patienten mit RA oder Vaskulitis (Carubbi et al. 2014; Jones 2014; Lopez-Olivo et al. 2015).

Die Leichtketten könnten daher als Kontrollparameter des Ansprechens auf eine Therapie mit Rituximab dienen (Bramlage et al. 2016). Dieser Aspekt sollte näher untersucht werden, insbesondere da Kormelink und Mitarbeiter (2010) einen Rückgang der LK unter Rituximab-Therapie sahen, jedoch nur bei Patienten, die die EULAR-Kriterien erfüllten (van Gestel et al. 1996).

Da die Rituximab-Therapie mit hohen Kosten einhergeht (Beresniak et al. 2013) und es anhaltende Diskussionen bezüglich der Frequenz der Gaben insbesondere bei den Vaskulitiden gibt, ist es ratsam, die Bedeutung der FLK als Kontrollparameter eines Therapieansprechens genauer zu untersuchen. 
Für die anderen Immunsuppressiva in dieser Studie konnte kein direkter Zusammenhang mit der Höhe der Leichtketten im Urin gesehen werden. Dies liegt vermutlich an der Wirkungsweise der einzelnen Medikamente oder an dem sehr heterogenen Therapieregime bei unseren Patienten hinsichtlich der Art der Immunsuppression und der Dosis.

Die Bedeutung der FLK als Verlaufsparameter und zur Therapiekontrolle im Allgemeinen konnte in dieser Studie aufgrund der mangelnden Datenmenge leider nicht erarbeitet werden. In den Einzelfallbeispielen wurde jedoch deutlich, dass die FLK durchaus eine gute Option sein könnten, den Krankheitsverlauf (Aktivität, Therapieansprechen, Organbefall) eines einzelnen Patienten widerzuspiegeln.

\subsubsection{Leichtketten und ihre Bedeutung bei Infektionen}

Die höchsten LK-Werte gab es in der Referenzgruppe Infektion. Erhöhte Werte in dieser Gruppe waren zu erwarten, da der Zusammenhang zwischen Infektion und LK bereits mehrfach in der Literatur beschrieben worden war (Hopper et al. 2000; Girón und Shah 2013). Die Gruppe mit den höchsten Werten war die kleine Gruppe der Endokarditiden (4,1 \%). Patienten mit pulmonalen Infekten (54,8 \%) hatten vergleichsweise geringe Leichtkettenwerte, obgleich auch diese deutlich über denen des Studienkollektivs lagen. Grund für die stark erhöhten LK-Werte der Referenzgruppe Infektion könnte die hohe Anzahl von Patienten mit Sepsis sein $(45,7 \%)$, bei der es zu einer sehr starken Aktivierung des Immunsystems mit vermehrter LK-Produktion kommt.

Die Ergebnisse der Patienten mit chronisch entzündlichen rheumatischen Erkrankungen (=Studienkollektiv) zeigten signifikante Unterschiede in der Höhe der Leichtketten zwischen Patienten mit erhöhten Entzündungsparametern durch vermehrte Aktivität der Grunderkrankung und Patienten mit systemischer Infektion. Die Auswertungen wiesen darauf hin, dass erhöhte FLK die Wahrscheinlichkeit erhöhen, dass der Patient an einer Infektion leidet. 
Diese Studie stimmte somit insbesondere mit der von Mastroianni-Kirsztajn und Mitarbeitern (2008) überein, die FLK im Urin von SLE-Patienten untersuchten und höhere Werte bei Patienten mit akuter Infektion fanden. Zudem waren auch dort die Werte der Referenzgruppe Infektion (ohne SLE) höher als die der Gruppe der SLE-Patienten (mit und ohne Infektion). Dies könnte an der immunsuppressiven Therapie der Patienten mit rheumatoider Erkrankung liegen, mit konsekutiver Verringerung der LK-Produktion. Da in dieser Studie jedoch auch bei der Gruppe der Patienten mit immunsuppressiver Therapie erhöhte LK auf eine Infektion hindeuteten, könnten die LK auch bei ihnen als Detektionsparameter für eine Infektion dienen (Bramlage et al. 2017).

Weitere Berechnungen sahen auch im CRP und PCT eine gute Möglichkeit als Parameter, um eine Entzündung zu identifizieren. PCT galt bislang als das Entscheidungskriterium für das Vorhandensein einer bakteriellen Infektion (Müller und Becker 2001). Dennoch sollte beachtet werden, dass PCT nicht immer als zuverlässiger Marker für systemische Infektionen dient und es insbesondere auch bei viralen Infektionen zu keinem Anstieg kommt (Tang et al. 2007; Schuetz et al. 2012).

Die Leukozyten und Lymphozyten zeigten sich in dieser Studie bei Patienten mit chronisch entzündlichen rheumatischen Erkrankungen als nicht hilfreich zur Detektion einer Infektion. Ihre Werte korrelierten zudem nicht mit den LK, was den Untersuchungen von Hanaoka und Mitarbeitern entsprach (2013). Grund hierfür könnte die Variabilität dieser Parameter bei Patienten mit chronisch entzündlichen rheumatischen Erkrankungen sein, verursacht durch die Grunderkrankung selbst (z. B. Lymphopenie bei SLE), die Beeinflussung der Leukozyten und Lymphozyten durch die Art und Dosis der Immunsuppression sowie die Unterschiede zwischen der Art der Infekte (z. B. Abfall bei viralen Infekten).

Auch wenn Mastroianni-Kirsztajn und Mitarbeiter (2008) in ihrer Studie zu dem Schluss gekommen waren, dass die FLK im Urin nicht als Unterscheidungskriterium zwischen einer Infektion und einer erhöhten Aktivität der 
Grunderkrankung als Ursache der erhöhten systemischen Entzündungsparameter dienen könnten, konnte ihr mögliches Potential in dieser Studie gezeigt werden. Eine alleinige Erhöhung der FLK reicht als Kriterium jedoch nicht aus, da Patienten mit rheumatischen Erkrankungen sowohl mit als auch ohne Infektion erhöhte Leichtkettenwerte haben. Es geht also nicht alleine um eine Erhöhung der LK an sich, sondern insbesondere um die absolute Höhe der Werte. So konnten für die $\mathrm{K}$ - und $\lambda$-LK optimale cut-off points berechnet werden, die bei Patienten mit rheumatischen Erkrankungen eine Aussage darüber treffen können, ob eine Infektion vorliegt (siehe Kapitel 3.4.5). Dabei gilt: Je höher die Werte liegen, desto wahrscheinlicher handelt es sich um eine Infektion. Bestätigt wird die Aussage auch durch die Referenzgruppe Infektion, die deutlich höhere LK-Werte hatte als das Studienkollektiv.

Dass die LK nicht nur ein Epiphänomen der allgemeinen systemischen Entzündung mit vermehrter B-Zell-Aktivität und erhöhter LK-Produktion sind, zeigte die Gruppe der Patienten mit rheumatischer Erkrankung ohne systemische Entzündungsaktivität: Denn auch in dieser Gruppe waren die LK im Vergleich zur Referenzgruppe Gesund erhöht.

Wenn man bedenkt, welch geringen Umstand eine einmalige Urinprobe für den Patienten darstellt und wie viel zeitsparender sie ist als eine Blutentnahme, sollten weitere Studien den Zusammenhang zwischen FLK und Infektionen bei Patienten mit chronisch entzündlichen rheumatischen Erkrankungen untersuchen. Dabei sollte insbesondere erforscht werden, ab welcher Höhe der FLK man sicher von einer Infektion sprechen kann. 


\section{Zusammenfassung}

Die Aussagekraft von freien Leichtketten bei Patienten mit chronisch entzündlichen rheumatischen Erkrankungen wurde zuvor in mehreren Studien, meist im Serum und an kleinen Fallzahlen, untersucht.

Ziel dieser Arbeit war es, den Stellenwert der FLK im Urin in der Diagnostik, Aktivitätsbestimmung und Therapie rheumatischer Erkrankungen zu analysieren. Zudem sollte herausgearbeitet werden, ob Infektionen in diesem Patientenkollektiv mithilfe der FLK früher identifiziert werden können.

In einer retrospektiven monozentrischen Studie wurden die Daten von 1500 Patienten der UMG mit LK-Bestimmung im Urin analysiert. Aus ihnen entstanden das Studienkollektiv $(\mathrm{N}=382)$, bestehend aus Patienten mit chronisch entzündlichen rheumatischen Erkrankungen, die Referenzgruppe Gesund $(\mathrm{N}=140)$ und die Referenzgruppe Infektion $(\mathrm{N}=219)$.

Patienten mit chronisch entzündlichen rheumatischen Erkrankungen wiesen signifikant höhere FLK im Urin auf als die gesunde Referenzgruppe ( $\mathrm{K}$-LK bei $84,0 \% ; \lambda$-LK bei $60,5 \%$ erhöht). Die Signifikanz der Unterschiede zeigte sich auch in der statistischen Auswertung der einzelnen Krankheitsgruppen, wobei die höchsten Werte bei Patienten mit Kollagenosen gefunden wurden, gefolgt von denen mit Vaskulitiden, Spondyloarthritiden und chronischen Polyarthritiden.

Aufgrund großer Unterschiede in der Höhe der FLK zwischen den einzelnen Untergruppen sowie in Abhängigkeit von der Organbeteiligung und von begleitenden Infekten sind die FLK keine zuverlässigen Parameter in der Diagnostik rheumatischer Erkrankungen. Sie könnten aber als ergänzende Parameter die Diagnostik unterstützen.

Bei Patienten mit rheumatoider Arthritis zeigte sich eine Korrelation der FLK im Urin mit den systemischen Entzündungsparametern CRP und BSG. Auch für die Vaskulitiden zeigte sich eine Korrelation vor allem mit dem CRP. Weitere Studien konnten für die RA auch eine Korrelation mit dem DAS-28 aufzeigen, so dass die FLK im Urin als einfache Aktivitätsparameter für diese Erkrankung fungieren können. Eine Therapieüberwachung bei Patienten, die 
Rituximab erhalten, ist zudem pathophysiologisch denkbar, auch wenn die Zahlen in unserer Studie für einen endgültigen Beweis zu gering waren.

Zudem können FLK im Urin zur Identifikation von Infekten hilfreich sein. So deuteten erhöhte Leichtketten auf das Vorhandensein einer Infektion hin ( $\lambda$ : OR: 25,51; 95 \% KI: 3,43-189,81). Zur Unterscheidung, ob die erhöhten Entzündungsparameter von einer Infektion oder einer erhöhten Aktivität der Grunderkrankung kommen, ist die Höhe der Leichtketten von Bedeutung (optimal cut-off point: $\mathrm{\kappa}$ : 32,2 mg/l; $\lambda$ : 9,5 mg/l) und könnte ergänzend in der Diagnostik verwendet werden.

Vor dem Hintergrund der Leichtigkeit der Gewinnung einer Urinprobe sollten aufgrund der Ergebnisse in dieser Studie weitere Untersuchungen folgen. Hierbei sollte der Fokus insbesondere auf die Bedeutung der FLK im Urin bei Patienten mit einer rheumatoiden Arthritis hinsichtlich der Aktivität, der Therapieüberwachung und der Abgrenzung von Infektionen gelegt werden. 


\section{Literaturverzeichnis}

Aggarwal R (2013): Urinary free light chains: a potential biomarker in lupus nephritis. Rheumatol Oxf Engl 2, 2106-2107

Aggarwal R, Sequeira W, Kokebie R, Mikolaitis RA, Fogg L, Finnegan A, Plaas A, Block JA, Jolly M (2011): Serum free light chains as biomarkers for systemic lupus erythematosus disease activity. Arthritis Care Res $\underline{63}$, 891-898

Alamanos Y, Drosos AA (2005): Epidemiology of adult rheumatoid arthritis. Autoimmun Rev 4 , 130-136

Aletaha D, Neogi T, Silman AJ, Funovits J, Felson DT, Bingham CO, Birnbaum NS, Burmester GR, Bykerk VP, Cohen MD (2010): 2010 Rheumatoid arthritis classification criteria: an American College of Rheumatology/European League Against Rheumatism collaborative initiative. Arthritis Rheum 62, 2569-2581

Arts EE, Fransen J, Den Broeder AA, van Riel PLCM, Popa CD (2017): Low disease activity (DAS28 $\leq 3.2$ ) reduces the risk of first cardiovascular event in rheumatoid arthritis: a time-dependent Cox regression analysis in a large cohort study. Ann Rheum Dis 76, 1693-1699

Avina-Zubieta JA, Thomas J, Sadatsafavi M, Lehman AJ, Lacaille D (2012): Risk of incident cardiovascular events in patients with rheumatoid arthritis: a meta-analysis of observational studies. Ann Rheum Dis $\underline{71}$, 1524-1529

Bence Jones H (1847): Papers on chemical pathology. The Lancet $\underline{50}, 511-$ 514

Beresniak A, Baerwald C, Zeidler H, Krüger K, Neubauer AS, Dupont D, Merkesdal S (2013): Cost-effectiveness simulation model of biologic strategies for treating to target rheumatoid arthritis in Germany. Clin Exp Rheumatol 31, 400-408

Bernatsky S, Boivin JF, Joseph L, Rajan R, Zoma A, Manzi S, Ginzler E, Urowitz M, Gladman D, Fortin PR (2005): An international cohort study of cancer in systemic lupus erythematosus. Arthritis Rheum 52, 14811490

Blaese RM, Grayson J, Steinberg AD (1980): Increased immunoglobulin-secreting cells in the blood of patients with active systemic lupus erythematosus. Am J Med $\underline{69}, 345-350$

Bombardier C, Gladman DD, Urowitz MB, Caron D, Chang CH, Austin A, Bell A, Bloch DA, Corey PN, Decker JL (1992): Derivation of the sledai. A disease activity index for lupus patients. Arthritis Rheum $\underline{35}$, 630-640 
Booth AD, Jayne DRW, Kharbanda RK, McEniery CM, Mackenzie IS, Brown J, Wilkinson IB (2004): Infliximab Improves Endothelial Dysfunction in Systemic Vasculitis. Circulation 109, 1718-1723

Bradwell AR (2005): Serum Free Light Chain Measurements Move to Center Stage. Clin Chem 51, 805-807

Bradwell AR, Carr-Smith HD, Mead GP, Tang LX, Showell PJ, Drayson MT, Drew R (2001): Highly Sensitive, Automated Immunoassay for Immunoglobulin Free Light Chains in Serum and Urine. Clin Chem 47, 673680

Bramlage CP, Froelich B, Wallbach M, Minguet J, Grupp C, Deutsch C, Bramlage $P$, Koziolek M, Müller GA (2016): The significance and predictive value of free light chains in the urine of patients with chronic inflammatory rheumatic disease. Clin Rheumatol 35, 2939-2946

Bramlage CP, Froelich B, Wallbach M, Minguet J, Grupp C, Deutsch C, Bramlage P, Müller GA, Koziolek M (2017): Urinary free light chains may help to identify infection in patients with elevated systemic inflammation due to rheumatic disease. Rheumatol Int 37, 599-605

Braun M: Rheumatologie. In: Renz-Polster H, Krautzig S (Hrsg.): Basislehrbuch Innere Medizin: kompakt - greifbar - verständlich. 5. Auflage; Elsevier, Urban \& Fischer, München 2012, 921-971

Brebner JA, Stockley RA (2013): Polyclonal free light chains: a biomarker of inflammatory disease or treatment target? F1000 Med Rep $\underline{5}$

Burmeister A, Assi LK, Ferro CJ, Hughes RG, Barnett AH, Bellary S, Cockwell P, Pratt G, Hutchison CA (2014): The relationship between high-sensitivity CRP and polyclonal Free Light Chains as markers of inflammation in chronic disease. Int J Lab Hematol $\underline{36}$, 415-424

Carubbi F, Alunno A, Cipriani P, Bartoloni E, Ciccia F, Triolo G, Gerli R, Giacomelli R (2014): Rituximab in primary Sjögren's syndrome: a ten-year journey. Lupus 23, 1337-1349

Chiche L, Cournac JM, Mancini J, Bardin N, Thomas G, Jean R, Schleinitz N, Kaplanski G, Durand JM, Boucraut J (2011): Normalization of serumfree light chains in patients with systemic lupus erythematosus upon rituximab treatment and correlation with biological disease activity. Clin Rheumatol 30, 685-689

Cooper A, Bluestone R (1968): Free immunoglobulin light chains in connective tissue diseases. Ann Rheum Dis 27, 537-543

Deng X, Crowson CS, Rajkumar SV, Dispenzieri A, Larson DR, Therneau TM, Matteson EL, Kyle RA, Katzmann J, Gabriel SE (2015): Elevation of serum immunoglobulin free light chains during the pre-clinical period of rheumatoid arthritis: impact on mortality. J Rheumatol $\underline{42}, 181-187$ 
Doran MF, Crowson CS, Pond GR, O'Fallon WM, Gabriel SE (2002): Frequency of infection in patients with rheumatoid arthritis compared with controls: a population-based study. Arthritis Rheum 46, 2287-2293

Draborg AH, Lydolph MC, Westergaard M, Olesen Larsen S, Nielsen CT, Duus K, Jacobsen S, Houen G (2015): Elevated Concentrations of Serum Immunoglobulin Free Light Chains in Systemic Lupus Erythematosus Patients in Relation to Disease Activity, Inflammatory Status, B Cell Activity and Epstein-Barr Virus Antibodies. PLoS ONE 10 e0138753

Epstein WV (1973): Immunologic events preceding clinical exacerbation of systemic lupus erythematosus. Am J Med 54, 631-636

Epstein WV, Tan M (1966): Increase of L-chain proteins in the sera of patients with systemic lupus erythematosus and the synovial fluids of patients with peripheral rheumatoid arthritis. Arthritis Rheum $\underline{9}$, 713-719

Fagnart OC, Sindic CJ, Laterre C (1988): Free kappa and lambda light chain levels in the cerebrospinal fluid of patients with multiple sclerosis and other neurological diseases. J Neuroimmunol 19, 119-132

Galloway JB, Hyrich KL, Mercer LK, Dixon WG, Fu B, Ustianowski AP, Watson KD, Lunt M, Symmons DPM, BSRBR Control Centre Consortium (2011): Anti-TNF therapy is associated with an increased risk of serious infections in patients with rheumatoid arthritis especially in the first 6 months of treatment: updated results from the British Society for Rheumatology Biologics Register with special emphasis on risks in the elderly. Rheumatol Oxf Engl $\underline{50}, 124-131$

Garrett S, Jenkinson T, Kennedy LG, Whitelock H, Gaisford P, Calin A (1994): A new approach to defining disease status in ankylosing spondylitis: the Bath Ankylosing Spondylitis Disease Activity Index. J Rheumatol 21, 2286-2291

Germano V, Cattaruzza MS, Osborn J, Tarantino A, Di Rosa R, Salemi S, D'Amelio R (2014): Infection risk in rheumatoid arthritis and spondyloarthropathy patients under treatment with DMARDs, corticosteroids and TNF-a antagonists. J Transl Med 12, 77

Giraudeau C, Babuty D, Goupille P, Casset-Senon D, de Muret A, Fauchier L, Hurreesing C, Valat JP, Cosnay P (2000): [Pericardial effusion revealing cardiac amyloidosis in the course of rheumatoid arthritis]. Arch Mal Coeur Vaiss 93, 1145-1149

Girón JA, Shah SL (2013): Helicobacter pylori infection and light chain gammopathy. Clin Dev Immunol 2013, 348562

Gottenberg J, Aucouturier F, Goetz J, Sordet C, Jahn I, Busson M, Cayuela J, Sibilia J, Mariette X (2007): Serum immunoglobulin free light chain assessment in rheumatoid arthritis and primary Sjögren's syndrome. Ann Rheum Dis $\underline{66}$, 23-27 
Gottenberg J-E, Miceli-Richard C, Ducot B, Goupille P, Combe B, Mariette X (2009): Markers of B-lymphocyte activation are elevated in patients with early rheumatoid arthritis and correlated with disease activity in the ESPOIR cohort. Arthritis Res Ther 11, R114

Hanaoka M, Gono T, Kawaguchi Y, Uchida K, Koseki Y, Katsumata Y, Kaneko H, Takagi K, Ichida H, Nitta K (2013): Urinary free light chain is a potential biomarker for ISN/RPS class III/IV lupus nephritis. Rheumatol Oxf Engl 52, 2149-2157

Herold G: Innere Medizin. Gerd Herold (Verlag), Köln 2017

Hopper JE, Papagiannes E (1986): Evidence by radioimmunoassay that mitogen-activated human blood mononuclear cells secrete significant amounts of light chain Ig unassociated with heavy chain. Cell Immunol $\underline{101}, 122-131$

Hopper JE, Golbus J, Meyer C, Ferrer GA (2000): Urine free light chains in SLE: clonal markers of B-cell activity and potential link to in vivo secreted Ig. J Clin Immunol $\underline{20}, 123-137$

Hutchison CA, Harding S, Hewins P, Mead GP, Townsend J, Bradwell AR, Cockwell P (2008): Quantitative Assessment of Serum and Urinary Polyclonal Free Light Chains in Patients with Chronic Kidney Disease. Clin J Am Soc Nephrol CJASN $\underline{3}$, 1684-1690

Jasin HE, Ziff M (1975): Immunoglobulin synthesis by peripheral blood cells in systemic lupus erythematosus. Arthritis Rheum $\underline{18}, 219-228$

Jennette JC, Falk RJ, Andrassy K, Bacon PA, Churg J, Gross WL, Hagen EC, Hoffman GS, Hunder GG, Kallenberg CG (1994): Nomenclature of systemic vasculitides. Proposal of an international consensus conference. Arthritis Rheum 37, 187-192

Jennette JC, Falk RJ, Bacon PA, Basu N, Cid MC, Ferrario F, Flores-Suarez LF, Gross WL, Guillevin L, Hagen EC, et al. (2013): 2012 Revised International Chapel Hill Consensus Conference Nomenclature of Vasculitides. Arthritis Rheum $\underline{65}, 1-11$

Jolly $M$, Francis S, Aggarwal R, Mikolaitis RA, Niewold TB, Chubinskaya S, Block JA, Scanzello C, Sequeira W (2014): Serum free light chains, interferon-alpha, and interleukins in systemic lupus erythematosus. Lupus $\underline{23}, 881-888$

Jones RB (2014): Rituximab in the treatment of anti-neutrophil cytoplasm antibody-associated vasculitis. Nephron Clin Pract 128, 243-249

Kassan SS (1978): Increased Risk of Lymphoma in Sicca Syndrome. Ann Intern Med $\underline{89}, 888$ 
Kidney Disease Improving Global Outcomes (KDIGO) CKD Work Group (2013): KDIGO 2012 Clinical Practice Guideline for the Evaluation and Management of Chronic Kidney Disease. Kidney International Supplement $\underline{3}$

Komano Y, Tanaka M, Nanki T, Koike R, Sakai R, Kameda H, Nakajima A, Saito K, Takeno M, Atsumi T (2011): Incidence and risk factors for serious infection in patients with rheumatoid arthritis treated with tumor necrosis factor inhibitors: a report from the Registry of Japanese Rheumatoid Arthritis Patients for Longterm Safety. J Rheumatol 38, 1258-1264

Kormelink TG, Tekstra J, Thurlings RM, Boumans MHJ, Vos K, Tak PP, Bijlsma JWJ, Lafeber FPJG, Redegeld FA, van Roon J (2010): Decrease in immunoglobulin free light chains in patients with rheumatoid arthritis upon rituximab (anti-CD20) treatment correlates with decrease in disease activity. Ann Rheum Dis 69, 2137-2144

Leitlinie KDIGO s. Kidney Disease Improving Global Outcomes

Lopez-Olivo MA, Amezaga Urruela M, McGahan L, Pollono EN, Suarez-Almazor ME (2015): Rituximab for rheumatoid arthritis. Cochrane Database Syst Rev 1 , CD007356

Mastroianni-Kirsztajn G, Nishida SK, Pereira AB (2008): Are urinary levels of free light chains of immunoglobulins useful markers for differentiating between systemic lupus erythematosus and infection? Nephron Clin Pract $\underline{110}$, c258-263

Müller B, Becker KL (2001): Procalcitonin: how a hormone became a marker and mediator of sepsis. Swiss Med Wkly 131, 595-602

Nakano T, Nagata A, Takahashi H (2004): Ratio of urinary free immunoglobulin light chain kappa to lambda in the diagnosis of Bence Jones proteinuria. Clin Chem Lab Med 42, 429-434

Ogdie A, Yu Y, Haynes K, Love TJ, Maliha S, Jiang Y, Troxel AB, Hennessy S, Kimmel SE, Margolis DJ (2015): Risk of Major Cardiovascular Events in Patients with Psoriatic Arthritis, Psoriasis and Rheumatoid Arthritis: A population-based cohort study. Ann Rheum Dis 74, 326-332

Pfeifer W, Braun W, Zentralinstitut für Sprachwissenschaft (Hrsg.): Etymologisches Wörterbuch des Deutschen. 2. Auflage; Dt. TaschenbuchVerlag, München 1997

Presslauer S, Milosavljevic D, Huebl W, Aboulenein-Djamshidian F, Krugluger W, Deisenhammer F, Senel M, Tumani H, Hegen H (2016): Validation of kappa free light chains as a diagnostic biomarker in multiple sclerosis and clinically isolated syndrome: A multicenter study. Mult Scler Houndmills Basingstoke Engl 22, 502-510 
Prevoo ML, van 't Hof MA, Kuper HH, van Leeuwen MA, van de Putte LB, van Riel PL (1995): Modified disease activity scores that include twentyeight-joint counts. Development and validation in a prospective longitudinal study of patients with rheumatoid arthritis. Arthritis Rheum $\underline{38}$, 44-48

Rajkumar SV, Kyle RA, Therneau TM, Melton LJ, Bradwell AR, Clark RJ, Larson DR, Plevak MF, Dispenzieri A, Katzmann JA (2005): Serum free light chain ratio is an independent risk factor for progression in monoclonal gammopathy of undetermined significance. Blood 106, 812-817

Ruof J, Stucki G (1999): Validity aspects of erythrocyte sedimentation rate and C-reactive protein in ankylosing spondylitis: a literature review. J Rheumatol $\underline{26}$, 966-970

Schuetz P, Briel M, Christ-Crain M, Stolz D, Bouadma L, Wolff M, Luyt C-E, Chastre J, Tubach F, Kristoffersen KB (2012): Procalcitonin to guide initiation and duration of antibiotic treatment in acute respiratory infections: an individual patient data meta-analysis. Clin Infect Dis Off Publ Infect Dis Soc Am 55, 651-662

Sieper J, Braun J, Rudwaleit M, Boonen A, Zink A (2002): Ankylosing spondylitis: an overview. Ann Rheum Dis 61 Suppl 3, iii8-18

Stokes MB, Valeri AM, Herlitz L, Khan AM, Siegel DS, Markowitz GS, D'Agati VD (2016): Light Chain Proximal Tubulopathy: Clinical and Pathologic Characteristics in the Modern Treatment Era. J Am Soc Nephrol JASN 27, 1555-1565

Tang BMP, Eslick GD, Craig JC, McLean AS (2007): Accuracy of procalcitonin for sepsis diagnosis in critically ill patients: systematic review and meta-analysis. Lancet Infect Dis $\underline{7}, 210-217$

van der Heijden M, Kraneveld A, Redegeld F (2006): Free immunoglobulin light chains as target in the treatment of chronic inflammatory diseases. Eur J Pharmacol 533, 319-326

van Gestel AM, Prevoo ML, van 't Hof MA, van Rijswijk MH, van de Putte LB, van Riel PL (1996): Development and validation of the European League Against Rheumatism response criteria for rheumatoid arthritis. Comparison with the preliminary American College of Rheumatology and the World Health Organization/International League Against Rheumatism Criteria. Arthritis Rheum 39, 34-40

Waldmann TA, Strober W, Mogielnicki RP (1972): The renal handling of low molecular weight proteins. J Clin Invest 51, 2162-2174

Wolfe F, Michaud K (2004): Lymphoma in rheumatoid arthritis: The effect of methotrexate and anti-tumor necrosis factor therapy in 18,572 patients. Arthritis Rheum 므, 1740-1751 
Ye Y, Li S-L, Xie M, Jiang P, Liu K-G, Li Y-J (2013): Judging disease activity in rheumatoid arthritis by serum free kappa and lambda light chain levels. Kaohsiung J Med Sci 29, 547-553

Yokoyama H, Okuyama H, Yamaya H (2011): Clinicopathological insights into lupus glomerulonephritis in Japanese and Asians. Clin Exp Nephrol 15, 321-330

Youinou P, Taher TE, Pers J-O, Mageed RA, Renaudineau Y (2009): B lymphocyte cytokines and rheumatic autoimmune disease. Arthritis Rheum $\underline{60}$, 1873-1880

Zhang R, Li M, Chouhan KK, Simon EE, Hamm LL, Batuman V (2013): Urine Free Light Chains as a Novel Biomarker of Acute Kidney Allograft Injury. Clin Transplant 27, 953-960 


\section{Danksagung}

Zuallererst möchte ich Herrn Priv.-Doz. Dr. Carsten Bramlage danken, der durch zahlreiche Anregungen und vor allem durch sein stetiges Motivieren zum Entstehen dieser Dissertation beigetragen hat. Ebenfalls vielen Dank für das schnelle Korrekturlesen und die ständige Bereitschaft, meine Fragen zu beantworten.

Ein großer Dank geht auch an Herrn Dr. Manuel Wallbach, der mir insbesondere zu Beginn der Arbeit mit viel Engagement zur Seite stand.

Außerdem möchte ich mich bei den Mitarbeitern der Abteilung für Medizinische Statistik der Universität Göttingen und bei Frau Dr. Cornelia Deutsch aus dem Institut für Pharmakologie und Präventive Medizin (Cloppenburg) bedanken, die mir bei der Statistik geholfen haben. Ebenso danke ich den Mitarbeitern der EDV-Abteilung der Universitätsmedizin Göttingen für das Heraussuchen der Patienten mit Leichtketten-Bestimmung im Urin.

Den Co-Autoren der beiden veröffentlichten Publikationen zu dieser Studie möchte ich für ihre Mitarbeit bei diesem Projekt danken.

Ferner danke ich Herrn Prof. Dr. G. Müller und Herrn Prof. Dr. M. Koziolek für die Möglichkeit, meine Promotion in der Abteilung für Nephrologie und Rheumatologie der Universitätsmedizin Göttingen zu schreiben. 